UNIVERSIDADE DE SÃO PAULO - USP

FACULDADE DE MEDICINA DE RIBEIRÃO PRETO

DANIELLA LEIROS CUNHA CAVALCANTI

\title{
EFEITOS DO TREINAMENTO DOS MÚSCULOS DO ASSOALHO PÉLVICO REALIZADOS DURANTE A GESTAÇÃO NA SUA FUNÇÃO E NO RELATO DE PERDA URINÁRIA
}




\section{EFEITOS DO TREINAMENTO DOS MÚSCULOS DO ASSOALHO PÉLVICO REALIZADOS DURANTE A GESTAÇÃO NA SUA FUNÇÃO E NO RELATO DE PERDA URINÁRIA}

Dissertação apresentada a Faculdade de Medicina de Ribeirão Preto da Universidade de São Paulo para a obtenção do título de Mestre em Ciências da Saúde

Área de Concentração: Tocoginecologia

Orientadora: Profa. Dra. Silvana Maria Quintana

Ribeirão Preto 
Nome: CAVALCANTI, Daniella Leiros Cunha

Título: Efeitos do treinamento dos músculos do assoalho pélvico realizados durante a gestação na sua sua função e no relato de perda urinária

Dissertação apresentada a Faculdade de Medicina de Ribeirão Preto da Universidade de São Paulo para a obtenção do título de Mestre em Ciências da Saúde.

Área de Concentração: Tocoginecologia

Orientadora: Profa. Dra. Silvana Maria Quintana

Aprovado em:

\section{BANCA EXAMINADORA}

Profa. Dra. Silvana Maria Quintana

Julgamento:

Prof. Dr.

Julgamento:

Prof. Dr.

Julgamento:
Instituição:FMRP USP

Assinatura:

Instituição:

Assinatura:

Instituição:

Assinatura: 
Aos meus pais, TÂAIA e JARBAS, que constituem o meu porto seguro, minha referência de amor, dedicação, compreensão e paciência. Obrigada por cada abraço, cada beijo, cada puxão de orelha e cada cobrança. Sem vocês este trabalho não seria possível. Obrigada por me incentivarem SEMPRE, por serem meus pais, meus amigos e companheiros e desculpa por, em muitos momentos, não ter sido a filha que vocês merecem. AMO MUITO VOCÊS! 


\section{AGRADECIMENTOS}

Em especial a minha orientadora Profa. Dra. Silvana Maria Quintana que me aceitou como orientanda sem nem conhecer a Fisioterapia, que lutou comigo por uma vaga na pós-graduação, que escreveu e reescreveu cada letrinha do nosso projeto inicial (estudando afinco um tema desconhecido), que me acolheu, me orientou, me acalentou e me ensinou a ser uma pesquisadora e a ser uma pessoa melhor.

Um especial, mais que especial OBRIGADA a Profa. Dra. Cristine Homsi Jorge Ferreira, minha orientadora adjunta que, na maioria das vezes, se fez como a verdadeira orientadora, não em papel, mas em palavras e em gestos. Uma coordenadora exemplar, uma professora íntegra e de inteligência admirável a qual digo sempre que “Quando crescer, quero ser igual a ela.”. Sem distinção alguma me aceitou e me acolheu como integrante da sua equipe de trabalho (LAFAP - Laboratório para Avaliação Funcional do Assoalho Pélvico). Com ela, aprendi a publicar, a pesquisar, a escrever e é que constitui para mim um modelo de Fisioterapeuta e pesquisadora.

Ao Prof. Dr. Geraldo Duarte por contribuir diretamente no desenvolvimento deste trabalho e por todo o incentivo dado ao LAFAP e durante toda a nossa trajetória.

Às parceiras Flaviane Souza, Letícia Dias, Roberta Batista, Luciane Naldoni e demais integrantes do LAFAP pelo companheirismo, pela dedicação, comprometimento e por nos "aturarmos" todos estes anos sem que uma deixasse a outra fraquejar.

Às mulheres que fizeram parte desta pesquisa, que mesmo num momento de fragilidade e tão único como a primeira gestação, se dispuseram a colaborar conosco, me ensinando muito sobre a maternidade, o ser mulher e o voluntariado.

Aos médicos Ricardo Cavalli, Marcos Okido e Fabiana Valeri pela calorosa colaboração e parceria. 
Às secretárias Ilza Mazzocato, Suelen Soares e Rosane Casula por me darem conforto e orientação quando precisei e por estarem sempre disponíveis aos meus questionamentos.

Ao meu noivo e futuro próximo marido, Eduardo, por me apoiar, por confiar em mim, por ter vibrado comigo em todos os momentos de vitória e por me colocar no colo nos momentos difíceis.

A toda minha família e meus amigos de Natal por terem de "doado" a Ribeirão Preto, por abdicarem da minha presença em tantos e tantos momentos durantes todos estes anos, por acreditarem em meu potencial e que, mesmo distantes, torceram e vibraram por mim. Obrigada por me fazerem me sentir tão querida e amada! 


\section{RESUMO}

CAVALCANTI, Daniella Leiros Cunha. Efeitos do treinamento dos músculos do assoalho pélvico realizados durante a gestação na sua função e no relato de perda urinária. 2009. 89f. Dissertação (mestrado) - Faculdade de Medicina de Ribeirão Preto, Universidade de São Paulo. 2009.

Apesar do treinamento dos músculos do assoalho pélvico ser considerado tratamento de primeira linha nos casos de IU de esforço em mulheres, a literatura ainda é escassa e controversa em relação a sua efetividade no período gestacional. Este estudo avaliou os efeitos de um programa de treinamento dos músculos do assoalho pélvico na melhora de sua função e na diminuição de relatos de perda urinária. Quarenta e duas primigestas de baixo risco foram randomicamente distribuídas para fazerem parte de um grupo controle ou de um grupo de treinamento dos MAP. O grupo de intervenção realizou 16 sessões de treinamento individual e supervisionado. Todas as gestantes foram avaliadas com 20 semanas de gestação, 24 semanas, 36 semanas de gestação e com 6 semanas após o parto quanto a força dos MAP utilizando-se a escala de Oxford modificada e o perineômetro Peritron ${ }^{\circledR}$. Foram consideradas incontinentes as mulheres que relataram um ou mais episódios de perda urinária no último mês. O pico e média da perineometria na avaliação com 20 semanas de IG para o grupo controle foram respectivamente $51,89 \mathrm{cmH}_{2} \mathrm{O}$ e $33,71 \mathrm{cmH}_{2} \mathrm{O}$ e para o grupo de treinamento $43,01 \mathrm{cmH}_{2} \mathrm{O}$ e $28,21 \mathrm{cmH}_{2} \mathrm{O}$. No grupo controle $52 \%$ relataram perder urina e $33 \%$ do grupo de treinamento na primeira avaliação. Não houve diferença significativa entre os grupos em relação a média $(\mathrm{p}=0,18)$ e o pico $(\mathrm{p}=0,47)$ da perineometria e relato de perda urinária $(\mathrm{p}=0,34)$ na primeira avaliação. Na avaliação com 36 semanas o pico e a média da perineometria para o grupo controle foram respectivamente $50,81 \mathrm{cmH}_{2} \mathrm{O}$ e $33,06 \mathrm{cmH}_{2} \mathrm{O}$ e para o grupo de treinamento $42,49 \mathrm{cmH}_{2} \mathrm{O}$ e $28,21 \mathrm{cmH}_{2} \mathrm{O}$. Não houve diferença estatística significante entre os grupos para a perineometria, mas houve diferença entre as avaliações para a média da perineometria para o grupo de treinamento ( $\mathrm{p}=0,03$ de 20 sem para 36 sem de gestação e $<0,01$ de 20 sem de gestação para 6 semanas após o parto). O número de mulheres que não perdiam urina aumentou de $48 \%$ para $52 \%$ no grupo controle, e de $67 \%$ para $87 \%$ no grupo exercício $(p=0,04)$. O treinamento dos MAP proporcionou aumento da perineometria (média) imediatamente após o treinamento, manteve a função dos MAP após o parto e foi eficaz na diminuição dos relatos de perda urinária. Palavras-chave: Fisioterapia; Gravidez; Exercício; Saúde da Mulher; Períneo; Incontinência Urinária 


\begin{abstract}
CAVALCANTI, Daniella Leiros Cunha. The effect of pelvic floor muscle training during pregnancy in the function of these muscles and self related urinary loss. 2009. 89f. Dissertação (mestrado) - Faculdade de Medicina de Ribeirão Preto, Universidade de São Paulo. 2009.

Although pelvic floor muscle training (PFMT) is considered a treatment of first line in the cases of UI in women, the literature still is scarce and controversy in relation its effectiveness in the gestacional period. This study it evaluated the effect of a program of PFMT in the improvement of its function and the reduction of self related urinary loss. Forty and two primiparous women of low risk pregnancy had been distributed to be part of a group have controlled or a group of training of the PFM. The group of intervention carried through 16 sessions of individual and supervised training. All the pregnant women had been evaluated with twenty, twenty four and thirty six of gestacional age and six weeks post partum using the perineometer Peritron ${ }^{\mathrm{TM}}$ and digital palparions (modified Oxford scale). The women had been considered not continents who told at least one episode of urinary loss in the last month. The peak and mean of the perineometry in the first evaluation with 20 weeks of IG for the control group had respectively $51,89 \mathrm{cmH}_{2} \mathrm{O}$ and $33,71 \mathrm{cmH}_{2} \mathrm{O}$ and the training group had $43,01 \mathrm{cmH}_{2} \mathrm{O}$ and $28,21 \mathrm{cmH}_{2} \mathrm{O}$. The control group $52 \%$ told to lose piss and $33 \%$ of the training group in the first evaluation. It did not have significant difference enters the groups in relation the average $(\mathrm{p}=0,18)$ and the peak $(\mathrm{p}=0,47)$ of the perineometry and self related urinary loss $(p=0,34)$ in the first evaluation. In the evaluation with 36 weeks the perineometry (peak and mean) for the control group had respectively $50,81 \mathrm{cmH}_{2} \mathrm{O}$ and $33,06 \mathrm{cmH}_{2} \mathrm{O}$ and for the training group $42,49 \mathrm{cmH}_{2} \mathrm{O}$ and $28,21 \mathrm{cmH}_{2} \mathrm{O}$. The perineometry did not have difference significant statistics between the groups, but e had difference between the evaluations for the perineometry (mean) in the training group ( $p=0,03$ between 20 weeks and 36 without of gestation and $p<0,01$ between 20 weeks of gestation and 6 weeks post partum).
\end{abstract}

Key-words: Physical Therapy; Pregnancy; Exercise; Women Health; Perineo; Urinary Incontinence 


\section{LISTA DE TABELAS}

Tabela 1 - $\quad$ significado dos valores do coeficiente da kappa, análise de concordância

Tabela 2 - influência da covariável peso na graduação de força (escala de Oxford modificada) no grupo geral e separadamente (controle e treinamento) na aval 3

Tabela 3 - comparações entre os grupos em relação as variáveis perineometria (pico e média) em cada uma das avaliações

Tabela 4 - comparações entre avaliações intra-grupo em relação as variáveis perineometria (pico e média)

Tabela 5 - $\quad$ associação entre efeito das avaliações nos escores de força por grupo .. 44

Tabela 6 - $\quad$ associação entre efeito das avaliações no RPU por grupo 45

Tabela 7 - médias das perineometrias (pico máximo) por escore de força por avaliação em cada um dos grupos 


\section{LISTA DE ABREVIATURAS E SIGLAS}

AP

MAP

TMAP

IU

CT

RPU

ICS

GC

GT

FAPESP

Paulo

COFFITO

UBS

IMC assoalho pélvico

músculos do assoalho pélvico

treinamento para os músculos do assoalho pélvico

incontinência urinária

cinesioterapia

relato de perda urinária

Sociedade Internacional de Continência

Grupo Controle

Grupo Treinamento

Fundação de Amparo a Pesquisa e Ensino do Estado de São

Conselho Federal de Fisioterapia e Terapia Ocupacional).

Unidade Básica de Saúde

Índice de massa corporal 


\section{LISTA DE SÍMBOLOS}

$\begin{array}{ll}\mathrm{cmH}_{2} \mathrm{O} & \text { centímetros de água } \\ \mathrm{kg} & \text { quilograma } \\ \mathrm{m} & \text { metro } \\ \mathrm{kg} / \mathrm{m}^{2} & \text { quilograma por metro ao quadrado } \\ \sigma^{2} & \text { variância }\end{array}$




\section{SUMÁRIO}

1 INTRODUÇÃ

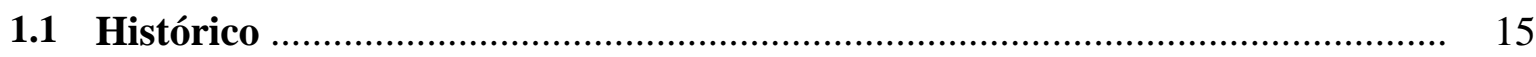

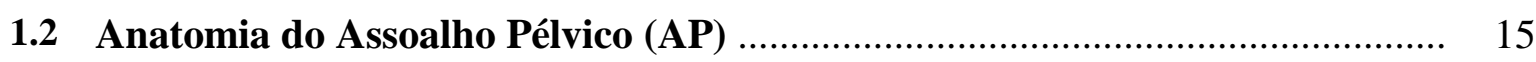

1.3 Treinamento dos Músculos do Assoalho Pélvico (TMAP) ................................ 17

1.4 Músculos do assoalho pélvico (MAP) e gravidez ….......................................... 19

1.5 Avaliação Fisioterapêutica do Assoalho Pélvico .............................................. 21

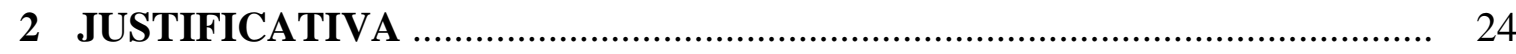

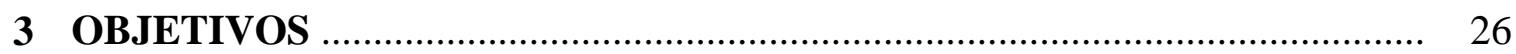

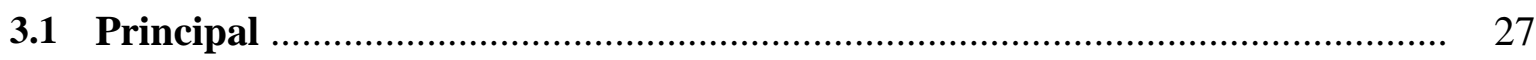

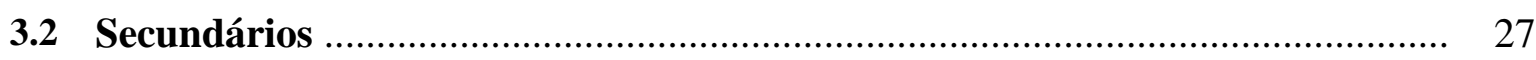

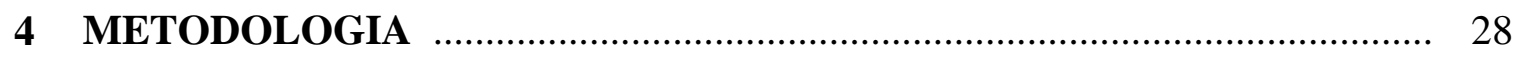

4.1 Caracterização da pesquisa .......................................................................... 29

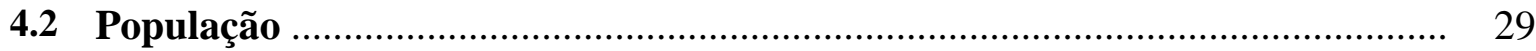

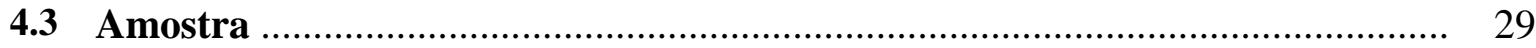

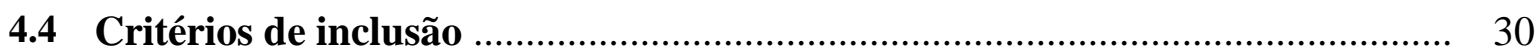

4.5 Critérios de exclusão ….............................................................................. 30

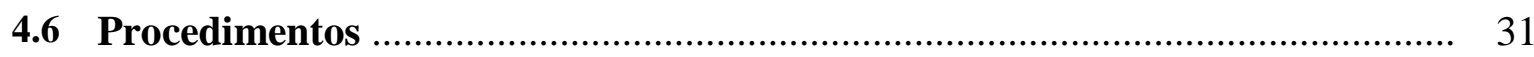

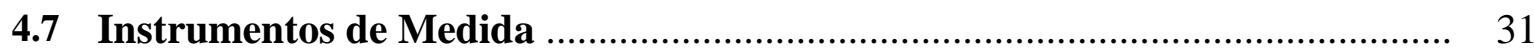

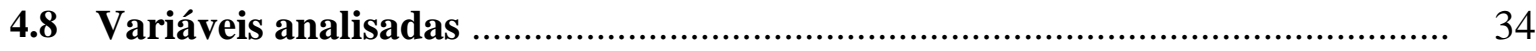

4.8.1 Variáveis de caracterização da amostra ................................................................. 34

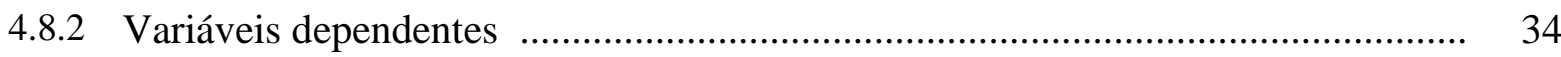

4.9 Análise estatística ................................................................................. 34

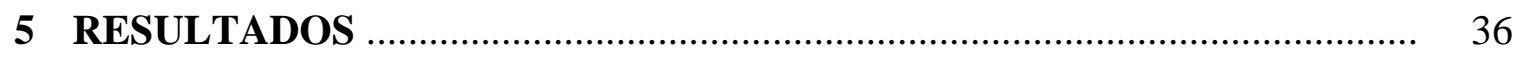

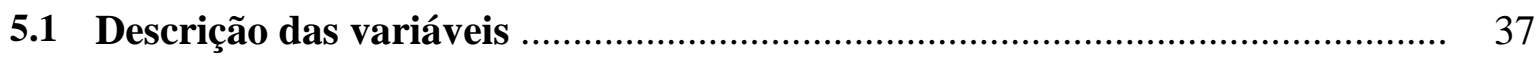

5.2 Análise da influência da caracterização da amostra (idade, peso, altura e IMC) vs grupo nas variáveis dependentes (perineometria, grau de força e relato de perda urinária) …......................................................................... 39

5.3 Análise da relação das variáveis dependentes entre si ................................... 41

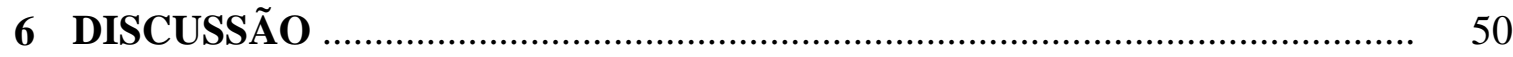

6.1 Descrição das variáveis ............................................................................... 51

6.2 Análise da influência da caracterização da amostra (idade, peso, altura e IMC) vs grupo nas variáveis dependentes (perineometria, grau de força e 


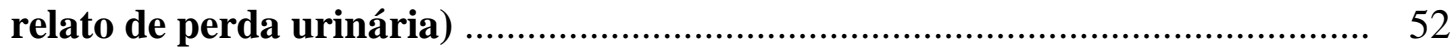

6.3 Análise da relação das variáveis dependentes entre si ................................... 53

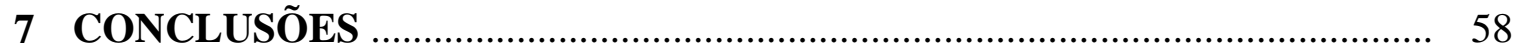

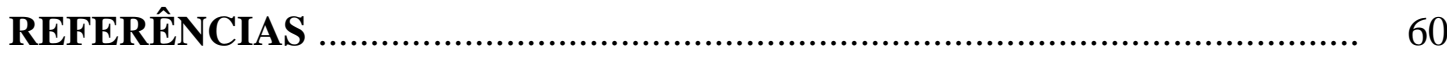

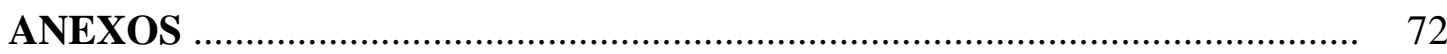


INTRODUÇÃO 


\section{INTRODUÇÃO}

\subsection{Histórico}

O pioneiro a utilizar exercícios para o fortalecimento dos músculos do assoalho pélvico (MAP) no tratamento das disfunções desta musculatura foi Arnold Kegel, em 1948. Os exercícios para os músculos assoalho pélvico são também conhecidos como "Exercícios de Kegel”, porém Bo (2004) afirmou que há pelo menos 6000 anos os chineses já utilizavam exercícios para os MAP e que fisioterapeutas britânicos utilizavam estes exercícios para tratar e prevenir incontinência fecal e urinária desde a década de 20. O real interesse pela recuperação funcional dos músculos do assoalho pélvico surgiu nos anos 80, com grande atenção dos profissionais de saúde aos exercícios e à estimulação elétrica funcional desta musculatura (BO et al., 1999; BENEDETTO, 2004).

No Brasil, Palhares em 1982 (Apud ZACCHI et al., 2001) demonstrou que o treinamento para os músculos do assoalho pélvico (TMAP) no tratamento da incontinência urinária (IU) apresenta bons resultados. Posteriormente, diversos trabalhos foram publicados demonstrando a melhora e/ou a cura de várias mulheres com incontinência urinária através do TMAP no Brasil (BERNARDES et al., 2000; ZACCHI et al., 2001; CASTRO et al., 2008; SCHMIDT et al., 2009).

\subsection{Anatomia do Assoalho Pélvico (AP)}

O assoalho pélvico feminino é composto de elementos musculares e ligamentares responsáveis pela sustentação dos órgãos pélvicos e abdominais, mantendo as continências urinárias e fecais (BEZERRA et al., 2001; QUIGLEY, 2007; CHEHREHRAZI et al., 2009). Estes músculos também participam da função sexual e durante a gravidez devem estar tônicos para sustentar o útero gravídico e elásticos para permitir a saída fetal, sofrendo distensão máxima no momento do parto (CALAISGERMAIN, 2005).

O conhecimento dos músculos do assoalho pélvico (MAP) é fundamental para a prática da fisioterapia obstétrica (QUIGLEY, 2007). Ele é dividido em três compartimentos: o anterior que sustenta a bexiga e é perfurado pela uretra, o médio que dá passagem à vagina e o posterior perfurado pelo reto. Devido à proximidade destes 
compartimentos assim como seus tênues limites, há uma grande dificuldade em identificar todas as falhas na integridade do assoalho pélvico e os pontos frágeis da musculatura podem não ser localizados nem restritos.

Os ligamentos e o sistema muscular suspendem e suportam os órgãos pélvicos e abdominais e os músculos do assoalho pélvico formam os diafragmas pélvico e urogenital. Estes diafragmas são os principais responsáveis pela sustentação do colo vesical, do útero e da uretra (STOKER et al., 2001; MOORE; DALLEY, 2001). O diafragma pélvico é composto pelos músculos coccígeo e levantador do ânus que se divide nos músculos iliococcígeo, pubococcígeo e puborretal (CHACEL, 1997; BEZERRA et al., 2001). O diafragma urogenital está localizado mais externamente que o diafragma pélvico e se divide em dois compartimentos: profundo e superficial. O compartimento superficial é formado pelos músculos bulbo cavernoso, ísquio cavernoso e transverso superficial do períneo com função predominante no esfíncter vaginal. $\mathrm{O}$ compartimento profundo é o espaço aberto da membrana do períneo até a fáscia profunda da pelve, composto pela parte proximal da uretra, músculo esfíncter externo da uretra e músculo transverso profundo do períneo (STOKER et al., 2001). Os ligamentos mais importantes na fixação dos órgãos pélvicos são o pubocervical, o cardinal, o pubovesical, o uterossacral e o pubouretral.

Os músculos do assoalho pélvico são formados por três camadas, onde as fibras musculares têm diferentes direções e cada músculo pode se contrair isoladamente, tendo diferentes funções. Contudo, a única função voluntária conhecida destes músculos é uma contração em massa como uma elevação interna e um aperto ao redor da uretra, vagina e reto (BO, 2004; AMARO et al., 2005).

As fibras musculares que compõem o assoalho pélvico são de dois tipos; as de contração lenta ou do tipo I e as de contração rápida ou do tipo II. Setenta por cento destas fibras são de contração lenta, responsáveis pela manutenção do tônus e $30 \%$ são fibras de contração rápida e de baixa resistência. A contração voluntária da musculatura do assoalho pélvico age especificamente nas fibras do tipo II (BERNARDES et al., 2000).

O suporte adequado das vísceras pélvicas e a contração adequada dos MAP são fundamentais na manutenção das continências urinária e fecal e dependem da integridade dos músculos do assoalho pélvico (AMARO; GAMEIRO; PADOVANI, 2003; THOMPSON et al., 2006), como também da habilidade do sistema nervoso em ativar estes músculos no momento correto (SALE, 1988). 


\subsection{Treinamento dos Músculos do Assoalho Pélvico (TMAP)}

A cinesioterapia (CT) é definida como a terapia pelos movimentos e baseia-se no conhecimento de que movimentos voluntários repetidos geram força muscular (GARDINER, 1995; AMARO; GAMEIRO; PADOVANI, 2003). É um recurso que abrange a prevenção da rigidez articular, a estimulação de um músculo ou grupo muscular diminuindo as contraturas e mantendo ou recuperando a força muscular, a restituição da imagem motora evitando a perda do esquema corporal, a melhora da atividade circulatória e conseqüente nutrição tecidual e a melhora da auto-estima (XHARDEZ, 2000; CONTI et al., 2003).

A cinesioterapia para os músculos do assoalho pélvico é conhecida como "treinamento para os músculos do assoalho pélvico" (TMAP) e é uma técnica não invasiva, de baixo risco e custo reduzido. Tem como objetivo a reeducação e restauração da estática pélvica e uroginecológica, melhorando as continências urinária e fecal além de atuar na função sexual (BOURCIER ${ }^{1}, 1986$ apud OLIVEIRA et al., 2007). O TMAP fortalece a musculatura estriada, melhora a coordenação e favorece os mecanismos de fechamento ativo do esfíncter uretral (CHACEL, 1997; LEON, 2001; HAY-SMITH, 2006; SCHMIDT et al., 2009), melhora a resistência uretral e o suporte visceral, muda a atividade do mecanismo de fechamento e modifica a transmissão das taxas de pressão extra-uretral e intra-vesical, equilibrando-as (LEON, 2001).

Para Kegel (1948), trata-se de uma técnica importante na preservação da função do sistema reprodutivo da mulher e na prevenção de danos na musculatura do assoalho pélvico. O recrutamento coordenado e sincronizado dos MAP é um pré-requisito para a manutenção das continências urinária e fecal, onde a tosse, o espirro e a torção do tronco com aumento da pressão intra abdominal ampliam a força de contração destes músculos (SAPSFORD et al., 2001a).

Para que o TMAP seja eficaz deve-se ensinar aos pacientes a isolar e/ou recrutar os músculos desta região, minimizando o uso da musculatura agonista e antagonista. A contração dos músculos do assoalho pélvico consiste na elevação desta musculatura para cima e para dentro, com o objetivo de reter o conteúdo abdominal. Algumas mulheres realizam a inversão do comando, isto é, fazem esforço de expulsão quando solicitada a contração desta musculatura. Esta inversão caracteriza a contração paradoxal e/ou utilizando a musculatura acessória como a abdominal, glútea ou adutora 
(BOURCIER $^{1}$, 1986 apud OLIVEIRA et al., 2007; BUMP et al., 1991; BO; FINCKENHAGEN, 2001). Estudos avaliando a contração fisiológica dos músculos agonistas durante a contração dos músculos do assoalho pélvico, através da eletromiografia, têm demonstrado que um nível de contração dos músculos da parede abdominal sempre ocorre e é normal, porém não deve ser perceptível visualmente pelo fisioterapeuta (SAPSFORD et al., 2001b).

Na preservação e restauração da função muscular, o fundamental é a repetição frequiente e correta dos exercícios (KEGEL, 1948; NEILSON, 2009). Além disso, a motivação e colaboração da paciente (BERNARDES et al., 2000; BENEDETTO, 2004) e da equipe que a trata (HERRMANN et al., 2003) com os exercícios é um fator importante para o sucesso do tratamento (Aksac et al., 2003; HAY-SMITH, 2006; BO, 2009a). O treinamento para realizar a contração correta dos MAP pode ser feito através do auto-exame digital, com a utilização de cones vaginais ou com o perineômetro, onde a mulher é orientada a contrair e relaxar a vagina, apertando o dedo ou os cones (CHACEL, 1997).

Existem inúmeros protocolos de TMAP descritos na literatura. A duração das sessões de tratamento varia de 30 minutos a 1 hora, a freqüência varia de 1 sessão diária a 1 sessão semanal e o tempo total do tratamento varia de 2 semanas a 6 meses. Contudo, vários autores demonstraram que a terapia programada para 20 a 30 sessões, durando 30 a 45 minutos apresenta melhores resultados cinco meses após o início do tratamento (BENEDETTO, 2004).

O TMAP é conhecido como tratamento de primeira linha para a incontinência urinária, sintoma é comum entre as mulheres, principalmente durante a gravidez (MOKVED et al., 2003; SHARMA et al., 2009; WESNES et al., 2009), com aumento de sua prevalência de acordo com a progressão da gravidez e retorno aos níveis prégravídicos ou aos níveis da fase inicial da gestação com cerca de um mês após o parto (HORIKAWA et al., 2009).

Inúmeros estudos afirmam que o TMAP para o tratamento da incontinência urinária é altamente eficaz com melhora na perda urinária por até 10 anos após a terapia (ZACCHI et al., 2001; JANSSEN; LAGRO-JANSSEN; FELLING, 2001; LEON, 2001, GOLDBERG et al., 2003; CAMMU et al., 2004). E estudos que compararam o TMAP com outras técnicas usadas para o tratamento da incontinência urinária, demonstraram

\footnotetext{
${ }^{1}$ BOURCIER Alain. Urodinamique et réadaptation em urogynecologie. Paris: Editions Vigot, 1986. p. 209-221.
} 
que as terapias associadas têm melhores resultados do que quando utilizadas individualmente, porém quando compararam as terapias entre si, o TMAP é a mais efetiva, melhorando a força os músculos do assoalho pélvico e reduzindo a incontinência urinária (BO et al., 1999; AMARO; GAMEIRO; PADOVANI, 2003; SCHMIDT et al., 2009). Para Leon (2001), o TMAP deve fazer parte de programas de educação em saúde que também deve incluir informações sobre o funcionamento dos MAP e qual a melhor forma de realizar estes exercícios.

\subsection{Músculos do assoalho pélvico (MAP) e gravidez}

As modificações fisiológicas observadas no organismo materno durante a gravidez são mediadas por mudanças hormonais e são indispensáveis para o pleno desenvolvimento da gestação. O útero gravídico fornece sobrecarga ainda maior ao assoalho pélvico e a cabeça do feto promove maior pressão ao longo da gravidez, fato que, associado às modificações hormonais promove alteração da biomecânica da pelve com alterações nos tecidos conectivos e mudanças no tônus e na força muscular. $\mathrm{O}$ tecido conjuntivo responsável pelo suporte pélvico, devido a tensão, sofre alongamento progressivo durante a gravidez permitindo excessiva mobilidade do colo vesical e da uretra proximal (WIJMA et al., 2001; QUIGLEY, 2007; DINC; BEJI; YALCIN, 2009). Ocorre a síndrome do relaxamento do cinturão pélvico, que agrupa os fatores acima citados e a maior deposição hídrica no tecido conjuntivo (TINCELLO et al., 2003).

A gravidez é fator crucial no aumento da incontinência urinária em mulheres, com a progressão da gravidez há um aumento na prevalência de incontinência urinária (IU). A perda urinária aumenta durante a gestação e regride após o parto, indicando que a pressão do útero gravídico sobre a bexiga e MAP é um fator importante na gênese da incontinência urinária (MORKVED; BO, 1999; CHALIHA et al., 2000; DOLAN et al., 2004; HORIKAWA et al., 2009; SHARMA et al., 2009; WESNES et al., 2009).

A prevalência de IU é alta durante a gravidez (DIEZ-ITZA et al., 2009) e maior ainda no pós-parto vaginal (WIJMA et al., 2001; SHARMA et al., 2009), que pode traumatizar o AP e provocar lesões ou alterações dos sistemas de sustentação, provocando estiramento ou lacerações durante o período expulsivo do trabalho de parto, sendo este um importante fator na gênese da incontinência urinária (TSUNODA et al., 1999; BOYINGTON; DOUGHERTY, 2000; PELOZO JR.; GARBELLOTTI JR., 2003; PREGAZZY et al., 2002; CHIARELLI et al., 2003). No entanto, o TMAP é 
recomendado durante a gravidez e no pós parto para prevenção e tratamento da IU (NEILSON, 2009; BO, 2009a), por saber que há uma queda na força dos MAP entre a $20^{\mathrm{a}}$ semana gestacional e a $6^{\mathrm{a}}$ semana do pós parto, favorecendo o desenvolvimento da incontinência urinária (LEMOS et al., 2008).

Assim como a gravidez e o parto vaginal são fatores de risco para a incontinência urinária, a prevalência dos sintomas de IU aumentam com a idade, o peso/ obesidade, com a incidência de histerectomia, asma e bronquite, hipertensão, diabetes e menopausa, além do número de filhos e dos hábitos de vida como o fumo e sedentarismo (BOYINGTON; DOUGHERTY, 2000; SCARPA et al., 2006; BROSTROM; LOSE, 2008; ZHU et al., 2008; CORREIA et al., 2009; DIEZ-ITZA et al., 2009), conforme foi demonstrado no estudo de Wesnes et al., (2007) que investigaram os fatores de risco potenciais para a IU em mais de 40 mil mulheres na $30^{\circ}$ semana gestacional e concluíram que a incidência de incontinência urinária aumenta durante a gravidez (com incremento de mais de $30 \%$ na $30^{\text {a }}$ semana de gestação, se comparada com os fatores pré gravídicos) e que tanto antes como durante a gestação, a ocorrência de incontinência urinária está associada a idade, paridade e IMC.

Através de um questionário, Sampselle et al. (1998) avaliaram o efeito do TMAP nos sintomas de IU durante a gravidez e o pós parto em primigestas e demonstraram uma melhora significativa na freqüência de IU na $35^{\text {a }}$ semana de gestação, na $6^{\mathrm{a}}$ semana de pós parto e com 6 meses após o parto no grupo que realizou TMAP. Da mesma forma, Morkved et al. (2003) randomizaram com 301 nulíparas (exercício e controle) e relataram que o TMAP realizado durante a gravidez previne a IU em 1 de cada 6 gestantes e em 1 de cada 6 puérperas, sugerindo que o TMAP melhora a força e melhora a consciência corporal desta região aumentando a eficácia de cada contração. Chiarelli e Cockburn (2002) também avaliaram a IU no pós-parto (em 1326 mulheres) e obtiveram 83,9\% de melhora nos episódios de IU daquelas que realizaram o TMAP. Na intenção de investigar a eficácia do TMAP na prevenção da IU, Lemos et al. realizaram uma revisão sistemática em 2008 e concluíram que mulheres que realizaram TMAP durante a gravidez apresentam uma considerável diminuição dos sintomas de IU até 3 meses após o parto.

A IU comumente é estudada através o relato de perda urinária (RPU) onde o sujeito é questionado se observou perda urinária em determinado período de tempo (pré determinado) e é descrito como relato positivo ou negativo de perda urinária. Contudo, a segurança do RPU é questionada, pois o nível de escolaridade, a atenção e a vergonha 
podem interferir na resposta final (WIJMA et al., 2001). A melhor forma de diagnosticar e de estabelecer um prognóstico da IU é através da urodinâmica. Porém, este exame não é realizado rotineiramente por ser um exame invasivo e que causa incômodo moderado. Portanto, é recomendada, inclusive pela Sociedade Internacional de Continência (ICS), a escolha da avaliação clínica em pesquisas sobre IU, principalmente envolvendo mulheres grávidas saudáveis (LEMOS et al., 2008). Na verdade, o relato de perda urinária deve ser uma avaliação complementar ou complementada (WIJMA et al., 2001) apresentando grande confiabilidade com métodos objetivos de avaliação, não devendo um substituir o outro (WIJMA et al., 2008).

\subsection{Avaliação Fisioterapêutica do Assoalho Pélvico}

A primeira avaliação deve ser feita antes de iniciar o tratamento para que o fisioterapeuta tenha um conhecimento preciso do estado inicial da região a ser tratada, estabelecendo um parâmetro de base que possa servir como registro do grau e da duração da resposta ao tratamento (DELGADO et al., 2004). A avaliação dos MAP proporciona a noção da sua capacidade de contração e consiste em um passo decisivo no tratamento fisioterapeutico, sendo uma ferramenta importante para monitorar os resultados, além de servir como aprendizado e motivação para a paciente (RETT et al., 2005). Existem diversos métodos objetivos e subjetivos, acessíveis ao fisioterapeuta, para avaliar os MAP, porém não existe consenso qual seria o melhor (BO; FINCKENHAGEN, 2001; CHEHREHRAZI et al., 2009).

- Palpação digital (Escala de Oxford modificada): é a forma clínica mais usada pelos fisioterapeutas para avaliar os MAP, nela a força de contração é graduada de maneira subjetiva (HUNDLEY; WU; VISCO, 2005; FRAWLEY et al., 2009). Esta avaliação proporciona ao fisioterapeuta a noção da capacidade que a paciente tem em contrair esta musculatura e é uma excelente forma de ensinar à mulher a maneira correta de contrair estes músculos (BO; FINCKENHAGEN, 2001; UYAR; BAYTUR; INCEBOZ, 2007), ajudando a diferenciar a contração dos MAP da contração dos músculos abdominais, adutores e glúteos (MORIN et al., 2004). Existem diversas maneiras de se graduar a força dos MAP descritas na literatura (BO; FINCKENHAGEN, 2001), contudo, a escala de Oxford foi modificada para se avaliar a força dos MAP e a gradua, através da palpação digital, em seis categorias; de zero (sem função perineal objetiva) a cinco (função perineal adequada) (MOREIRA et al., 2002) 
descrita no Anexo A. A sensibilidade da palpação digital entre as avaliações é questionável e em estudos controlados, a diferença entre níveis da escala é aplicável somente aos valores médios do grupo e não em medidas individuais (MORIN et al., 2004). Além disso, não é um método válido para medir a força dos MAP, não é reprodutível, nem sensível, mas com boa correlação quando utilizada em pesquisas científicas em combinação com outros métodos de avaliação dos MAP (BO; FINCKENHAGEN, 2001).

- Perineometria: é uma forma objetiva de se avaliar os MAP e a mais utilizada pela fisioterapia (ISHERWOOD; RANE, 2000; HUNDLEY; WU; VISCO, 2005). Existem vários modelos de perineômetros, com diferentes tamanhos de sondas vaginais e parâmetros de avaliação, os quais não devem ser comparados entre si. O perineômetro de Kegel (primeiro a utilizar) consiste em uma sonda inflável de oito centímetros de comprimento e dois centímetros de diâmetro, conectada a um transdutor de pressão a ser ajustada no terço externo da cavidade vaginal a fim de graduar as pressões ali exercidas, fornecendo informações numéricas e/ou visuais em relação às contrações da musculatura do assoalho pélvico (MOREIRA et al., 2002). Além disso, não há um valor mínimo a ser obtido, sobretudo em mulheres, o que pode variar de população para população, dependendo da idade da mulher, do número e tipo de partos, peso atividade que exerce, etc. (OLIVEIRA et al., 2007). A perineometria é um instrumento simples e confiável que traduz de maneira objetiva a pressão exercida pelos MAP (CHEHREHRAZI et al., 2009), sua eficácia é potencializada quando no acompanhamento evolutivo das condições do assoalho pélvico (NAGIB et al, 2005).

Muitas mulheres não têm boa propriocepção da sua região urogenital e as medidas registradas no perineômetro equivalem às pressões exercidas pelos adutores do quadril, glúteos e abdominais, é importante isolar estes músculos acessórios a fim de facilitar somente a contração perineal (CHEHREHRAZI et al., 2009). A melhor forma de se controlar este fator é a observação dos músculos acessórios e o comando verbal realizados por um fisioterapeuta treinado (AMARO et al., 2005).

Diversas outras formas são utilizadas para medir e mensurar os MAP como eletromiografia, cones vaginal, ultrassonografia e ressonância nuclear magnética (ISHERWOOD; RANE, 2000; BO; FINCKENHAGEN, 2001; MOREIRA et al., 2002). Vários são os estudos que mostram boa correlação entre os diversos métodos de avaliação dos MAP, por exemplo: entre a palpação digital e a perineometria (ISHERWOOD; RANE, 2000; KERSCHAN-SCHINDL et al., 2002; HUNDLEY; WU; 
VISCO, 2005; UYAR; BAYTUR; INCEBOZ, 2007), o ultrassom e a palpação digital (THOMPSON et al., 2005; SHERBURN et al., 2005; THOMPSON et al., 2006; CHEHREHRAZI et al., 2009) ou a perineometria (DIETZ; JARVIS; VANCAILLIE, 2002; SHERBURN et al., 2005; CHEHREHRAZI et al., 2009) e entre diferentes tipos de perineômetro (BO; RAASTAD; FINCKENHAGEN, 2005). 
JUSTIFICATIVA 


\section{JUSTIFICATIVA}

Apesar de vários trabalhos comprovarem a eficiência do TMAP nos tratamento da IU em mulheres, a literatura ainda é escassa e controversa em relação a sua efetividade no período gestacional. Os poucos trabalhos disponíveis colocam em dúvida as questões relacionadas perda da função dos MAP ao longo da gravidez e o quanto o TMAP pode ser eficaz neste período, inclusive a descrição da metodologia para mensuração da força dos músculos do assoalho pélvico é deficiente, motivando a pesquisa deste tema.

A escolha do TMAP durante a gestação e dos métodos de análise (perioneometria e escala de Oxford modificada) justifica-se por ser um procedimento sem risco para a gestante e feto, apresentar baixo custo, fácil adesão e excelente reprodutibilidade. 


\section{OBJETIVOS}




\section{OBJETIVOS}

Os objetivos deste trabalho são:

\subsection{Principal}

- Avaliar os efeitos do TMAP durante a gestação na força dos MAP

\subsection{Secundários}

- Comparar as avaliações (digital e perineometria) ao longo da gravidez e no puerpério

- Comparar os relatos de perda urinária inicial e final

- Comparar a perineometria (pico e média) com o relato de perda urinária 
METODOLOGIA 


\section{METODOLOGIA}

\subsection{Caracterização da pesquisa}

A pesquisa foi do tipo experimental, baseada na realização de exercícios para os músculos do assoalho pélvico durante a gravidez. As pacientes arroladas tiveram esta musculatura avaliada durante a gestação (em três períodos distintos) e no puerpério (com 6 semanas após o parto). As avaliações foram realizadas baseadas em um protocolo pré-determinado desenvolvido de acordo com experiências anteriores descritas na literatura e os atendimentos individuais foram realizados semanalmente no Hospital das Clínicas da Faculdade de Medicina de Ribeirão Preto em horário previamente marcado e combinado com a gestante.

\subsection{População}

A população foi formada por gestantes de baixo risco que receberam Assistência Pré-Natal nas Unidades Básicas de Saúde interligadas do Município Ribeirão Preto.

\subsection{Amostra}

Considerando um nível de significância de $5 \%$, poder do teste $80 \%$, com teste de hipótese bicaudal para um desvio padrão estimado em 17,2 $\mathrm{cmH}_{2} \mathrm{O}$ (centímetros de água) no grupo controle (MORKVED et al., 2003) e diferença mínima detectável entre os grupos de $15,0 \mathrm{cmH}_{2} \mathrm{O}$, o tamanho amostral mínimo (n) é de 20 pacientes por grupo de acordo com o cálculo feito para comparação de duas médias através do site do Laboratório de Epidemiologia e Estatística do Instituto Dante Pazzanese de Cardiologia.

Esta amostra foi constituída por 42 gestantes com idade gestacional, na primeira avaliação de 20 semanas e que atenderam aos critérios de inclusão no estudo. A participação na pesquisa foi feita de forma voluntária e aleatória, onde a gestante foi distribuída de forma randomizada através de sorteio gerado por computador possibilitando que todas as participantes tivessem igual oportunidade de participar de qualquer dos grupos do estudo (LAKATOS; MARCONI, 1995). 
As gestantes foram divididas em dois grupos:

- Grupo Controle (GC): composto por 21 pacientes que não realizaram treinamento para os músculos do assoalho pélvico (TMAP), mas receberam orientações gerais quanto aos desconfortos músculo-esqueléticos e foram acompanhadas em datas pré-determinadas na primeira avaliação.

- Grupo Treinamento (GT): composto por 21 pacientes que realizaram TMAP semanal em 4 posições conforme protocolo utilizado por Morkved et al. (2003).

\subsection{Critérios de inclusão}

Para homogeneidade do grupo de pesquisa, foram incluídas neste estudo somente as gestantes que preencheram todos os pré-requisitos abaixo:

- Ser residente na cidade de Ribeirão Preto

- Ter entre 20 anos e 35 anos de idade

- Ser primigesta

- Estar com 20 semanas de gestação na primeira avaliação

- Gravidez de baixo risco

- Desejar participar da pesquisa

\subsection{Critérios de exclusão}

Foram excluídas do estudo as mulheres que não preencham todos os pré-requisitos citados acima ou que apresentaram as seguintes características:

- Contração paradoxal dos músculos do assoalho pélvico (no sentido caudal ao invés do cranial);

- Ausência de contração dos MAP na palpação digital (escore 0 na escala de Oxford modificada);

- Contração sinérgica visível dos MAP e dos músculos abdominais, adutores da coxa e glúteos, após orientação e treino adequados;

- Gestação múltipla;

- Qualquer outra contra-indicação relatada pela equipe médica que acompanhava a paciente durante o pré-natal. 


\subsection{Procedimentos}

Este estudo é resultado da união de dois projetos semelhantes previamente aprovados pelo Comitê de Ética e Pesquisa do Hospital das Clínicas da Faculdade de Medicina de Ribeirão Preto através do protocolo No 13756-2006. A FAPESP (Fundação de Amparo à Pesquisa do Estado de São Paulo) custeou os aparelhos e material necessários às avaliações.

No primeiro contato, explicamos à gestante o que pretendíamos realizar e o que pretendíamos alcançar com a pesquisa, onde foram demonstradas figuras a região do assoalho pélvico e seus músculos. Explicamos os procedimentos realizados na avaliação e o que pode ser observado durante as contrações. A mulher, então, foi convidada a participar de uma sessão de treinamento, uma vez que, mais de $30 \%$ das mulheres não sabem contrair os MAP corretamente, elas confundem a contração dos MAP com a contração dos glúteos, adutores do quadril e músculos abdominais (BO, 2009a), onde foi enfatizando a correta contração dos MAP, elevação sincronizada e simultânea no sentido cranio-ventral, de acordo com Thompson et al. (2006). E, na tentativa de minimizar estes erros, pelo menos uma sessão de treinamento foi realizada previamente a avaliação inicial para que a mulher aprendesse e se habituasse à contração correta dos MAP. Então, com 20 semanas de idade gestacional (IG), a mulher era avaliada e assinava o termo de consentimento livre e esclarecido para a participação na pesquisa (Anexo B).

\subsection{Instrumentos de Medida}

Foi utilizado o protocolo de avaliação (Anexo C) nas quatro avaliações distintas;

- $\quad \mathrm{Na} 20^{\mathrm{a}}$ semana de gestação

- $\quad \mathrm{Na} 24^{\mathrm{a}}$ semana de gestação

- $\quad \mathrm{Na} 36^{\mathrm{a}}$ semana de gestação

- Com 6 semanas após o parto

A avaliação foi feita por um avaliador-cego, que não entrou em contato com a gestante em nenhum momento durante o estudo, a não ser nas quatro avaliações previamente agendadas, e não sabia qual grupo a paciente se encontrava. No protocolo constavam dados referentes à identificação geral e exame físico de cada paciente incluída na pesquisa. No exame físico constavam dados sobre: 
- Avaliação geral da gestante: baseada na visualização e questionamento da paciente, descartando as características citadas nos critérios de exclusão ou qualquer qualidade física que viesse a influenciar nos MAP.

- Avaliação dos MAP: feita sempre em posição de litotomia, onde a posição da paciente durante a avaliação pode influenciar nos resultados e em decúbito dorsal as forças gravitacionais podem ser atenuadas, assim como facilitar a visualização da região abdominal, adutores do quadril e glúteos (BO; FINCKENHAGEN, 2001; AMARO et al., 2005). A posição de decúbito dorsal com os joelhos dobrados é a posição recomendada para avaliar os MAP de acordo com estudo de Frawley et al. (2009) que avaliou os MAP através da perineometria e palpação digital de 20 mulheres em diferentes posições e concluiu que a posição sentada é a que apresenta maiores valores na pressão dos MAP, porém não é uma posição confortável, nem de fácil acesso a região, além da força gravitacional e como os valores nas posições em decúbito dorsal (com joelhos dobrados e com joelhos estendidos) apresentaram valores semelhantes, recomendam utilizar uma ou outra posição, dando preferência a com os joelhos dobrados, por apresentar menor variação e maior conforto a paciente.

- Inspeção perineal e vaginal: na busca de dados referentes a pele, tônus, presença de cicatriz ou feridas, edema, prolapsos e hemorróidas (MORENO, 2004; OLIVEIRA, 2006).

- Palpação perineal e vaginal: palpação externa dos músuclos da região, observando sensibilidade e dor local, volume dos músculos, contraturas ou atrofias, tônus em repouso e durante a contração, simetria muscular, trofismo, força e resposta reflexa dos músculos durante a tosse, além da observação da presença ou não de contração dos músculos acessórios (MORENO, 2004; STEPHENSON; O’CONNOR, 2004). A palpação vaginal foi realizada através do toque bidigital, introduzindo os dedos indicador e médio três a quatro centímetros na cavidade vaginal, realizando movimento semicircular de $180^{\circ}$ palpando os músculos perivaginais (BO et al., 1990b; BERNARDES et al., 2000; OLIVEIRA, 2006). Durante a palpação digital, a força dos MAP foi classificada através dos escores da escala de Oxford modificada (Anexo A), e feita classificação de acordo com a função perineal objetiva (se a contração é perceptível ou não) e a função perineal subjetiva (se a contração muscular é capaz de se manter por alguns segundos).

- Perineometria: onde foi utilizada uma sonda inflável $(28 \mathrm{~mm}$ de diâmetro e $108 \mathrm{~mm}$ de comprimento) revestida por uma preservativo masculino não lubrificado, 
coberto por gel carbopol em quantidade padronizada (aproximadamente 20g). Esta sonda era acoplada ao aparelho Peritron ${ }^{\circledR}$ (Cardio-Design, Australia) que permite a transmissão da pressão dos MAP a ser interpretada em centímetros da água $\left(\mathrm{cmH}_{2} \mathrm{O}\right)$. A sonda foi introduzida na vagina lentamente de modo a restar cerca de 2 centímetros da sonda para fora, a partir dos lábios vaginais.

O aparelho era, então, zerado no início de cada contração e solicitada a contração dos MAP. Foram registradas somente contrações com observação simultânea dos músculos acessórios e movimento interno dos MAP. Durante todo o período em que a paciente era solicitada a contrair os MAP foram dados estímulos verbais para que a mesma mantivesse sua contração o mais alta possível e foram computadas 3 contrações ao todo e as medidas de pico e média registradas para análise.

Os pesquisadores envolvidos na coleta de dados (avaliação e treinamento) eram fisioterapeutas formadas, com especialização em Fisioterapia na Saúde da Mulher e todos os procedimentos realizados eram adequados à prática do profissional fisioterapeuta mediante a Resolução $N^{\circ}$ 08/78 do COFFITO (Conselho Federal de Fisioterapia e Terapia Ocupacional).

$\mathrm{Na}$ ocasião da primeira avaliação, as mulheres assinaram o termo de consentimento livre e esclarecido e foram randomizadas. A randomização foi realizada previamente por computador, onde a fisioterapeuta só tinha acesso a legenda do grupo a qual pertencia a paciente no momento da randomização.

No protocolo de tratamento, o TMAP foi realizado em quatro posições distintas (decúbito lateral esquerdo, sentada, joelhos - 4 apoios - e posição ortostática), conforme Anexo D e cada posição consistia de:

- 10 contrações submáximas mantidas por 6 a 8 segundos, pausa de aproximadamente seis segundos entre cada contração e

- 3 a 4 contrações rápidas.

As contrações foram associadas à respiração, ou seja, no momento da contração muscular, a paciente deveria expirar o ar, evitando apnéia e facilitando respiração.

Todas as sessões foram individualizadas, apenas com o fisioterapeuta e a paciente no ambiente para uma maior compreensão dos exercícios e propriocepção da região, pois é sabido que as pacientes que realizam TMAP supervisão adequada podem obter maior intensidade dos exercícios, com melhores resultados (MORENO, 2004; BO, 2009a). 
O fisioterapeuta permaneceu sempre ao lado das pacientes incentivando e auxiliando nos exercícios que foram realizados apenas no período gestacional, não sendo incentivada ou desestimulada a prática dos exercícios durante o puerpério. Cada atendimento teve a duração média de 20 minutos e o protocolo consistiu em exercícios para os MAP durante 16 semanas.

As mulheres do grupo exercício foram incentivadas a realizar os exercícios em casa, duas vezes por dia, em sua posição preferida, realizando 8 a 12 contrações para a musculatura do assoalho pélvico com igual intensidade. Este protocolo foi publicado anteriormente por Bo, Talseth e Holme (1999).

\subsection{Variáveis analisadas}

4.8.1 Variáveis de caracterização da amostra

- Unidade Básica de Saúde (UBS) de procedência

- Profissão

- Anos de estudo

- Estado civil

- Raça

- Idade

- Peso

- Altura

- Índice de massa corporal (IMC)

4.8.2 Variáveis dependentes

- Perineometria (pico e média)

- Grau de força dos MAP (escala de Oxford modificada)

- Relato de perda urinária (RPU)

\subsection{Análise estatística}

Após a coleta das variáveis, os dados foram analisados estatisticamente a fim de se avaliar os efeitos do TMAP durante a gestação na força dos MAP, levando-se em consideração um valor P>0,05, ou seja, índice de significância a 5\% (cinco por cento).

Para a descrição da amostra utilizou-se os procedimentos PROC FREQ e PROC MEANS do software $S A S^{\circledR}$ 9.0. Nas analises de associação entre os grupos (variáveis de 
caracterização da amostra, escala de Oxford modificada e relato de perda urinária) e na análise da influência das covariáveis na graduação de força e no relato de perda urinária foi utilizado o teste exato de Fisher (PAGANO; GAUVREAU, 2004) utilizando o procedimento PROC FREQ do software $S A S^{\circledR}$ 9.0.

Nas análises da perineometria (influência das covariáveis; ao longo das avaliações; $v s$ relato de perda e $v s$ escala de Oxford modificada) foi utilizado o modelo de regressão linear com efeitos mistos (efeitos aleatórios e fixos), os quais são utilizados na análise de dados em que as respostas estão agrupadas com mais de uma medida para um mesmo indivíduo e não há independência entre as observações de um mesmo grupo (SCHALL, 1991). Esses modelos têm como pressuposto que seus resíduos tem distribuição normal com média 0 e variância $\sigma^{2}$. Quando os valores não apresentaram distribuição normal, foram realizadas transformações da variável, realizado através do software SAS ${ }^{\circledR}$ 9.0, utilizando a PROC MIXED e utilizando contrastes ortogonais para as comparações.

Nas análises da escala de Oxford modificada e do relato de perda urinária ao longo das avaliações, utilizou-se o coeficiente kappa, introduzido por Cohen (1960), o qual mede o grau de concordância entre os testes em variáveis categóricas. O coeficiente kappa é representado pela letra grega $\kappa$ e indica a probabilidade de concordância observacional em excesso à probabilidade de concordância oriunda do acaso (LANDIS; KOCH, 1977; AGRESTI, 1990). O coeficiente kappa pode assumir o valor máximo de 1 (correspondendo a uma perfeita concordância) e mínimo de 0 (indicando que a concordância é igual àquela esperada pelo acaso), de acordo com os valores obtidos, a concordância varia de acordo com a tabela a seguir:

Tabela 1 - significado dos valores do coeficiente da kappa, análise de concordância

\begin{tabular}{cc}
\hline COEFICIENTE KAPPA & FORÇA DA CONCORDÂNCIA \\
\hline menor que zero & poor (pobre) \\
$0,00-0,20$ & slight (desprezível) \\
$0,21-0,40$ & fair (suave) \\
$0,41-0,60$ & moderate (moderada) \\
$0,61-0,80$ & substantial (substancial, grande) \\
$0,81-1,00$ & almost perfect (quase perfeita) \\
\hline Fonte: Landis e Koch (1977)
\end{tabular}


RESULTADOS 


\section{RESULTADOS}

A apresentação dos resultados do presente estudo será feita, inicialmente, pela caracterização da amostra estudada, quanto as variáveis clínicas e epidemiológicas. Logo após, as variáveis dependentes do estudo serão descritas de maneira geral no início do estudo em cada um dos grupos estudados.

Posteriormente serão apresentados os dados das variáveis dependentes quanto a influencia dos dados de caracterização da amostra por grupo nestas variáveis. E, finalmente, serão feitas análises das relações das variáveis dependentes entre si, fazendo referência aos objetivos deste estudo.

\subsection{Descrição das variáveis}

As variáveis de caracterização da amostra (profissão, anos de estudo, estado civil, raça, idade, peso, altura e índice de massa corporal) apresentaram-se homogêneas entre os grupos, conforme pode ser observado no Anexo E.

As variáveis dependentes do estudo (perineometria, grau de força e relato de perda urinária) também se apresentaram homogêneas entre os grupos no início do estudo, como pode ser observado a seguir.

\section{- PERINEOMETRIA}

O gráfico 1 mostra as médias das perineometrias (pico e média) na avaliação 1 (com 20 semanas de gestação) em cada um dos grupos estudados. Verificamos que o grupo controle apresentava médias dos valores de pico $\left(51,89 \mathrm{cmH}_{2} \mathrm{O}\right)$ e média $\left(33,71 \mathrm{cmH}_{2} \mathrm{O}\right)$ maiores que o grupo treinamento $\left(\right.$ pico $=43,01 \mathrm{cmH}_{2} \mathrm{O}$ e média $=28,21 \mathrm{cmH}_{2} \mathrm{O}$ ). Apesar desta diferença, estes valores não foram considerados significativos estatisticamente com um valor $\mathrm{p}$ entre os grupos de 0,18 para o pico e 0,47 para a média, demonstrando homogeneidade da amostra. 


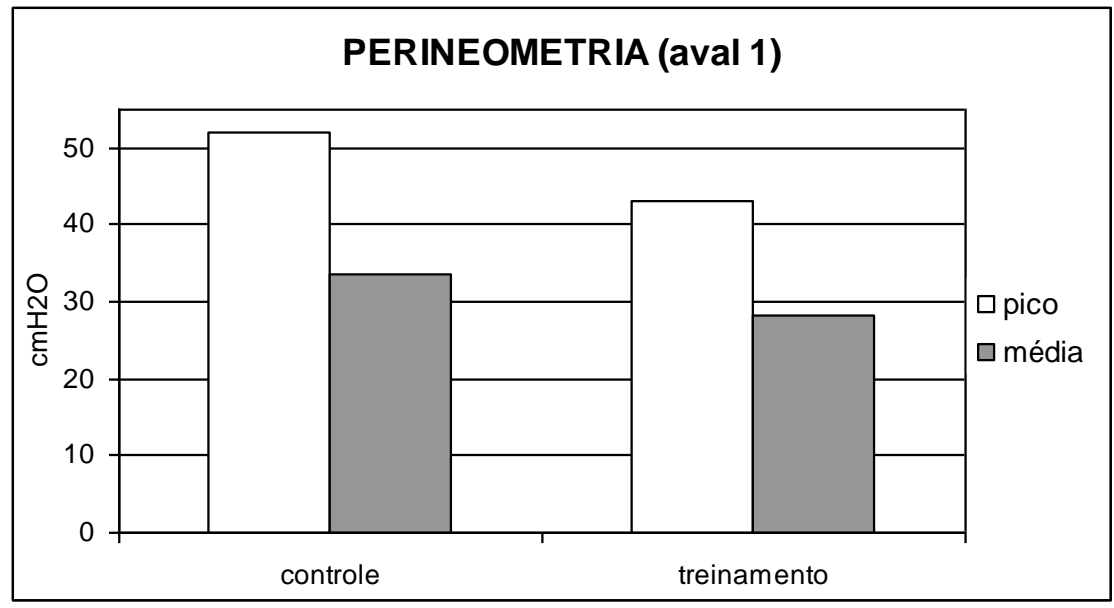

aval 1 = avaliação 1 (20 semanas de gestação) $\mathrm{cmH}_{2} \mathrm{O}=$ centímetros de água

Gráfico 1 - Médias das perineometrias (pico e média) dos grupos controle e treinamento na aval 1

- GRAU DE FORÇA (escala de Oxford modificada)

$\mathrm{Na}$ análise da graduação de força pelos escores da escala de Oxford modificada, foi observado que no grupo controle, o grau de força tendeu a se concentrar entre os escores 2 e $3(66 \%)$ e no grupo treinamento a concentração maior foi observada no grau $2(48 \%)$. Ainda, $57 \%$ das mulheres do grupo controle e $48 \%$ do grupo treinamento apresentaram graduação maior que 3. Nesta análise, o valor $p$ entre os grupos foi de 0,81 .

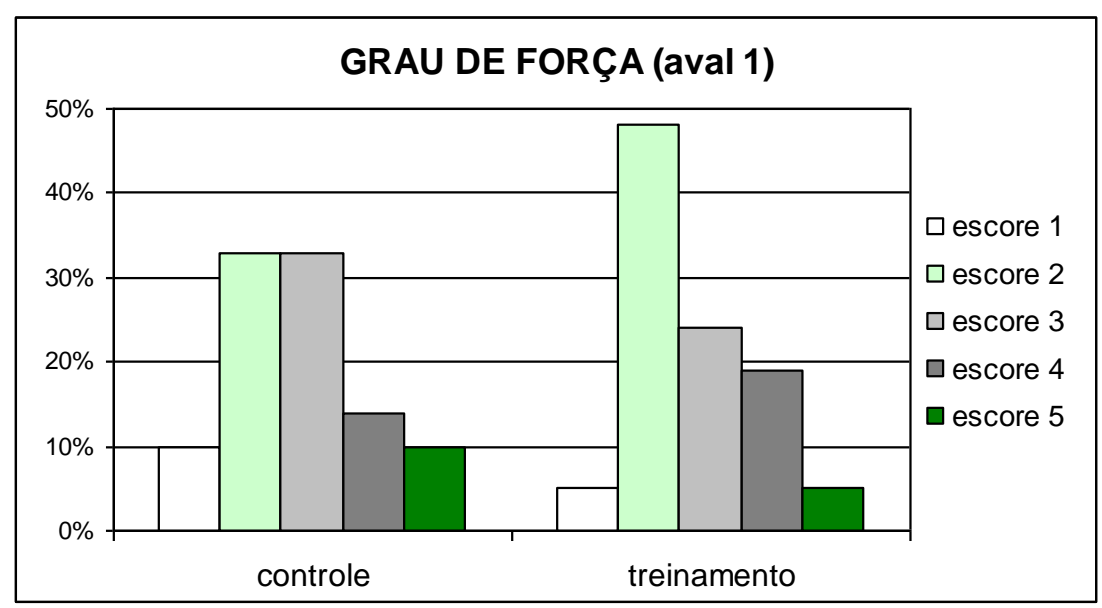

aval 1 = avaliação 1 (20 semanas de gestação)

Gráfico 2 - Porcentagens por escores de grau de força (escala de Oxford modificada) nos grupos controle e treinamento na avaliação 1 .

\section{- RELATO DE PERDA URINÁRIA (RPU)}

$\mathrm{Na}$ aval 1, as pacientes foram questionadas quanto a perda urinária prévia a gravidez e se houve perda de urina no último mês (entre a $16^{\mathrm{a}}$ e $20^{\mathrm{a}}$ semana de gestação). Como pode ser observado no gráfico 3, a maioria das pacientes não perdiam 
urina antes de ficar grávida ( $86 \%$ em ambos os grupos). Após engravidarem, 52\% das gestantes do grupo controle e $33 \%$ do grupo treinamento, relataram perda urinária no último mês, quando questionadas na aval 1 (com 20 semanas de gestação). Esta diferença não foi significativa, com um valor $\mathrm{p}=0,99$ para incontinência urinária (IU) prévia a gestação e 0,34 para a perda de urina entre a $16^{\mathrm{a}}$ e $20^{\mathrm{a}}$ semana de gestação.

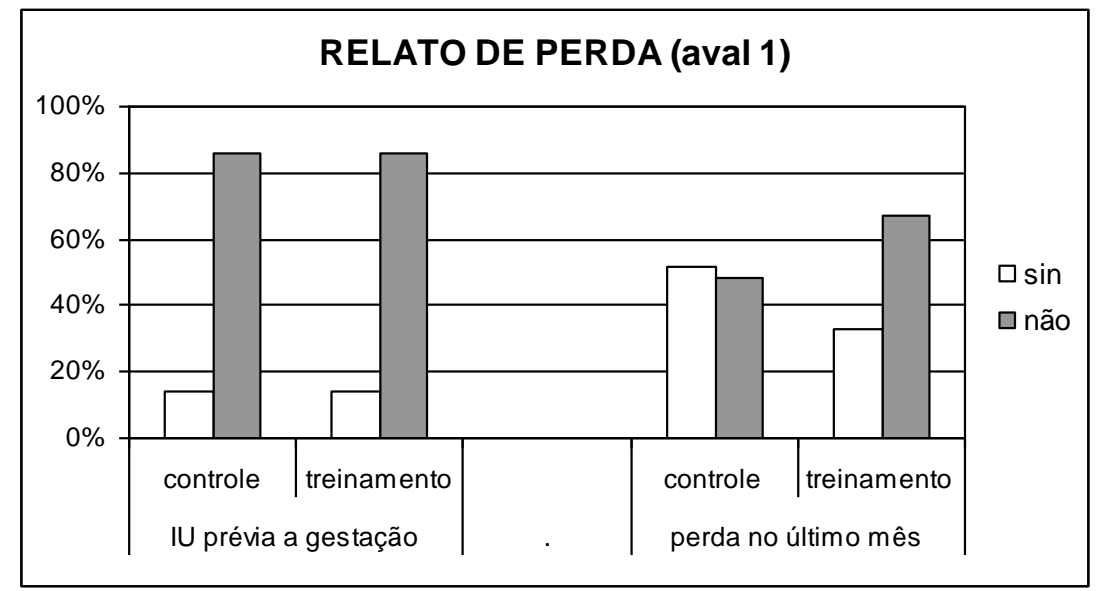

aval 1 = avaliação 1 (20 semanas de gestação)

IU = incontinência urinária

Gráfico 3 - Porcentagens do RPU antes da gravidez e entre $16^{\mathrm{a}}$ e $20^{\mathrm{a}}$ semana de idade gestacional nos grupos controle e treinamento na avaliação 1 .

\subsection{Análise da influência da caracterização da amostra (idade, peso, altura e IMC)} vs grupo nas variáveis dependentes (perineometria, grau de força e relato de perda urinária)

\section{- PERINEOMETRIA}

Pode ser observado nas tabelas a seguir que as variáveis de caracterização da amostra (idade, peso e altura) não influenciaram na perineometria (pico e média) em nenhuma das avaliações e em nenhum dos grupos. O cálculo de influência do IMC não foi possível ser feito, uma vez que ele é dependente das variáveis peso e altura, já presentes neste cálculo de influência.

- pico

Por não apresentarem distribuição normal os valores da perineometria (pico) foram transformados para log do pico. Os P-valores encontradas para a variável pico foram de 0,58 para a idade, 0,87 para o peso e 0,92 para a altura.

\section{- média}

Os valores da perineometria (média) também foram transformados, para raiz quadrada da média, pois não apresentavam distribuição normal. Após a transformação, 
obteve-se um P-valor para o cálculo de influência de cada uma das covariáveis (idade, peso e altura) sobre a variável média, onde para a idade foi de 0,76 , para o peso 0,35 e para a altura 0,62 .

\section{- GRAU DE FORÇA}

A influência das variáveis de caracterização da amostra (idade, peso, altura e IMC) na graduação da força pela escala de Oxford modificada (variável categórica) foi avaliada separadamente, uma por vez, em relação aos grupos estudados em cada uma das três avaliações. Não foi encontrada influência das covariáveis nas avaliações nos grupos estudados, com exceção da variável peso na avaliação 3 dos dois grupos $(\mathrm{p}=0,02)$. Porém, quando foi feita a análise da influência do peso nos escores de graduação de força nos grupos separadamente, esta influência não foi observada, sendo $\mathrm{p}=0,14$ para o grupo controle e $\mathrm{p}=0,5$ para o grupo treinamento. $\mathrm{O}$ Anexo $\mathrm{F}$ mostra todos os dados desta análise de influência detalhadamente.

Tabela 2 - Influência da covariável peso na graduação de força (escala de Oxford modificada) no grupo geral e separadamente (controle e treinamento) na aval 3

\begin{tabular}{|c|c|c|c|c|c|c|}
\hline VARIÁVEIS & $\begin{array}{c}\text { escore } 1 \\
\%(n) \\
\end{array}$ & $\begin{array}{c}\text { escore } 2 \\
\%(n) \\
\end{array}$ & $\begin{array}{c}\text { escore } 3 \\
\%(n) \\
\end{array}$ & $\begin{array}{c}\text { escore } 4 \\
\%(n) \\
\end{array}$ & $\begin{array}{c}\text { escore } 5 \\
\%(n) \\
\end{array}$ & P-valor \\
\hline \multicolumn{7}{|l|}{ Peso $(\mathrm{kg})$} \\
\hline \multicolumn{7}{|l|}{ AVAL 3 GERAL } \\
\hline$<51 \mathrm{~kg}$ & $0 \%(0)$ & $50 \%(3)$ & $33 \%(2)$ & $17 \%(1)$ & $0 \%(0)$ & \multirow{3}{*}{$0,02 *$} \\
\hline $51 \mathrm{~kg}-70 \mathrm{~kg}$ & $15 \%(4)$ & $31 \%(8)$ & $19 \%(5)$ & $31 \%(8)$ & $4 \%(1)$ & \\
\hline$>70 \mathrm{~kg}$ & $0 \%(0)$ & $0 \%(0)$ & $60 \%(6)$ & $10 \%(1)$ & $30 \%(3)$ & \\
\hline \multicolumn{7}{|l|}{ AVAL 3 CONTROLE } \\
\hline$<51 \mathrm{~kg}$ & $0 \%(0)$ & $33 \%(1)$ & $33 \%(1)$ & $33 \%(1)$ & $0 \%(0)$ & \multirow{3}{*}{0,14} \\
\hline $51 \mathrm{~kg}-70 \mathrm{~kg}$ & $27 \%(3)$ & $27 \%(3)$ & $18 \%(2)$ & $18 \%(2)$ & $9 \%(1)$ & \\
\hline$>70 \mathrm{~kg}$ & $0 \%(0)$ & $0 \%(0)$ & $57 \%(4)$ & $0 \%(0)$ & $43 \%(3)$ & \\
\hline \multicolumn{7}{|l|}{ AVAL 3 TREINAMENTO } \\
\hline$<51 \mathrm{~kg}$ & $0 \%(0)$ & $67 \%(2)$ & $33 \%(1)$ & $0 \%(0)$ & $0 \%(0)$ & \multirow{3}{*}{0,5} \\
\hline $51 \mathrm{~kg}-70 \mathrm{~kg}$ & $7 \%(1)$ & $33 \%(5)$ & $20 \%(3)$ & $40 \%(6)$ & $0 \%(0)$ & \\
\hline$>70 \mathrm{~kg}$ & $0 \%(0)$ & $0 \%(0)$ & $67 \%(2)$ & $33 \%(1)$ & $0 \%(0)$ & \\
\hline $\begin{array}{l}n=\text { número } \\
\mathrm{kg}=\text { quilog } \\
\text { aval } 3=\text { ava } \\
* \text { dado sign }\end{array}$ & $\begin{array}{l}\text { mulhere } \\
\text { ma } \\
\text { ação } 3 \text { (3r } \\
\text { cativo est }\end{array}$ & $\begin{array}{l}\text { nanas de } \\
\text { icamente }\end{array}$ & $\begin{array}{l}\text { tação) } \\
\text { 95\%) }\end{array}$ & & & \\
\hline
\end{tabular}

\section{- RELATO DE PERDA URINÁRIA (RPU)}

Também foi analisada a influência das variáveis de caracterização da amostra (idade, peso, altura e IMC) sobre o relato positivo ou negativo de perda urinária nas 
avaliações 1 e 3 e não foi encontrada influência em nenhuma análise, conforme pode ser observado no Anexo G.

\subsection{Análise da relação das variáveis dependentes entre si.}

\section{- PERINEOMETRIA vs AVALIAÇÃO}

O gráfico a seguir mostra os valores da perineometria (pico e média) nas três avaliações em cada um dos grupos estudados. Verificamos que a mudança do grupo não influencia nos valores da perineometria ( $\mathrm{p}=0,18$ para o pico e $\mathrm{p}=0,21$ para a média), mas a mudança da avaliação influencia na perineometria ( $\mathrm{p}<0,01$ para pico e média), porém não há efeito de interação conforme muda-se o grupo e a avaliação $(\mathrm{p}=0,22$ para pico e $\mathrm{p}=0,11$ para média. As medidas descritivas da perineometria (pico e média) en todas as avaliações são demonstradas no Anexo H. Conforme a tabela 3, não foi encontrada diferença significativa na análise entre os grupos em cada uma das avaliações.

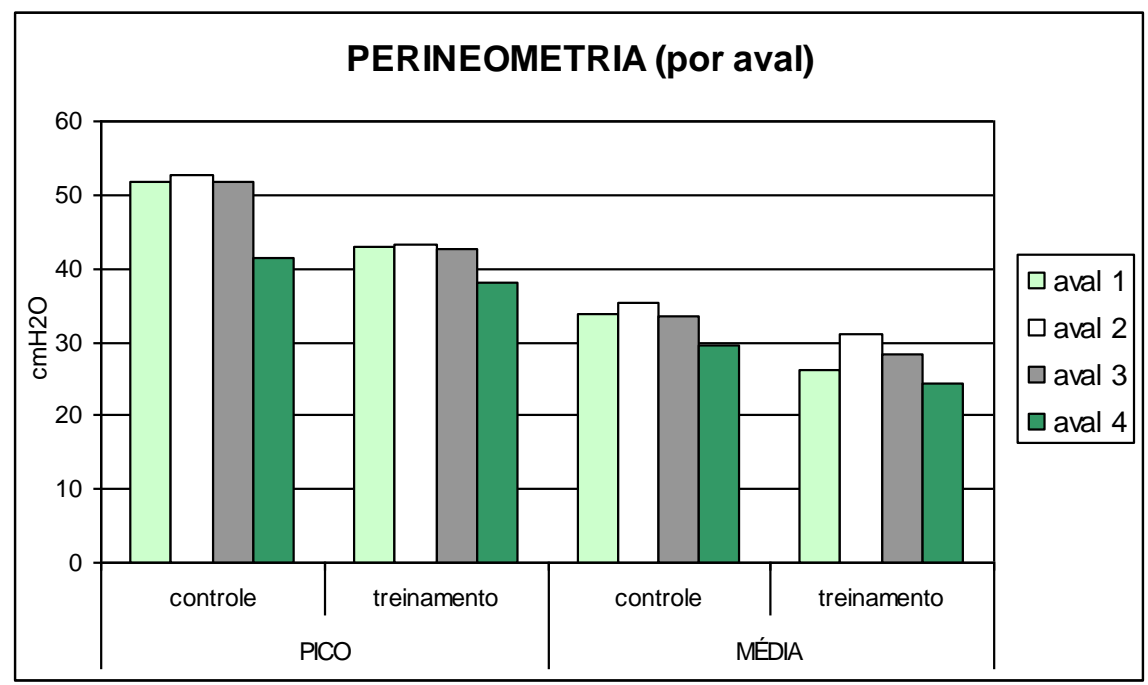

aval $=$ avaliação $\mathrm{cmH}_{2} \mathrm{O}=$ centímetros de água

Gráfico 4. Valores da perineometria (pico e média) em cada uma das avaliações por grupo.

Tabela 3 - Comparações entre os grupos em relação as variáveis perineometria (pico e média) em cada uma das avaliações.

\begin{tabular}{ccccc}
\hline COMPARAÇÕES & \multirow{2}{*}{ ESTIMATIVA } & \multicolumn{2}{c}{ IC (95\%) PARA } & \multirow{2}{*}{ PIFERENÇA } \\
\cline { 3 - 4 } & & \multicolumn{1}{c}{ LI } & \multicolumn{1}{c}{ LS } & \\
\hline Perineometria (pico) & & & & \\
aval 1 (controle - treinamento) & 0,1901 & $-0,08975$ & 0,4699 & 0,18 \\
aval 2 (controle - treinamento) & 0,1726 & $-0,1072$ & 0,4524 & 0,22 \\
aval 3 (controle - treinamento) & 0,2497 & $-0,03195$ & 0,5313 & 0,08 \\
aval 4 (controle - treinamento) & 0,1218 & $-0,158$ & 0,4016 & 0,39 \\
\hline $\begin{array}{c}\text { Perineometria (média) } \\
\text { aval 1 (controle - treinamento) }\end{array}$ & 0,4242 & $-0,3897$ & 1,2381 & 0,30
\end{tabular}


aval 2 (controle - treinamento) aval 3 (controle - treinamento)

0,3205

$-0,4934$

1,1344

0,43

aval 4 (controle - treinamento)

0,7688

$-0,05106$

1,5888

0,06

0,4571

$-0,3568$

1,2709

0,27

Apesar da queda nos valores da perineometria ao longo da gravidez, os valores demonstram-se semelhantes nas avaliações durante a gestação em ambos os grupos. Foi encontrada diferença significativa estatisticamente na variável perineometria (pico e média) somente nas análises com a aval 4 no grupo controle (ver tabela 4). O grupo treinamento também apresentou diferença significativa nas análises com a aval 4 e também na variável perineometria (média) entre as avaliações ao longo da gravidez, conforme a tabela 6 com nenhuma diferença significa entre a aval 3 e a aval 4 .

Tabela 4 - Comparações entre avaliações intra-grupo em relação as variáveis perineometria (pico e média).

\begin{tabular}{|c|c|c|c|c|}
\hline \multirow[t]{2}{*}{ COMPARAÇÕES } & \multirow[t]{2}{*}{ ESTIMATIVA } & \multicolumn{2}{|c|}{$\begin{array}{c}\text { IC }(95 \%) \text { PARA } \\
\text { DIFERENÇA }\end{array}$} & \multirow{2}{*}{$\begin{array}{c}\text { P- } \\
\text { VALOR }\end{array}$} \\
\hline & & LI & LS & \\
\hline \multicolumn{5}{|l|}{ Perineometria (pico) } \\
\hline controle (aval $1-$ aval 2) & $-0,000851$ & $-0,09185$ & 0,07483 & 0,84 \\
\hline controle (aval 1 - aval 3) & $-0,0059$ & $-0,0921$ & 0,08029 & 0,89 \\
\hline controle (aval 1 - aval 4) & 0,2801 & 0,1967 & 0,3634 & $<0,01 *$ \\
\hline controle (aval 2 - aval 3) & 0,002607 & $-0,08359$ & 0,0888 & 0,95 \\
\hline controle (aval 2 - aval 4) & 0,2886 & 0,2052 & 0,3719 & $<0,01 *$ \\
\hline controle (aval 3 - aval 4) & 0,286 & 0,1998 & 0,3722 & $<0,01 *$ \\
\hline treinamento (aval 1 - aval 2) & $-0,02601$ & $-0,1093$ & 0,05733 & 0,54 \\
\hline treinamento (aval 1 - aval 3) & 0,05371 & $-0,03249$ & 0,1399 & 0,22 \\
\hline treinamento (aval 1 - aval 4) & 0,2118 & 0,1285 & 0,2951 & $<0,01 *$ \\
\hline treinamento (aval 2 - aval 3) & 0,07971 & $-0,00648$ & 0,1659 & 0,06 \\
\hline treinamento (aval 2 - aval 4) & 0,2378 & 0,1545 & 0,3212 & $<0,01 *$ \\
\hline treinamento (aval 3 - aval 4) & 0,1581 & 0,07191 & 0,2443 & $<0,01 *$ \\
\hline \multicolumn{5}{|l|}{ Perineometria (média) } \\
\hline controle (aval 1 - aval 2) & $-0,1622$ & $-0,4211$ & 0,09675 & 0,21 \\
\hline controle (aval 1 - aval 3) & $-0,05215$ & $-0,3199$ & 0,2156 & 0,70 \\
\hline controle (aval 1 - aval 4) & 0,3963 & 0,1374 & 0,6552 & $<0,01 *$ \\
\hline controle (aval 2 - aval 3) & 0,11 & $-0,1578$ & 0,3778 & 0,41 \\
\hline controle (aval 2 - aval 4) & 0,5584 & 0,2995 & 0,8174 & $<0,01 *$ \\
\hline controle (aval 3 - aval 4) & 0,4484 & 0,1807 & 0,7162 & $<0,01 *$ \\
\hline treinamento (aval 1 - aval 2) & $-0,4658$ & $-0,5247$ & $-0,00693$ & $0,04 *$ \\
\hline treinamento (aval 1 - aval 3) & $-0,2925$ & 0,02471 & 0,5602 & $0,03 *$ \\
\hline treinamento (aval 1 - aval 4) & 0,4291 & 0,1702 & 0,688 & $<0,01 *$ \\
\hline treinamento (aval 2 - aval 3) & 0,3583 & 0,2905 & 0,8261 & $<0,01 *$ \\
\hline treinamento (aval 2 - aval 4) & 0,695 & 0,4361 & 0,9539 & $<0,01 *$ \\
\hline treinamento (aval 3 - aval 4) & 0,1367 & $-0,1311$ & 0,4044 & 0,31 \\
\hline
\end{tabular}

\section{- GRAU DE FORÇA vs AVALIAÇÃO}

A graduação da força pelos escores pela escala de Oxford modificada também foi analisada ao longo das avaliações em cada um dos grupos. Na comparação entre os 
grupos em cada uma das avaliações, não foi encontrada nenhuma diferença significativa estatisticamente (aval $1 \mathrm{p}=0,81$, aval $2 \mathrm{p}=0,73$ e aval $3 \mathrm{p}=0,11$ ), na aval 4 o valor $\mathrm{p}$ foi $<0,01$, como pode ser visto no Anexo I.

Na comparação intra grupo, valor p encontrado para o grupo controle ao longo das avaliações foi de 0,97 e para o grupo treinamento de 0,9 , o que significa que a mudança na porcentagem dos escores ao longo das avaliações (gráfico 5) não foi considerada significativa estatisticamente.

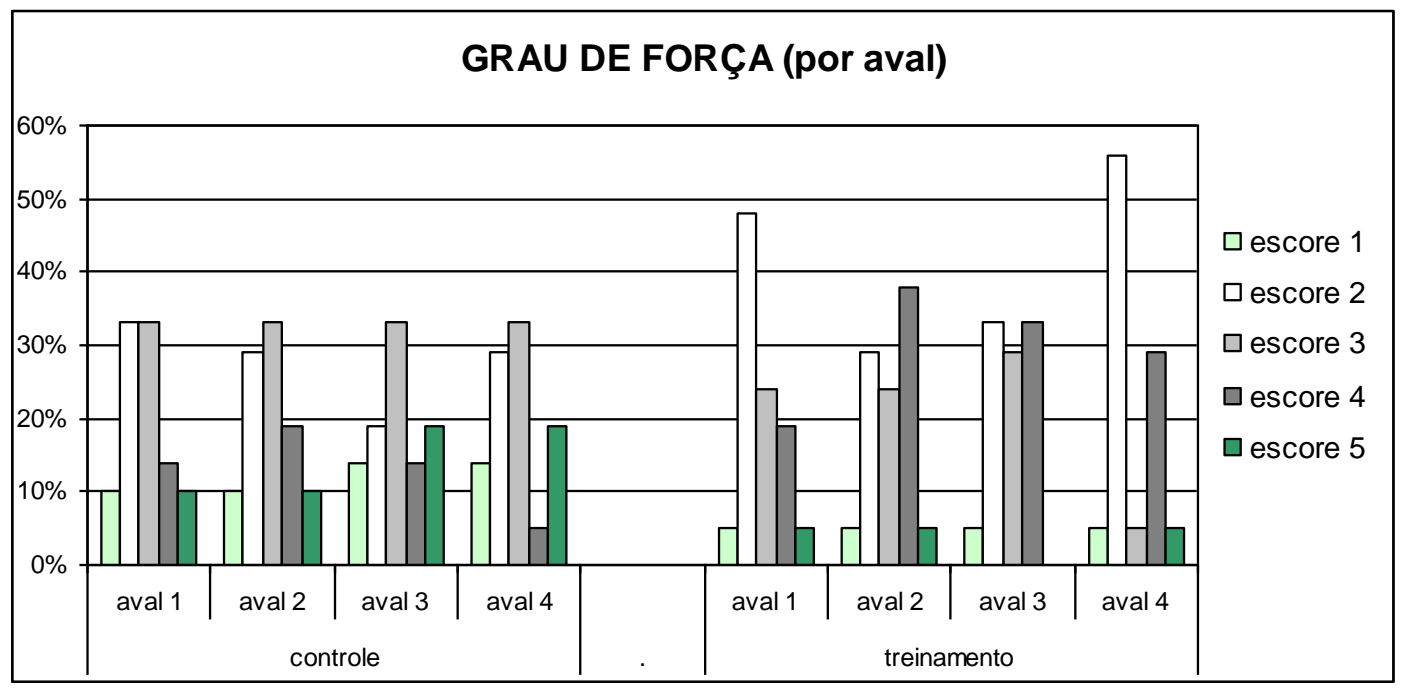

aval $=$ avaliação

Gráfico 5. Porcentagem de mulheres por escore de força de acordo com a escala de Oxford modificada por grupo em cada uma das avaliações.

A mudança existente foi, então, analisada pelo coeficiente de kappa (descritos no Anexo J) que analisa o grau de concordância entre as avaliações. As concordâncias das avaliações foram consideradas moderadas, com exceção das avaliações 2 e 3 e das avaliações 3 e 4 no grupo treinamento, que apresentaram grande concordância, ou seja, os valores não mudaram muito de uma avaliação parta outra.

Os coeficientes de kappa permitem comparações entre si e o que se pode observar é que entre as avaliações 1 e 3 o grupo controle (Kappa=0,54) concorda mais que o, grupo treinamento (Kappa=0,46), o grupo treinamento mudou mais de escore. Entre as avaliações 1 e 4, o grupo controle (Kappa=0,52) concorda menos que o grupo treinamento (Kappa=0,41), o grupo treinamento tende a manter no pós-parto os escores semelhantes aos do $2^{\circ}$ trimestre gestacional. E entre as avaliações 3 e 4 , o grupo controle $($ Kappa $=0,49)$ concorda menos que o grupo treinamento grupo treinamento (Kappa=0,73). Ou seja, treinamento parece influenciar na concordância da aval 1 para a 3 e manter os escores da aval 1 para 4 e da aval 3 para 4 . 
Diante dos resultados, foi feita a análise de associação dos escores de força entre as avaliações analisando o número de mulheres que diminuiu, manteve ou aumentou de escore de força entre uma avaliação e outra (tabela 5) e nenhum resultado significativo estatisticamente foi encontrado.

Tabela 5 - Associação entre efeito das avaliações nos escores de força por grupo.

\begin{tabular}{|c|c|c|c|c|}
\hline \multirow{2}{*}{$\begin{array}{c}\text { grau de força } \\
\text { (aval } 1 \rightarrow \text { aval 3) }\end{array}$} & \multicolumn{2}{|c|}{ GRUPO } & \multirow{2}{*}{ TOTAL } & \multirow{2}{*}{$\begin{array}{c}\text { P- } \\
\text { VALOR }\end{array}$} \\
\hline & CONTROLE & TREINAMENTO & & \\
\hline diminuiu & 4 & 2 & 6 & \\
\hline manteve & 6 & 7 & 13 & 0,82 \\
\hline aumentou & 11 & 12 & 23 & \\
\hline \multirow{2}{*}{$\begin{array}{c}\text { grau de força } \\
(\text { aval } 1 \rightarrow \text { aval 4) }\end{array}$} & \multicolumn{2}{|c|}{ GRUPO } & \multirow{2}{*}{ TOTAL } & \multirow{2}{*}{$\begin{array}{c}\text { P- } \\
\text { VALOR }\end{array}$} \\
\hline & CONTROLE & TREINAMENTO & & \\
\hline diminuiu & 6 & 4 & 10 & \\
\hline manteve & 10 & 13 & 23 & 0,70 \\
\hline aumentou & 5 & 4 & 9 & \\
\hline \multirow{2}{*}{$\begin{array}{c}\text { grau de força } \\
\text { (aval } 3 \rightarrow \text { aval 4) }\end{array}$} & \multicolumn{2}{|c|}{ GRUPO } & \multirow{2}{*}{ TOTAL } & \multirow{2}{*}{$\begin{array}{c}\text { P- } \\
\text { VALOR }\end{array}$} \\
\hline & CONTROLE & TREINAMENTO & & \\
\hline diminuiu & 7 & 5 & 12 & \\
\hline manteve & 10 & 15 & 25 & 0,24 \\
\hline aumentou & 4 & 1 & 5 & \\
\hline
\end{tabular}

\section{- RELATO DE PERDA URINÁRIA (RPU) vs AVALIAÇÃO}

Como foi dito anteriormente, na ocasião da primeira avaliação, as mulheres foram questionadas quanto a perda de urina no último mês (entre a $16^{\mathrm{a}}$ e $20^{\mathrm{a}}$ semana de gestação) e foi encontrado que $48 \%$ das mulheres do grupo controle e $67 \%$ no grupo treinamento não perderam urina neste período $(\mathrm{p}=0,34)$. Na aval 3 (com 36 semanas de gestação), as mulheres foram novamente questionadas quanto a perda de urina no último mês (entre a $32^{\mathrm{a}}$ e $36^{\mathrm{a}}$ semana gestacional), onde $52 \%$ das mulheres do grupo controle não perderam urina e no grupo treinamento, $86 \%$ das mulheres não perderam urina $(\mathrm{p}=0,04)$, ver gráfico a seguir. 


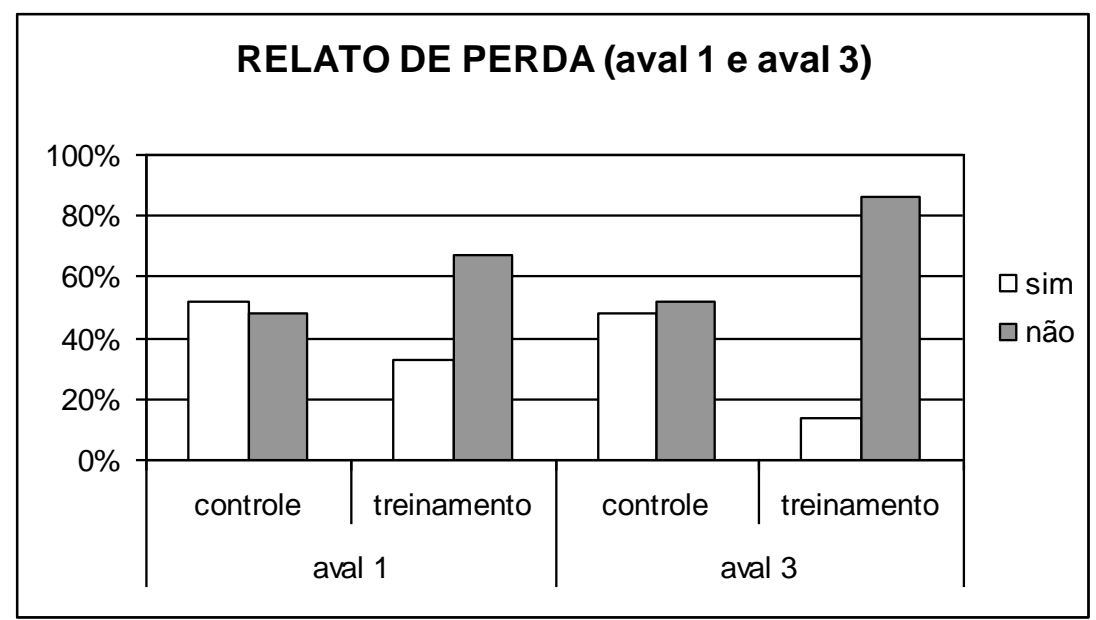

aval 1 = avaliação 1 (20 semanas de gestação)

aval 3 = avaliação 3 (36 semanas de gestação)

Gráfico 6 - Porcentagem de mulheres em relação ao RPU nas avaliações 1 e 3 em cada um dos grupos.

$\mathrm{Na}$ análise do coeficiente de kappa, o grupo controle obteve o valor de 0,35 e o grupo treinamento de 0,00 , ou seja, a concordância no grupo treinamento é desprezível. Os dados da análise do coeficiente de kappa encontram-se detalhados no Anexo L.

$\mathrm{Na}$ análise da associação entre o relato positivo e negativo de perda urinária entre as avaliações 1 e 3 (tabela 6), observamos que $28 \%$ das mulheres do grupo treinamento deixaram de perder urina e 57\% continuaram a não perder. No grupo controle, $14 \%$ das mulheres deixaram de perder urina e $38 \%$ continuaram a perder $(\mathrm{p}=0,04)$.

Tabela 6 - Associação entre efeito das avaliações no RPU por grupo.

\begin{tabular}{ccccc}
\hline $\begin{array}{c}\text { RELATO DE } \\
\text { PERDA } \\
\text { (aval 1 } \rightarrow \text { aval }\end{array}$ & CONTROLE & TREINAMENTO & TOTAL & $\begin{array}{c}\text { P- } \\
\text { VALOR }\end{array}$ \\
\cline { 2 - 4 } C) & & & & \\
\hline Não $\rightarrow$ Não & 8 & 12 & 20 & \\
Sim $\rightarrow$ Sim & 8 & 1 & 9 & $0,04^{*}$ \\
Sim $\rightarrow$ Não & 3 & 6 & 9 & \\
Não $\rightarrow$ Sim & 2 & 2 & 4 & \\
\hline Total & 21 & 21 & 42 & \\
\hline
\end{tabular}

* dado significativo estatísticamente (IC 95\%)

\section{- PERINEOMETRIA (pico máximo) vs GRAU DE FORÇA}

A comparação entre a perineometria e a graduação de força pelos escores da escala de Oxford modificada foi feita considerando-se apenas o pico máximo encontrado entre as três medidas realizadas. No gráfico 7 e na tabela 7 pode ser visto que, a medida que se aumentam os escores de graduação de força, aumenta-se também as medidas de perineometria, em ambos os grupos, o que indica que a avaliação 
subjetiva pelos escores de força pela escala de Oxford modificada está de acordo com a avaliação objetiva (perineometria) em todas as avaliações.

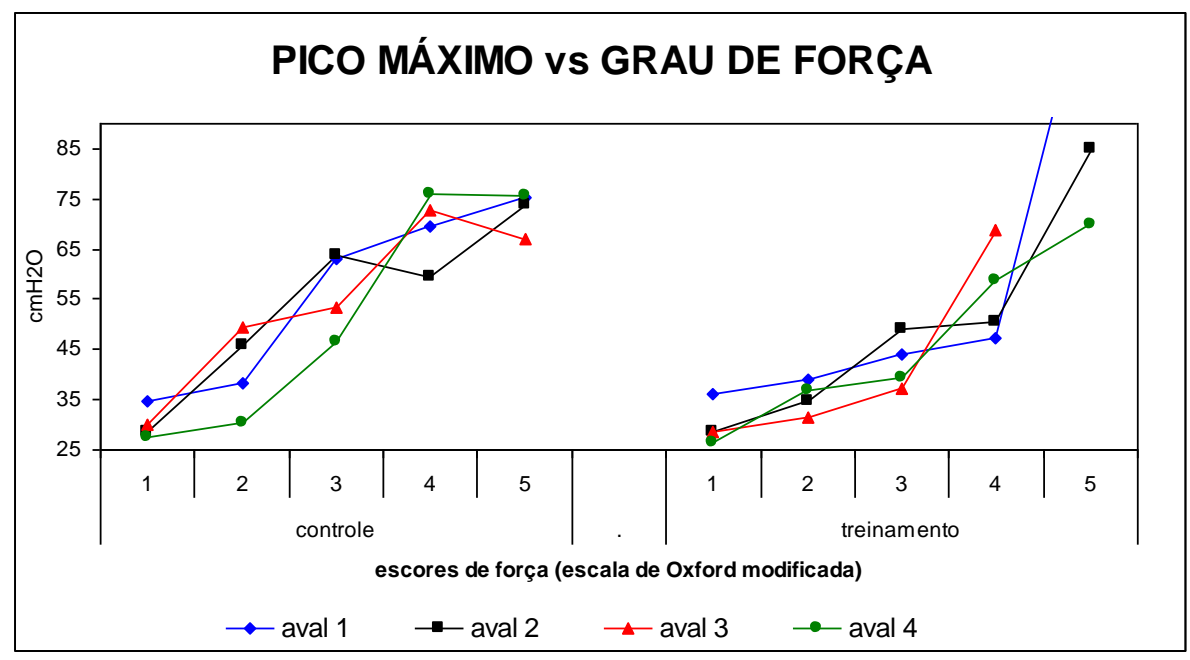

$\mathrm{cmH}_{2} \mathrm{O}=$ centímetros de água

aval 1 = avaliação 1 (20 semanas de gestação)

aval 2 = avaliação 2 (24 semanas de gestação)

aval $3=$ avaliação 3 ( 36 semanas de gestação)

aval 4 = avaliação 4 (6 semanas após o parto)

Gráfico 7 - Valores da perineometria (pico máximo) por avaliação em cada escore de força nos grupos controle e treinamento.

Tabela 7 - Médias das perineometrias (pico máximo) por escore de força por avaliação em cada um dos grupos.

\begin{tabular}{|c|c|c|c|c|}
\hline $\begin{array}{c}\text { AVALIAÇ } \\
\tilde{\tilde{A} O}\end{array}$ & $\begin{array}{c}\text { grau } \\
\text { de } \\
\text { força }\end{array}$ & $\begin{array}{l}\text { perineometria } \\
\text { (pico máx) } \\
\text { CONTROLE }\end{array}$ & $\begin{array}{c}\text { perineometria } \\
\text { (pico máx) } \\
\text { TREINAMENT } \\
\text { O }\end{array}$ & $\begin{array}{c}\text { P- } \\
\text { VALOR }\end{array}$ \\
\hline \multirow{5}{*}{1} & 1 & 34,55 & 36,1 & \multirow{5}{*}{0,47} \\
\hline & 2 & 38,38 & 39,1 & \\
\hline & 3 & 63,15 & 44,22 & \\
\hline & 4 & 69,66 & 47,12 & \\
\hline & 5 & 73,35 & 122 & \\
\hline \multirow{5}{*}{2} & 1 & 28,5 & 28,7 & \multirow{5}{*}{0,14} \\
\hline & 2 & 45,66 & 34,61 & \\
\hline & 3 & 63,71 & 48,9 & \\
\hline & 4 & 59,5 & 50,53 & \\
\hline & 5 & 73,9 & 85,1 & \\
\hline \multirow{5}{*}{3} & 1 & 30,1 & 28,7 & \multirow{5}{*}{0,14} \\
\hline & 2 & 49,57 & 31,37 & \\
\hline & 3 & 53,54 & 37,33 & \\
\hline & 4 & 72,66 & 68,8 & \\
\hline & 5 & 66,85 & - & \\
\hline \multirow{5}{*}{4} & 1 & 27,4 & 26,61 & \multirow{5}{*}{0,12} \\
\hline & 2 & 30,4 & 36,8 & \\
\hline & 3 & 46,44 & 39,4 & \\
\hline & 4 & 76,1 & 58,71 & \\
\hline & 5 & 75,6 & 69,8 & \\
\hline
\end{tabular}


No gráfico abaixo pode ser observada a mudança na média da perineometria (pico máximo) por escore de grau de força em cada uma das avaliações.

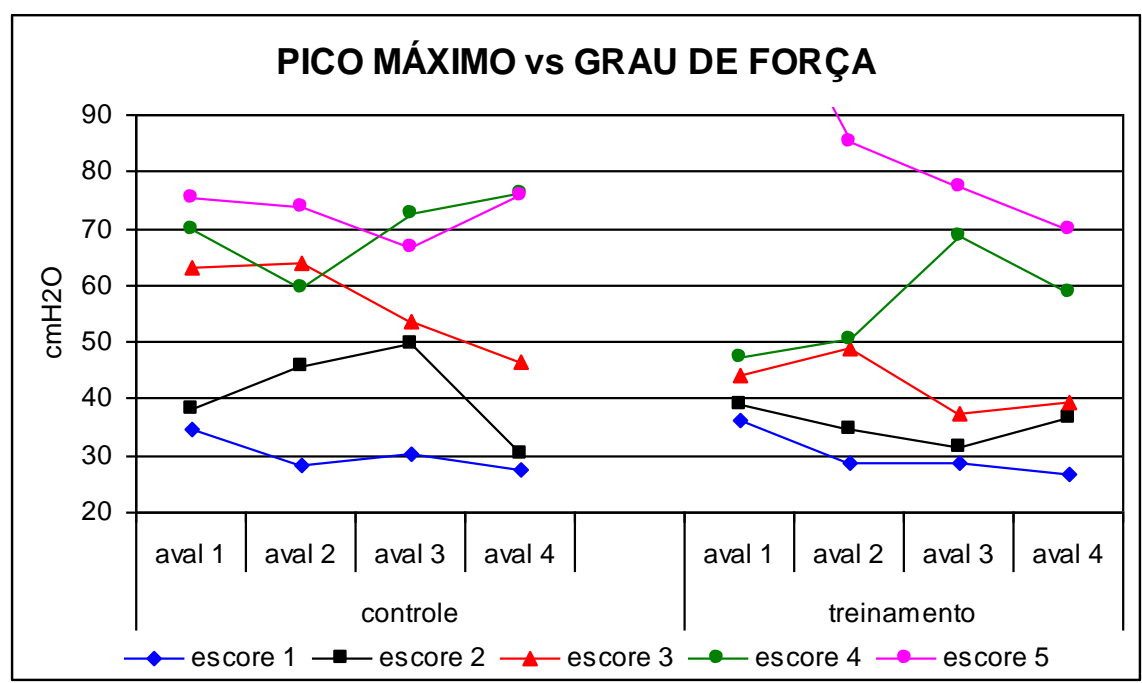

$\mathrm{cmH}_{2} \mathrm{O}=$ centímetros de água

aval 1 = avaliação 1 (20 semanas de gestação)

aval 2 = avaliação 2 (24 semanas de gestação)

aval 3 = avaliação 3 ( 36 semanas de gestação)

aval 4 = avaliação 4 (6 semanas após o parto)

Gráfico 8 - Médias das perineometrias (pico máximo) por avaliação em cada escore de força nos grupos estudados

\section{- PERINEOMETRIA vs RELATO DE PERDA URINÁRIA (RPU)}

Para melhor compreensão dos resultados, a análise da perineometria (pico e média) foi feita em relação ao relato positivo e negativo de perda urinária e foi observado que, em todas as avaliações, quem relatava não perder urina apresentava perineometria maior do que aquelas que relatavam perder urina.

No Anexo $\mathrm{M}$ encontram-se os dados relativos às comparações das perineometria (pico e média) e o RPU nas avaliações em cada um dos grupos analisados e representados nos gráficos abaixo. Foram encontrados dados significativos estatísticamente em relação a perineometria (média) no grupo treinamento, na aval 1 $(\mathrm{p}=0,04)$, a perineometria (média) das mulheres que não perdiam urina era maior do que a média das mulheres que perdiam urina e em relação ao relato negativo de perda entre as avaliações 1 e $3(\mathrm{p}<0,01)$, a perineometria (média) da aval 1 era maior que a da avaliação 3 . 


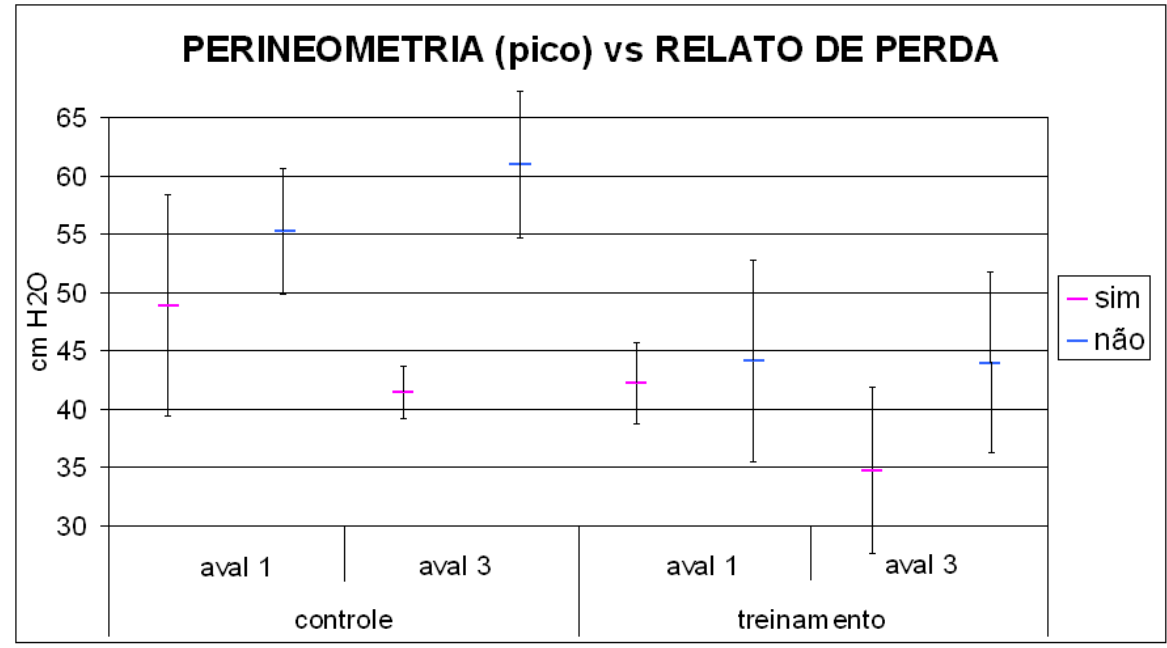

$\mathrm{cmH}_{2} \mathrm{O}=$ centímetros de água

aval 1 = avaliação 1 (20 semanas de gestação)

aval 3 = avaliação 3 ( 36 semanas de gestação)

Gráfico 9 -. Médias das perineometrias (pico) por avaliação em relação ao relato positivo e negativo de perda urinária nos grupos estudados

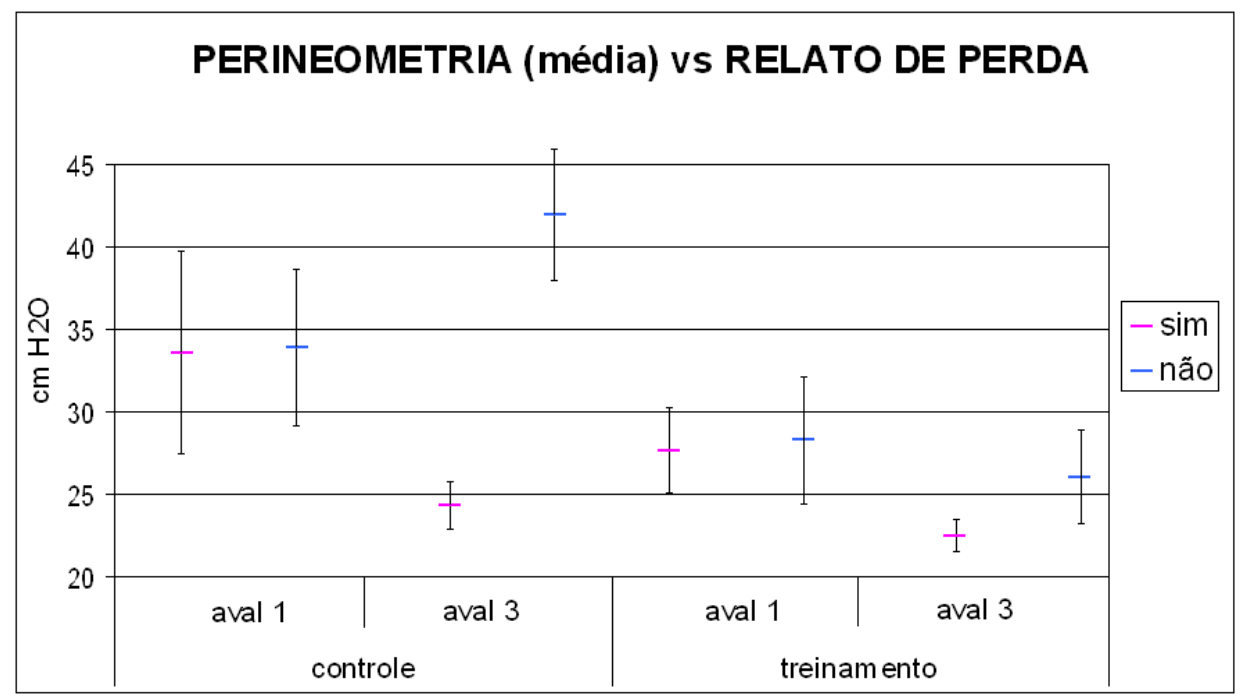

$\mathrm{cmH}_{2} \mathrm{O}=$ centímetros de água

aval 1 = avaliação 1 (20 semanas de gestação)

aval 3 = avaliação 3 ( 36 semanas de gestação)

Gráfico 10 - Médias das perineometrias (média) por avaliação em relação ao relato positivo e negativo de perda urinária nos grupos estudados 
DISCUSSÃO 


\section{DISCUSSÃO}

\subsection{Descrição das variáveis PERINEOMETRIA}

Enquanto o estudo de Morkved et al. (2003) apresentou perineometrias iniciais semelhantes de $35,7 \mathrm{cmH}_{2} \mathrm{O}$ para o grupo controle e $34,4 \mathrm{cmH}_{2} \mathrm{O}$ para o grupo treinamento (com 20 semanas de IG) e o estudo de Dinc, Beji e Yalcin (2009) encontrou valores de baseline da perineometria em gestantes de $30,05 \mathrm{cmH}_{2} \mathrm{O}$ no grupo controle e $28,08 \mathrm{cmH}_{2} \mathrm{O}$ no grupo treinamento, o estudo de Reilly et al. (2002) apresentou valores iniciais da perineometria de $10,4 \mathrm{cmH}_{2} \mathrm{O}$ no grupo controle e $9,5 \mathrm{cmH}_{2} \mathrm{O}$ no grupo treinamento. É válido salientar de que não existem valores mínimos a serem obtidos com a perineometria, principalmente em mulheres grávidas (ISHERWOOD; RANE, 2000; OLIVEIRA et al., 2007) e que o importante é estabelecer um baseline no início do trabalho para se obter um padrão inicial, ponto estável, sendo a partir deste dado que as mudanças são analisadas, assim como, é imprescindível que os grupos sejam homogêneos no início do trabalho, o que foi observado em nosso estudo.

- GRAU DE FORÇA (escala de Oxford modificada)

A palpação digital é uma ferramenta importante na comparação dos efeitos do TMAP (AMARO et al., 2005) e a mais comumente utilizada por ser barata, minimamente invasiva e com boa tolerância (HUNDLEY; WU; VISCO, 2005). Apesar disso, este não é um método reprodutível sensível e válido para avaliar os MAP em pesquisas científicas (BO; FINCKENHAGEN, 2001), contudo, diversos estudos tem demonstrado boa confiabilidade da palpação digital com outros métodos de avaliação dos MAP como o ultrassom transperineal e transabdominal (THOMPSON et al., 2005) e o perineômetro (MORIN et al., 2004; UYAR; BAYTUR; INCEBOZ, 2007).

\section{- RELATO DE PERDA URINÁRIA (RPU)}

De fato, há relatos de que a incontinência urinária possa existir antes mesmo de qualquer gravidez (CHALIHA et al., 2000), mas o aumento dos sintomas de incontinência urinária é fato comum durante a gravidez (DOLAN et al., 2004; HORIKAWA et al., 2009; SHARMA et al., 2009) e mais freqüente durante a primeira gravidez do que em nulíparas (WIJMA et al., 2001), podendo ser o resultado da 
combinação de diversos fatores como a predisposição individual e genética, a mudança do sistema de suporte uretral (CHALIHA et al., 2000), a mudança fisiológica nos parâmetros de pressão e volume da bexiga (DOLAN et al., 2004), a mudança anatômica devido ao crescimento do útero, a mudança nos níveis hormonais e a diminuição da força de suporte das fáscias e conseqüente fraqueza dos MAP (WIJMA et al., 2001), não estando diretamente ligados aos danos provocados pelo parto vaginal traumático (SCARPA et al., 2006).

A prevalência de IU em nulíparas antes da gravidez é bem baixa. O estudo de Chaliha et al. (2000) demonstrou uma prevalência de 9\%, o de Diez-Itza et al. (2009) de 5\%, de $4 \%$ no estudo de Sharma et al. (2009) e de 25\% no estudo de Dinc, Beji e Yalcin (2009). No presente estudom a porcentagem de IU (de acordo com o relato de perda urinária) antes da gravidez foi de $14 \%$ em ambos os grupos.

Em relação a perda urinária no segundo trimestre, Dinc, Beji e Yalcin (2009) relatam que $32,5 \%$ perdem urina neste período, Sharma et al. (2009) encontraram 37,1\% de prevalência de IU no segundo trimestre, dados semelhantes ao nosso estudo, onde $38 \%$ das gestantes relataram ter perdido urina neste período.

6.2 Análise da influência da caracterização da amostra (idade, peso, altura e IMC) vs grupo nas variáveis dependentes (perineometria, grau de força e relato de perda urinária)

- PERINEOMETRIA

- GRAU DE FORÇA

- RELATO DE PERDA URINÁRIA (RPU)

Quando os MAP não estão fortes o suficiente, seus mecanismos de suporte das vísceras pélvicas e fechamento uretral não funcionam coordenadamente e a incontinência urinária é o problema mais comum ocasionado pela fraqueza destes músculos (LEON, 2001; WESNES et al., 2007; SCHMIDT et al., 2009). A idade, a paridade, o peso e a altura (na relação com o IMC) apresentam influência na prevalência de incontinência urinária tanto em mulheres grávidas como em não grávidas (WESNES et al., 2007; DIEZ-ITZA et al., 2009). Outros fatores como tipo de parto, uso de drogas, obesidade, asma, diabetes e menopausa também apresentam suas influências bem descritas na literatura (ZHU et al., 2008; CORREIA et al., 2009; DIEZ-ITZA et al., 2009; SHARMA et al., 2009). E de acordo com o estudo de Wesnes et al. (2009) que 
analisou mais de 12 mil primigestas continentes antes de gravidez, as mulheres que apresentam IU durante a gestação são mais velhas e com IMC mais altos. Ou seja, todas as situações que sobrecarregam os MAP como o aumento da pressão intra abdominal (exemplo: tossir, espirrar e levantar peso) (SAPSFORD et al., 2001a), a sobrecarga do peso do útero gravídico, o peso corporal elevado, a distenção durante o trabalho de parto e parto (MORKVED; BO, 1999; CHALIHA et al., 2000; WIJMA et al., 2001; PREGAZZY et al., 2002; CHIARELLI et al., 2003; DOLAN et al., 2004; HORIKAWA et al., 2009; WESNES et al., 2009) e a queda da higidez em decorrência da idade (BROSTROM; LOSE, 2008) influenciam na força, coordenação e atuação dos MAP. Contudo, em nosso estudo, estas variáveis não influenciaram a força dos músculos do assoalho pélvico (perineometria e escala de Oxford modificada) nem o relato de perda urinária em nenhuma das avaliações.

\subsection{Análise da relação das variáveis dependentes entre si.}

- PERINEOMETRIA vs PERINEOMETRIA

A semelhança dos valores da perineometria (pico) ao longo da gravidez não é uma realidade que pode ser generalizada nas demais populações de gestantes em torno do mundo, contudo, em relação a perineometria (média), nosso estudo concorda com a literatura, comprovando haver aumento de valores da perineometria durante a gravidez em gestantes que realizaram TMAP neste período (LEMOS et al., 2008; BO, 2009b). O estudo Morkved et al. (2003) com 301 primigestas na Noruega encontrou um incremento na perineometria destas mulheres imediatamente ao programa de treinamento de $34,4 \mathrm{cmH}_{2} \mathrm{O}$ (com 20 semanas de IG) para $39,9 \mathrm{cmH}_{2} \mathrm{O}$ (com 36 semanas de IG), inclusive com desvio padrão semelhante ao nosso $\left(17,2 \mathrm{cmH}_{2} \mathrm{O}-\mathrm{o}\right.$ nosso foi de $22,43 \mathrm{mH}_{2} \mathrm{O}$ ). No Reino Unido, Reilly et al. (2002) analisaram 230 primíparas e observaram um aumento da perineometria, apesar de não significativo estatisticamente de $9,5 \mathrm{cmH}_{2} \mathrm{O}$ (20 semanas de IG) para $11,5 \mathrm{cmH}_{2} \mathrm{O}$ (36 semanas de IG) com desvio padrão de $5,4 \mathrm{cmH}_{2} \mathrm{O}$. No Brasil, um estudo de 2007, sem grande qualidade metodológica como os anteriores, Oliveira et al. comprovaram haver aumento significante da força dos MAP de mulheres que realizaram TMAP durante a gravidez (de $8,16 \mathrm{mmHg}$ para $11,63 \mathrm{mmHg}$ com desvio padrão de 4,66mmHg).

A correta contração dos MAP fortalece a musculatura da região (MORKVED; BO, 1999; CHACEL, 1997; LEON, 2001; SCHMIDT et al., 2009) e, de acordo com a 
revisão do Cochrane de Hay-Smith et al. (2006), o tempo mínimo de treinamento encontrado para que se possa obter resultados em relação a força dos MAP, entre os 43 estudos compilados, é de 4 semanas, mas somente ente 6 e 8 semanas de treino é que se obtém resultados em relação a força muscular, isto devido a adaptação neural (SALE, 1988). Porém, a maioria dos estudos analisados por Hay-Smith et al. (2006) relatam que o tempo mínimo de 12 semanas de treinamento. Devido a isto, o aumento perineometria (média) no grupo exercício na aval 2 (apenas 4 semanas após o início do estudo) não pode ser atribuído ao TMAP, cabe, no entanto, um estudo futuro da análise laboratorial dos hormônios gestacionais que podem influenciar na força dos MAP.

No puerpério observa-se considerável perda de força dos MAP (LEMOS et al., 2008), como foi observado no nosso estudo, e, mulheres que realizaram TMAP durante a gravidez apresentam melhor força nos MAP após o parto do que aquelas que não realizaram, corroborando com os achados de Sampselle et al. (1998) e Bo (2009).

\section{- GRAU DE FORÇA vs AVALIAÇÃO}

Conforme Morin et al. (2004), a avaliação digital possui uma limitada capacidade em revelar a diferença de força ocasionada pelo ganho de habilidade (após treinamento) ou pelo tempo principalmente devido a sua subjetividade (UYAR; BAYTUR; INCEBOZ, 2007). Além disso, a distinção (sensibilidade) entre os escores 3 e 5 é difícil, o que pode dificultar a avaliação do incremento de força dos MAP (BO; FINCKENHAGEN, 2001), o que justifica os resultados sem significância estatítistica entre as avaliações (teste de Fisher e coeficiente de kappa).

\section{- RELATO DE PERDA URINÁRIA (RPU) vs AVALIAÇÃO}

A IU no final da gravidez é bastante relatada na literatura e sua prevalência gira em torno de $36 \%$ a $67 \%$ (WIJMA et al., 2001) ou 28\% a 48\% (DIEZ-ITZA et al., 2009). O estudo de Reilly et al. (2002) apresentou uma prevalência de 33\% e o de Dolan et al. (2004) de 37\%, nós encontramos uma prevalência semelhante de perda urinária (48\% no grupo controle) no último trimestre gestacional.

De acordo com Morkved et al.(2003) e Neilson (2009), o TMAP realizado durante a gravidez previne a incontinência urinária neste período, Morkved et al. (2003) observaram uma redução de $15 \%$ no número de relatos positivos de perda de urina (entre 20 e 36 semanas de IG) no grupo treinamento e incremento de $1 \%$ no grupo controle, corroborando com estes achados, em nosso estudo, observamos uma redução 
de $19 \%$ nos relatos positivos no grupo treinamento e de $4 \%$ no grupo controle corroborando com os achados de Sampselle et al. que já em 1998 haviam comprovado a diminuição significativa dos sintomas de IU, da $20^{\mathrm{a}}$ semana gestacional para a $35^{\mathrm{a}}$ semana, em primigestas que realizaram o TMAP durante a gravidez, comparando-as com o grupo controle.

Apesar do aumento no controle da continência urinária por parte do grupo controle em nosso estudo, a gravidez é considerada um dos principais fatores de risco para o desenvolvimento da incontinência urinária ocasionada pelos danos as fáscias, ligamentos e musculatura que suportam e controlam a continência (MORKVED et al., 2003; SHARMA et al., 2009). Na análise de concordância (Kappa), os dados do grupo treinamento não concordam de uma avaliação para outra e a análise de associação demonstra que o TMAP mantém ou promove a continência urinária durante a gravidez com maior eficiência do que quem não o realiza, dado anteriormente relatado por Aksac et al. (2003) ao afirmar que o TMAP é eficaz para o controle e prevenção da perda urinária.

Ainda de acordo com Morkved et al. (2003) e Neilson (2009), estes exercícios que devem ser encorajados durante a gravidez tanto para mulheres continentes, como para mulheres incontinentes, uma realidade não condizente com o Brasil, onde os exercícios para os MAP não fazem parte da rotina obstétrica brasileira. No Reino Unido, 69\% das mulheres grávidas relatam realizar TMAP durante a gravidez, na Noruega, certa de $20 \%$ das grávidas realizam exercícios para o músculos do assoalho pélvico semanalmente durante a gestação e na Austrália 54\% das gestantes realizam os TMAP neste período (BO, 2009b), no Brasil, nenhuma das mulheres incluídas em nosso estudo, sequer havia ouvido falar de assoalho pélvico.

Outros estudos afirmam que a IU tende a regredir normalmente cerca de um mês após o parto (HORIKAWA et al., 2009) com prevalência de $31 \%$ com 6 meses após o parto (WESNES et al., 2009), mas mulheres que realizam TMAP durante a gestação, apresentam resultados significativamente melhores do que aquelas que não o realizam (SAMPSELLE et al., 1998; BO, 2009a). O estudo de Wesnes et al (2009) encontrou que $52 \%$ das mulheres que eram incontinentes durante a gravidez, tornaram-se continentes 6 meses após o parto. Assim como em nosso estudo (15\%), o trabalho de revisão de Neilson (2009) encontrou que $20 \%$ a menos das mulheres que realizaram o TMAP durante a gravidez apresentam IU no pós-parto, comparado com o grupo controle. De $5 \%$ a $20 \%$ das mulheres que eram continentes antes e durante a gravidez são 
incontinentes após o parto (WESNES et al., 2009), ou seja, a maioria das mulheres continentes antes da gravidez, tende a permanecer continente no pós parto (BO, 2009b).

\section{- PERINEOMETRIA (pico máximo) vs GRAU DE FORÇA}

A graduação de força pela palpação digital é um dado subjetivo, avaliadordependente (HUNDLEY; WU; VISCO, 2005; FRAWLEY et al., 2009) e, como vimos, os valores da perioneometria nem sempre correspondem ao mesmo escore da escala de Oxford, ou seja, um mesmo valor encontrado na perineometria pode ser classificado em diversos escores. Essa grande sobreposição de valores através das categorias da escala de Oxford é justificada pela grande sensibilidade da palpação digital (MORIN et al., 2004), o que justifica as diferenças estatísticamente significantes encontradas na análise da perineometria por escore de força.

Existe uma relação linear entre a perineometria e a graduação de força, permitindo a comparação destes. A confiabilidade dos testes é maior quando se compara a palpação digital e o pico do que com a média e a duração da perineometria (HUNDLEY; WU; VISCO, 2005), em nosso estudo, foi utilizado o pico máximo obtido entre as três medidas da perineometria.

Diversos estudos têm demonstrado a boa associação entre a perineometria e a avaliação digital. Isherwood e Rane (2000) avaliaram 263 mulheres a fim de verificar se a avaliação dos MAP pela palpação digital (escala de Oxford) é tão confiável quanto a perineometria e não só concluíram que sim, como recomendaram a palpação como forma de avaliação desta musculatura. Na comparação das avaliações de 100 mulheres, Hundley, Wu e Visco (2005), apresentam uma boa correlação entre a perineometria e a palpação digital e sugerem que estes métodos possuem níveis similares de reprodutibilidade. O estudo de Uyar, Baytur e Inceboz (2007), que avaliou 131 mulheres não-grávidas na Turquia, também encontrou grande concordância entre a palpação digital e a perineometria, tanto em relação a perineometria (média) como a perineometria (pico). Já o estudo de Bo e Finckenhagen (2001) não encontrou relação entre os dois métodos, porém, neste estudo foram analisadas somente 20 mulheres.

\section{- PERINEOMETRIA vs RELATO DE PERDA URINÁRIA (RPU)}

O RPU é um instrumento de medida amplamente utilizado na comunidade cientifica, contudo, seus resultados analisados de maneira isolada pouco têm a concluir uma vez que são dependentes do nível de escolaridade, da atenção e da vergonha em 
responder a pergunta, apresentando grande confiabilidade quando associado a métodos objetivos (WIJMA et al., 2001; WIJMA et al., 2008) como em nosso estudo. Os sinais clínicos como o relato de perda de urina são facilmente observados quando os MAP não funcionam adequadamente (BOYINGTON; DOUGHERTY, 2000), havendo grande correlação entre a força muscular e a habilidade de controlar a urina (ISHERWOOD; RANE, 2000), sendo este um dado importante para a comprovação dos efeitos clínicos do TMAP durante a gravidez.

Conforme nossos dados, o estudo de Thompson et al. (2006), que analisou 120 mulheres continentes e incontinentes através de ultrassom, perineômetro e avaliação digital, demonstrou que mulheres continentes possuem maior força dos MAP do que mulheres incontinentes. 
CONCLUSÕES 


\section{CONCLUSÕES}

- O treinamento dos músculos do assoalho pélvico (TMAP) promove um aumento da perineometria (média) durante a gestação;

- O aumento da perineometria (média) pode ser observado com apenas 4 semanas de exercícios;

- A realização do TMAP na gravidez facilita o retorno dos MAP às condições prégravídicas;

- Mulheres que realizaram TMAP na gestação apresentam valores da perineometria (média) semelhantes aos do final da gestação, sem grandes perdas de força;

- As mulheres que realizaram TMAP durante a gestação apresentaram, na avaliação pela palpação bidigital (Escala de Oxford modificada), maior mudança entre os escores;

- A avaliação subjetiva pelos escores de força pela escala de Oxford modificada está de acordo com a avaliação objetiva (perineometria) durante a gravidez e com 6 semanas após o parto;

- A realização de TMAP durante a gravidez favorece o controle e a prevenção do relato de perda urinária ao final da gestação;

- As mulheres com relato negativo de perda urinária apresentam perineometria maior do que aquelas com relato positivo de perda urinária. 


\section{REFERÊNCIAS $^{2}$}

AGRESTI, Alan. Categorical Data Analysis. New York: John Wiley, 1990.

AKSAC, Buket; AKI, Semih; KARAN, Ayse; YALCIN, Onay; ISIKOGLU, Mete; ESKIYURT, Nurten. Biofeedback and Pelvic Floor Exercises for the Rehabilitation of Urinary Stress Incontinence. Gynecol Obstet Invest, Switzerland, v. 56, p. 23-27, 2003.

AMARO, Joao Luiz; GAMEIRO, Monica de Oliveira Orsi; PADOVANI, Carlos Roberto. Treatment of urinary stress incontinence by intravaginal electrical stimulation and pelvic floor physiotherapy. Int Urogynecol J, England, v. 14, p. 204208, 2003.

AMARO, Joao Luiz; MOREIRA, Eliane Cristina Hilberath; GAMEIRO, Monica de Oliveira Orsi; PADOVANI, Carlos Roberto. Pelvic floor muscle evaluation in incontinent patients. Int Urogynecol J, England, v. 16, p. 352-354, 2005.

BENEDETTO, P. D. Female urinary incontinence rehabilitation. Minerva Ginecol, Italy, p. 56, n. 4, p. 353-369, 2004.

BERNARDES, N. O.; PERES, F. R.; SOUZA, E. L. B. L.; SOUZA, O. L. Métodos de tratamento utilizados na incontinência urinária de esforço genuína: um estudo comparativo entre cinesioterapia e eletroestimulação endovaginal. Rev Bras Ginecol Obst, Brasil, v. 22, n. 1, p. 49-54, 2000.

BEZERRA, M. R. L.; SOARES, A. F. F.; FAINTUCH, S.; GOLDMAN S. M.; AJZEN, S. A.; GIRÃO, M.; D’IPPOLITO, G.; SZEJNFELD, J. Identificação das estruturass músculo-ligamentares do assoalho pélvico feminino na ressonância magnética. Radiol Bras. v. 34, n. 6, p. 323-326, 2001.

\footnotetext{
${ }^{2}$ De acordo com a Associação Brasileira de Normas Técnicas. NBR 6023.
} 
BO, Kari. Pelvic floor muscle training is effective in treatment of female stress urinary incontinence, but how does irt work? Int Urogynecol J, England, v. 15, p. 76-84, 2004.

BO, Kari. Effect of antenatal pelvic floor muscle training on labor and birth. Obstet Gynecol, United States, v. 113, n. 6, p. 1279-1284, 2009a.

BO, Kari. Does pelvic floor muscle training prevent and treat urinary and fecal incontinence in pregnancy? Nat Clin Pract Urol, United States, v. 6, n. 3, p.122-123, 2009b.

BO, Kari; FINCKENHAGEN, H. B. Vaginal palpation of pelvic floor muscle strength: inter-test reproducibility and comparison between palpation and vaginal squeeze pressure. Acta Obstet Gynecol Scand, England, v. 80, n. 10, p. 883-887, 2001.

BO, K.; KVARSTEIN, B.; HAGEN, R.; LARSEN, S. Pelvic floor muscles exercise for the treatment of female stress urinary incontinence: II. Validity of vaginal pressure strength and the necessity of suplementaru methods for control of correct contraction. Neurourol Urodyn, United States, v. 9, n. 5, p. 479-487, 1990.

BO, Kari; RAASTAD, R.; FINCKENHAGEN, H. B. Does the size of the vaginal probe affect measurement of pelvic floor muscle strength? Acta Obstet Gyn Scand, England, v. 84, n. 2, p. 29-33, 2005.

BO, K.; TALSETH, T.; HOLME, I. Single blind, randomised controlled trial of pelvic floor exercises, electrical stimulation, vaginal cones, and no treatment in management of genuine stress incontinence in women. Br Med J, England, v. 318, n. 7182, p.487-493, 1999.

BOYIngton, A. R.; DOUGHERTy, M. C. Pelvic muscle exercise effect on pelvic muscle performance in women. Int Urogynecol J, England, v. 11, n. 4, p. 212-218, 2000. 
BROSTROM, Soren; LOSE, Gunnar. Pelvic floor muscle training in the prevention and treatment of urinary incontinence in women: what is the evidence? Acta Obstet Gynecol Scand, England, v. 87, n. 4, p. 384-402, 2008.

BUMP, R. C.; HURT, W. G.; FANTL, J. A.; WYMAN, J. F. Assessment of kegel pelvic muscle exercise performance after brief verbal instruction. Am J Obstet Gynecol, United States, v. 165, n. 2, p. 322-327, 1991.

CALAIS-GERMAIN, Blandine. O períneo feminino e o parto: elementos de anatomia e exercícios práticos. 1. ed. São Paulo: Manole, 2005.

CAMMU, H.; NYLEN, M. V.; BLOCKEEL, C.; KAUFMAN, L.; AMY, J. J. Who will benefit from pelvic floor muscle training for stress urinary incontinence? Am $J$ Obstet Gynecol, United States, v. 191, n. 4, p. 1152-1157, 2004.

CASTRO, R. A.; ARRUDA, R. M.; ZANETTI, M. R. D.; SANTOS, P. D.; SARTORI, M. G. F.; GIRÃO, M. J. B. C. Single-blind, randomized, controlled trial of pelvic floor muscle training, electrical stimulation, vaginal cones, and no active treatment in the management of stress urinary incontinence. Clinics, Brasil, v. 63, n. 4, p. 465$472,2008$.

CHACEL, Marta. Incontinência urinária (na mulher, no homem e na criança). Revista Fisio \& Terapia, Brasil, v. 1, n. 4, p. 2, 1997.

CHALIHA, C.; BLAND, J. M.; MONGA, A.; STANTON, S. S. L.; SULTAN, A. H. Pregnancy and delivery: a urodynamic viewpoint. Br J Obstet Gynaecol, England, v. 107, n. 11, p. 1354-1359, 2000.

CHEHREHRAZI, Mahshid; ARAB, Amir Massoud; KARIMI, Noureddin; ZARGHAM, Mahtab. Assessment of pelvic floor muscle contraction in stress urinary incontinent women: comparison between transabdominal ultrasound and perineometry. Int Urogynecol J, England, Aug 20, 2009. No prelo. 
CHIARELLI, P.; COCKBURN, J. Promoting urinary continence in women after delivery: randomised controlled trial. Br Med J, England, n. 324, n. 7148, p. 12411246, 2002.

CHIARELLI, P.; MURPHY, B.; COCKBURN, J. Acceptability of a urinary continence promotion programme to women in postpartum. Br J Obstet Gynaecol, England, v. 110, n. 2, p. 188-196, 2003.

CONSELHO FEDERAL DE FISIOTERAPIA E TERAPIA OCUPACIONAL (COFFITO). Resolução $\mathrm{n}^{\circ} 08$ de 20 de fevereiro de 1978. Diário Oficial da União, ${ }^{\circ}$ 216 - de 13 de novembro de 1978, Seção I, Parte II, Pág. 6.322/32. Disponível em: < http://www.coffito.org.br/publicacoes/pub_view.asp?cod=935\&psecao=9>. Acesso em: 15 set. 2005.

COHEN, J. A Coefficient of agreement for nominal scales. Educational and Psychological Measurement, United States, v. 20, n. 3, p. 37-46, 1960.

CONTI, M. H.; CALDERON, I. M.P.; CONSONNI, E. B.; PREVEDEL, T. T. S.; DALBEM, I.; RUDGE, M. V. C. Efeito de técnicas fisioterápicas sobre os desconfortos músculo-esqueléticos da gestação. Rev Bras Ginecol Obst, Brasil, v. 25, n. 9 , p. $647-654,2003$.

CORREIA, S.; DINIS, P.; ROLO, F.; LUNET, N. Prevalence, treatment and known risk factors of urinary incontinence and overactive bladder in the noninstitutionalized Portuguese population. Int Urogynecol J Pelvic Floor Dysfunct, England, Aug 14, 2009. No prelo.

DELGADO, C.; FERNANDES FILHO. J.; BARBOSA, F. P.; OLIVEIRA, H. B. Utilização do esfigmomanômetro na avaliação da força dos músculos extensores e flexores da articulação do joelho em militares. Rev Bras Med Esporte, Brasil, v. 10, n. 5, p. 362-366, 2004. 
DINC. Ayten; BEJI. Nezihe Kizilkaya; YALCIN, Onay. Effect of pelvic floor muscle exercises in the treatment of urinary incontinence during pregnancy and the postpartum period. Int Urogynecol J Pelvic Floor Dysfunct, England, v. 20, n. 10, p. 1223-1231, 2009.

DIETZ, H. P.; JARVIS, S. K.; VANCAILLIE, T. G. The assessment of levator muscle strength: a validation of three ultrasound techniques. (Resumo). Int Urogynecol J Pelvic Floor Dysfunct, England, v. 13, n. 3, p. 156-159, 2002.

DIEZ-ITZA, Irene; IBAÑEZ, Larraitz; ARRUE, Miren; PAREDES, Jone; MURGIONDO, Arantzazu; SARASQUETA, Cristina. Influence of maternal weight on the new onset of stress urinary incontinence in pregnant women. Int Urogynecol J Pelvic Floor Dysfunct, England, v. 20, n. 10, p. 1259-1263, 2009.

DOLAN, Lucia M.; WALSH, Deirdre; HAMILTON, Shona; MARSHALL, Kaye; THOMPSON, Kate; ASHE, Robin G. A study of quality of life in primigravidae with urinary incontinence. Int Urogynecol J, England, v. 15, p. 160-164, 2004.

FRAWLEY, Helena C.; GALEA, Mary P.; PHILLIPS, Bev A.; SHERBURN, Margaret; BO, Kari. Reliability of pelvic floor muscle strength assessment using different test positions and tools. Neurourol Urodyn, United States, v. 25, n. 3, p. 236-242, 2005.

GARDINER, M. Dena. Manual de terapia por exercícios. 4. ed. São Paulo: Santos, 1995 .

GOLDBERG, R. P.; KWON, C.; GANDHI, S.; ATKURU, L. V.; SORENSEN, M.; SANDURINARY, P. K. Incontinence among mothers of multiples: the protetive effect of cesarean delivery. Am J Obstet Gynecol, United States, v. 189, n. 6, p. 16271630, 2003.

HAY-SMITH, J.; BO, K.; BERGHMANS, B.; HENDRIKS, E.; DE BIE, R.; VAN WAALWIJK VAN DOORN, E. S. C. Pelvic floor muscle training for urinary incontinence in women. Cochrane Database of Systematic Reviews, v. 1, n. CD001407. DOI: 10.1002/14651858.CD001407.pub2. 2006. 
HERRMANN, V.; POTRICK, B. A.; PALMA, P. C. R.; ZANETTINI, C. L.; MARQUES, A.; NETTO JÚNIOR, N. R. Eletroestimulação transvaginal do assoalho pélvico no tratamento da incontinência urinária de esforço: avaliações clínica e ultra-sonográfica. Rev Assoc Med Bras, Brasil, v. 49, n. 4, p. 401-405, 2003.

HORIKAWA, S.; MATSUMOTO, S.; HANAI, T.; YAMAMOTO, T.; KISHIMOTO, T.; UEMURA, H. Change of lower urinary tract symptoms during pregnancy and after delivery--investigations using IPSS/QOL and Urinary Incontinence Questionnaires. (Resumo). Hinyokika Kiyo, Japan, v. 55, n. 6, p. 311-314, 2009.

HUNDLEY, A. F.; WU, J. M.; VISCO, A. G. A comparison of perineometer to brink score for assessment of pelvic floor muscle strength. Am J Obstet Gynecol, United States, v. 192, n. 5, p. 1583,1591, 2005.

ISHERWOOD, P. J.; RANE, A. Comparative assessment of pelvic floor strength using a perineometer and digital examination. $\mathrm{Br} \mathrm{J}$ Obstet Gynaecol, England, v. 107 , n. 8 , p. 1007-1011, 2000.

JANSSEN, C. C. M.; LAGRO-JANSSEN, A. L. M.; FELLING, A. J. A. The effects of physiotherapy for female urinary incontinence: individual compared with group treatment. Br J Urol, England, v. 87, n. 3, p. 201-206, 2001.

PELOZO JÚNIOR, Osvaldo; GARBELLOTTI JÚNIOR, Sílvio A. Anatomia funcional da pelve e do períneo. In: MORENO, Adriana L. Fisioterapia em uroginecologia. São Paulo: Manole, 2004. p. 01-22.

KEGEL, Arnold H. Progressive resistance exercise in the functional restoration of the perineal muscles. Am J Obstet Gynecol, United States, v. 56, n. 2, p. 238-248, 1948.

KERSCHAN-SCHINDL， K.; UHER, E.; WIESINGER， G.; KAIDER, A.; EBENBICHLER, G.; NICOLAKIS, P.; KOLLMITZER, J.; PREISINGER, E.; FIALKA-MOSER, V. Reliability of pelvic floor muscle strength measurement in 
elderly incontinent women. Neurourol Urodyn, United States, v. 21, n. 1, p. 42-47, 2002.

LAKATOS, Eva Maria; MARCONI, Marina de Andrade. Metodologia científica. 2 a. ed., São Paulo, 1995.

LANDIS, R. J.; KOCH, G, G. The measurement of observer agreement for categorical data. Biometrics, United States, v. 33, n. 1, p. 159-174, 1977.

LEMOS, Andréa; SOUZA, Ariani Impieri de; FERREIRA, Ana Laura Carneiro Gomes; FIGUEIROA, José Natal; CABRAL-FILHO, José Eulálio. Do perineal exercises during pregnancy prevent the development of urinary incontinence? A systematic review. Int J Urol, Austrália, v. 5, n. 10, p. 875-880, 2008.

LEON, M. I. W. H. A eficácia de um programa cinesioterapêutico para mulheres idosas com incontinência urinária. Fisioterapia Brasil, Brasil, v. 2, n. 2, p. 107-115, 2001.

MOORE, Keith L.; DALLEY, Arthur F. Anatomia orientada para a clínica. 4. ed. Guanabara Koogan: Rio de Janeiro, 2001.

MOREIRA, S. F. S.; GIRAO, M. J. B. C.; SARTORI, M. G. F.; BARACAT, E. C.; LIMA, G. R. Mobilidade do colo vesical e avaliação funcional do assoalho pélvico em mulheres continentes e com incontinência urinária de esforço, consoante o estado hormonal. Rev Bras Ginecol Obst, Brasil, v. 24, n. 6, p. 365-70, 2002.

MORENO, Adriana L. Fisioterapia em ginecologia. 1. ed. São Paulo: Manole, 2004.

MORIN, M.; DUMOULIN, C.; BOURBONNAIS, D.; GRAVEL, D.; LEMIEUX, M. Pelvic floor maximal strength using vaginal digital assessment compared to dynamometric measurements. Neurourol Urodyn, United States, v. 23, n. 4, p. 336$341,2004$. 
MORKVED Siv, BO Kari, SCHEI Berit, SALVESEN Kjell Åsmund. Pelvic Floor Muscle Training During Pregnancy to Prevent Urinary Incontinence: A Single-Blind Randomized Controlled Trial. ACOG, Unetd States, v. 101, n. 2, p. 313-319, 2003.

MORKVED, Siv; BO, Kari. Prevalence of urinary incontinence during pregnancy and postpartum. Int Urogynecol J, England, v. 10, p. 394-398, 1999.

NAGIB, A. B. L.; GUIRRO, E. C. O.; PALAURO, V. A.; GUIRRO, R. R. J. Avaliação da sinergia da musculatura abdomino-pélvica em nulíparas em eletromiografia e biofeedback perineal. Rev Bras Ginecol Obst, Brasil, v. 27, n. 4, p. 210-215, 2005.

NEILSON, James P. Pelvic floor muscle training for prevention and treatment of urinary and faecal incontinence in antenatal and postnatal women. Obstet Gynecol, United Satates, v. 113, n. 3, p. 733-5, 2009.

OLIVEIRA, Claudia de. Efeitos da cinesioterapia no assoalho pélvico durante o ciclo gravídico-puerperal. Dissertação (Mestrado em Ciências) - Faculdade de Medicina. Universidade de São Paulo, São Paulo, 2006.

OLIVEIRA Claudia de, LOPES Marco Antonio Borges, PEREIRA Luciana Carla Longo, ZUGAIB Marcelo. Effects of pelvic floor muscle training during pregnancy. Clinics, Brasil, v. 62, n. 4, p. 439-46, 2007.

PAGANO, Marcello; GAUVREAU, Kimberlee. Princípios de Bioestatística. São Paulo: Thomson. 2004.

PREGAZZY，R.; SARTORE，A.; BORTOLO，P.; GRIMALDI，E.; RICCI，G.; GUASCHINO, S. Immediate postpartum perineal examination as a predictor of puerperal pelvic floor dysfunction. Obstet Gynecol, United States, v. 99, n. 4, p. 581$581,2002$.

QUIGLEY, Eamonn M. M. Impact of pregnancy and parturition on the anal sphincters and pelvic floor. Best Pract Res Clin Gastroenterol, Netherlands, v. 21, n. 5, p. 879-891, 2007. 
REILLY, E. T. C.; FREEMAN, R. M.; WATERFIELD, M. R.; WATERFIELD, A. E.; STAGGLES, P.; PEDLAR, F. Preventions of postpartum stress incontinence in primigravidae with increased bladder neck mobility: a randomized controlled trial of antenatal pelvic floor exercises. Br J Obstet Gynaecol, England, v. 109, n. 1, p. 68-76, 2002

RETT, M. T.; SIMÕES, J. A.; HERMANN, V.; MARQUES, A.; A.; MORAIS, S. S. Existe diferença na contratilidade da musculatura do assoalho pélvico feminino em diversas posições? Rev Bras Ginecol Obst, Brasil, v. 27, n. 1, p. 20-23, 2005.

SALE, D. G. Neural adaptation to resistance training. Med Sci Sports Exerc, United States, v. 20, n. 5 (Supplement), p. S135-S145, 1988.

SAMPSELlE, C. M.; MILLER, J. M.; MIMS, B. L.; DELANCEY, J. O.; ASHTONMILLER, J. A.; ANTONAKOS, C. L. Effect of pelvic muscle exercise on transient incontinence during pregnancy and after birth. (Resumo). Obstet Gynecol, United States, v. 91, n. 3, p. 406-412, 1998.

SAPSFORD, R. R.; HODGES, P. W. Contraction of the pelvic floor muscles during abdominal manuevers. Arch Phys Med Rehabil, United States, v. 82, n. 8, p. 10811088, 2001a.

SAPSFORD, R. R.; HODGES, P. W.; RICHARDSON, C. A.; COOPER, D. H.; MARKWELL, S. J.; JULL, G. A. Co-activation of the abdominal and pelvic floor muscles during voluntary exercises. Neurourol Urodyn, United States, v. 20, n. 1, p. 31-42, $2001 b$.

SAS Institute Inc., SAS/STAT® User's Guide, Version 9, Cary, NC: SAS Institute Inc., 2003.

SCARPA, K. P.; HERRMANN, V.; PALMA, P. C. R.; RICCETTO, C. L. Z.; MORAIS, S. S. Prevalence and correlates of stress urinary incontinence during 
pregnancy: a survey at UNICAMP Medical School, Sao Paulo, Brazil. Int Urogynecol J, England, v. 17, p. 219-223, 2006.

SCHALL, R. Estimation in generalized linear models with random effects. Biometrika, England, v. 78, n. 4, p. 719-727, 1991.

SCHMIDT, Adriana P.; SANCHES, Paulo R. S.; SILVA JÚNIOR, Danton P.; RAMOS, José G. L.; NOHAMA, Percy. A new pelvic muscle trainer for the treatment of urinary incontinence. Int J Gynaecol Obstet, Ireland, v. 105, n. 3, p. 218 $222,2009$.

SHARMA, J. B.; AGGARWAL, Shena; SINGHAL, Saurabh; KUMAR, S.; ROY, K. K. Prevalence of urinary incontinence and other urological problems during pregnancy: a questionnaire based study. Arch Gynecol Obstet, Germany, v. 279, n. 6, p. 845-851, 2009.

SHERBURN, M.; MURPHY, C. A.; CARROLL, S.; ALLEN, T. J.; GALEA, M. P. Investigation of transabdominal real-time ultrasound to visualize the muscles of the pelvic floor. Aust J Physiother, Austrália, v. 51, n. 3, p.167-170, 2005.

STEPHENSON, Rebecca G.; O'CONNOR, Linda J. Fisioterapia aplicada à ginecologia e obstetrícia. Tradução: Angela Cristina Horokosky; revisão científica Elizabeth Alves Ferreira. 2. ed. Barueri: Manole, 2004.

STOKER, J.; HALligAN, S.; BARTRAM, C. I. Pelvic floor imaging. Radiology, United States, v. 218, n. 3, p. 621-641, 2001.

THOMPSON, Judith A.; O’SULLIVAN, Peter B.; BRIFFA, Kathryn; NEUMANN, Patricia; COURT, Sarah. Assessment of pelvic floor movement using transabdominal and transperineal ultrasound. Int Urogynecol J, England, v. 16, p. 285-292, 2005.

THOMPSON, Judith A.; O'SULLIVAN, Peter B.; BRIFFA, Kathryn; NEUMANN, Patricia; Assessment of voluntary pelvic floor muscle contraction in continent and 
incontinent women using transperineal ultrasound, manual muscle testing and vaginal squeeze pressure measurements. Int Urogynecol J, England, v. 17, p. 624630, 2006.

TINCELLO, D. G.; TEARE, J.; FRASER, W. D. Second trimester concentrations of relaxin and pregnancy related incontinence. Eur J Obstet Gynecol Reprod Biol, Ireland, v. 106, n. 2, p. 237,238, 2003.

TSUNODA, A.; SHIBUSAWA, M.; KAMIYAMA, G.; KUSANO, M.; SHIMIZU, Y.; YANAIHARA, T. The effect of vaginal delivery on the pelvic floor. Jpn J Surg, Japan, v. 29, n. 12, p. 1243-1247, 1999.

UYAR, Y.; BAYTUR, Y.; INCEBOZ, U. Perineometer and digital examination for assessment of pelvic floor strength. Int J Gynaecol Obstet, Ireland, v. 98, n. 1, p. 64$65,2007$.

WESNES, S. L.; RORTVEIT, G.; BO, K.; HUNSKAAR, S. Urinary incontinence during pregnancy. (resumo). Obstet Gynecol, United States, v. 109, n. 4, p. 922-928, 2007.

WESNES, S. L.; HUNSKAAR, S.; BO, K.; RORTVEIT, G. The effect of urinary incontinence status during pregnancy and delivery mode on incontinence postpartum. A cohort study. . Br J Obstet Gynaecol, England, v. 116, n. 5, p. 700-707, 2009.

WIJMA, Jacobus; WEIS POTTERS, Annemarie E.; WOLF, B. T.; TINGA, Dick J.; AARNOUDSE, Jan G. Anatomical and functional changes in the lower urinary tract during pregnancy. . Br J Obstet Gynaecol, England, v. 108, n. 7, p. 726-732, 2001.

WIJMA, Jacobus, WEIS POTTERS, Annemarie E.; TINGA, Dick J.; AARNOUDSE, Jan G. The diagnostic strength of the 24-h pad test for self-reported symptoms of urinary incontinence in pregnancy and after childbirth. Int Urogynecol J, England, v. 19, p. 525-530, 2008. 
XHARDEZ, Yves. Manual de cinesioterapia: técnicas, patologias, indicações, tratamento. São Paulo: Atheneu, 2000.

ZACCHI, A. S.; BRUSE, C. F.; SOUZA, R. M. N. A utilização da cinesioterapia na incontinência urinária de esforço. Revista Fisio \& Terapia, Brasil, v. 5, n. 28, p .10$11,2001$.

ZHU, Lan; LANG, Jinghe; WANG, Hong; HAN, Shaomei; HUANG, Jianshi. The prevalence of and potential risk factors for female urinary incontinence in Beijing, China. J North Am Menopause Soc, United States, v. 15, n. 3, p. 566-569, 2008. 
ANEXOS

ANEXO A - ESCALA DE OXFORD MODIFICA

ESCORE AFA

0

1

2

3

4

5

\section{OBSERVAÇ̃̃O CLÍNICA}

Sem função perineal objetiva, nem à palpação.

Função perineal objetiva ausente, reconhecível somente à palpação.

Função perineal objetiva, reconhecível à palpação.

Função perineal objetiva, sem resistência opositora à palpação.

Função perineal objetiva e resistência opositora não mantida à palpação.

Função perineal objetiva e resistência opositora mantida à palpação por mais de 5 segundos.

Fonte: MOREIRA et al. (2002) 
ANEXO B - TERMO DE CONSENTIMENTO LIVRE E ESCLARECIDO

\section{HOSPITAL DAS CLÍNICAS DA FACULDADE DE MEDICINA DE RIBEIRÃO PRETO DA UNIVERSIDADE DE SÃO PAULO \\ PESQUISA CIENTÍFICA TERMO DE CONSENTIMENTO PÓS-INFORMAÇÃO}

NOME DO PACIENTE / IDADE: REGISTRO E/OU DOCUMENTO DE IDENTIFICAÇÃO:

NOME DA PESQUISA: Efeitos dos exercícios cinesioterápicos realizados durante a gestação para a musculatura do assoalho pélvico

RESPONSÁVEL CLÍNICO: Professora Doutora Silvana Maria Quintana

\section{CONSENTIMENTO PÓS-INFORMAÇÃO}

Declaro que em______________ eu,

concordei voluntariamente em participar, como paciente, do projeto de pesquisa acima referido. Fui devidamente informada em detalhes que:

1- O estudo implica em que eu me submeta aos procedimentos e exames complementares devidamente planejados, conforme texto a seguir:

"Muitas mulheres não conhecem o seu corpo adequadamente e não sabem da importância dos músculos que sustentam os órgãos pélvicos, a vagina e o canal da urina e fezes. Estes músculos participam da função sexual da mulher e são importantes na gravidez e no momento do parto. Muitas mulheres se preocupam em ter um parto normal e prejudicar esta região muscular. O propósito deste trabalho será fortalecer os músculos da região da vagina da mulher através de exercícios próprios para esta região, realizados durante a gestação. A avaliação dos efeitos destes exercícios será realizada no período pós-parto. Você será acompanhada em seis consultas com a fisioterapeuta; realizadas na $20^{\mathrm{a}}$ semana de gestação (por volta do $4^{\circ}$ mês), na $24^{a}$ semana de gestação (no $6^{\circ}$ mês), na $36^{a}$ semana de gestação (entrada do $9^{\circ}$ mês) e com seis semanas após o parto".

Aceitando participar do estudo você será sorteada para um dos grupos:

- Grupo Exercício: onde você realizará exercícios para fortalecer os músculos das regiões de vagina e ânus orientados pela fisioterapeuta.

- Grupo Controle: onde não serão realizados exercícios para estes músculos, porém você será acompanhada da mesma forma que o grupo exercício, realizando todas as seis avaliações durante a gravidez e no pós-parto.

A sua colaboração será importante para entendermos melhor como trabalhar com musculatura perineal, comparar os efeitos destes exercícios durante a gravidez e poder ajudar outras gestantes futuramente. "Estes exercícios não causam prejuízos para você nem para o seu filho e podem ser realizados em qualquer período da gestação."

2- Você não é obrigada a continuar participando do projeto e pode, a qualquer momento, sair do mesmo, sem que isso impeça que você deixe de ser tratada como as demais pacientes.

3- A pesquisa não será feita se houver, relacionados à mesma, grandes riscos para você. Da mesma forma, caso algum risco proibitivo venha a se revelar no decurso do estudo, o pesquisador se compromete a alertá-la sobre o fato e a suspender, de imediato, a sua participação como paciente.

4- Os pesquisadores garantem que responderão a qualquer pergunta ou farão esclarecimento a qualquer dúvida acerca dos procedimentos, riscos, benefícios e outros assuntos relacionados com a pesquisa e com o tratamento a que você será submetida.

5- Os pesquisadores se comprometem a proporcionar a você informações atualizadas durante o estudo, ainda que estas possam afetar a sua vontade de continuar participando da pesquisa.

6- Os pesquisadores se comprometem a manter o sigilo da sua participação e de publicar os resultados da pesquisa para a comunidade médica e científica pertinente.

OBSERVAÇÕES COMPLEMENTARES:

Ribeirão Preto, de de
Assinatura da paciente
ou de seu responsável
Professora Doutora Silvana Quintana CREMESP 67715

Ft Daniella Leiros Cunha Cavalcanti CREFITO59546-F

\section{TESTEMUNHAS NÃO LIGADAS À PESQUISA}

1 -

assinatura

identificação
2

assinatura 
ANEXO C - FICHA DE AVALIAÇÃO

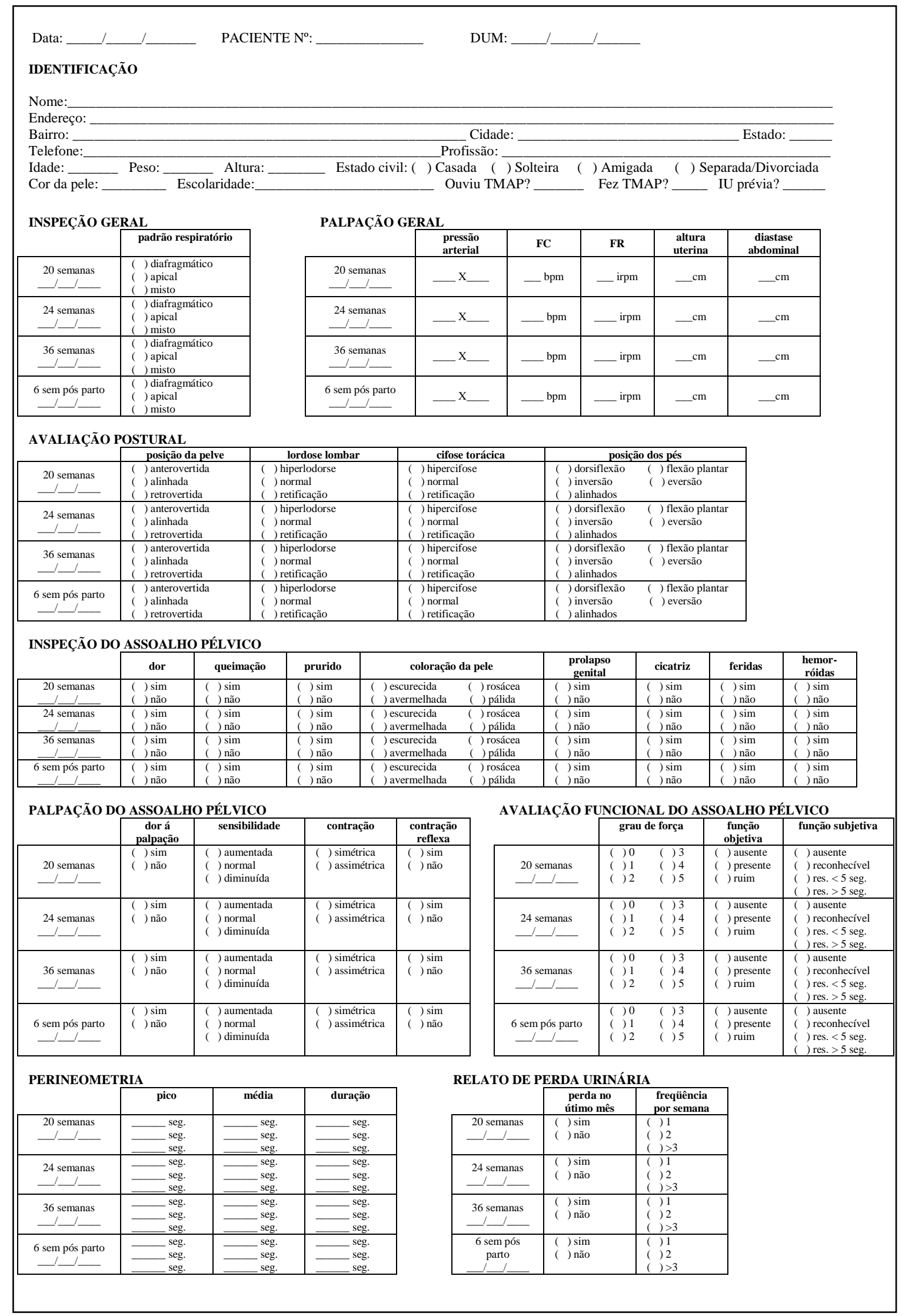


ANEXO D - EXERCÍCIOS PERINEAIS E GERAIS SEGUNDO PROTOCOLO DE Morkved et al., 2003.

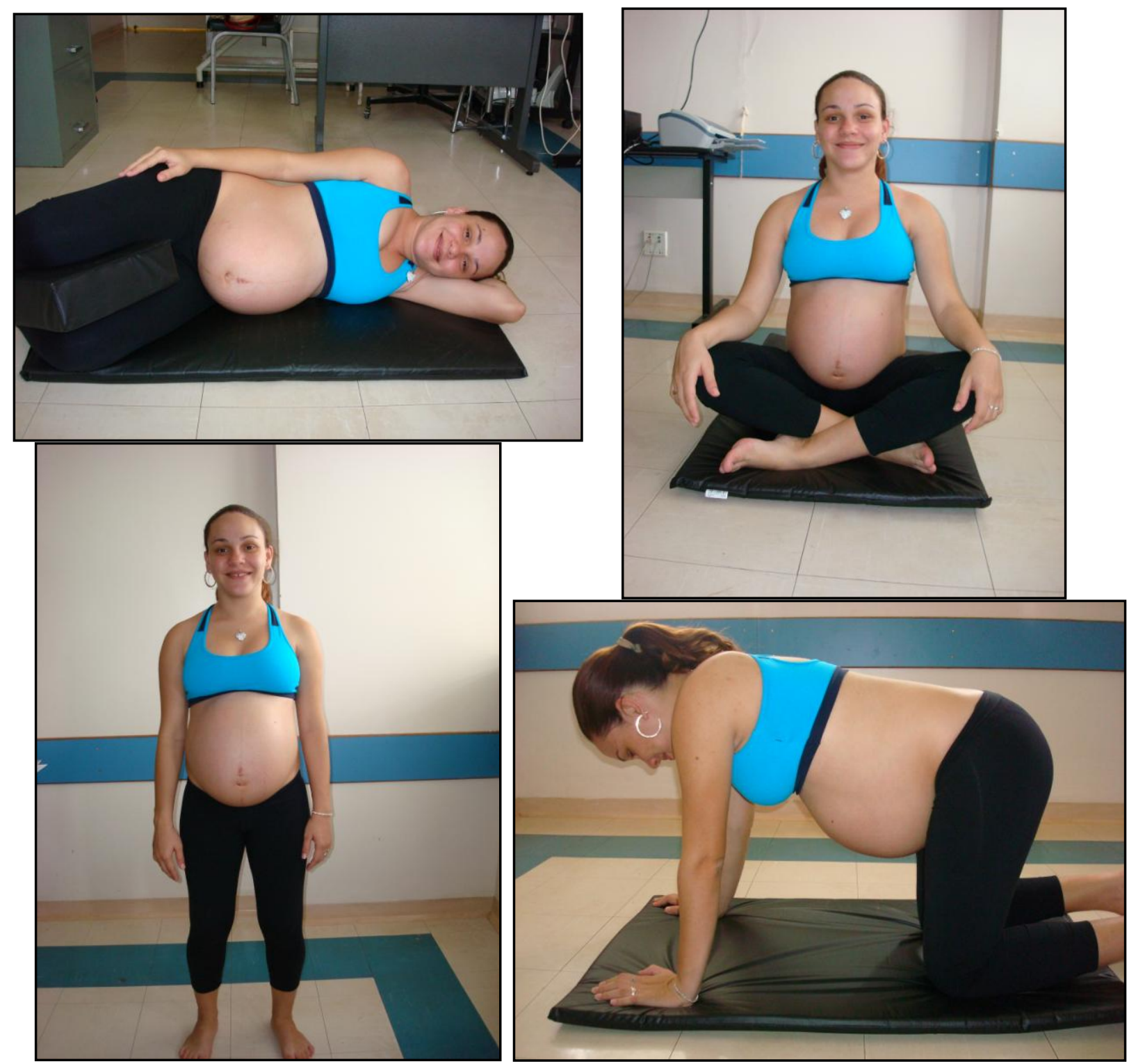


ANEXO E - Caracterização da amostra por grupo de acordo com as variáveis

\begin{tabular}{|c|c|c|c|}
\hline VARIÁVEIS & $\begin{array}{c}\text { GRUPO CONTROLE } \\
\%(n)\end{array}$ & $\begin{array}{c}\text { GRUPO } \\
\text { TREINAMENTO } \\
\%(n)\end{array}$ & P-VALOR \\
\hline \multicolumn{4}{|c|}{ Unidade Básica de Saúde de procedência } \\
\hline Adão do Carmo & $0 \%(0)$ & $5 \%(1)$ & \multirow{9}{*}{0,94} \\
\hline Castelo Branco & $5 \%(1)$ & $10 \%(2)$ & \\
\hline Dom Pedro & $57 \%(12)$ & $38 \%(8)$ & \\
\hline João Rossi & $5 \%(1)$ & $5 \%(1)$ & \\
\hline Saudade & $14 \%(3)$ & $14 \%(3)$ & \\
\hline Valentina Figueiredo & $5 \%(1)$ & $10 \%(2)$ & \\
\hline Vila Albertina & $0 \%(0)$ & $5 \%(1)$ & \\
\hline Vila Lobato & $10 \%(2)$ & $10 \%(2)$ & \\
\hline Vila Tibério & $5 \%(1)$ & $0 \%(0)$ & \\
\hline \multicolumn{4}{|l|}{ Profissão } \\
\hline assistente social & $0 \%(0)$ & $5 \%(1)$ & \multirow{13}{*}{0,24} \\
\hline auxiliar administrativo & $10 \%(2)$ & $14 \%(3)$ & \\
\hline auxiliar geral & $5 \%(1)$ & $10 \%(2)$ & \\
\hline babá & $0 \%(0)$ & $5 \%(1)$ & \\
\hline balconista & $5 \%(1)$ & $5 \%(1)$ & \\
\hline costureira & $5 \%(1)$ & $5 \%(1)$ & \\
\hline decoradora & $5 \%(1)$ & $0 \%(0)$ & \\
\hline do lar & $0 \%(0)$ & $10 \%(2)$ & \\
\hline esteticista & $0 \%(0)$ & $5 \%(1)$ & \\
\hline estudante & $19 \%(4)$ & $10 \%(2)$ & \\
\hline relações públicas & $0 \%(0)$ & $5 \%(1)$ & \\
\hline secretária & $10 \%(2)$ & $10 \%(2)$ & \\
\hline vendedora & $43 \%(9)$ & $19 \%(4)$ & \\
\hline \multicolumn{4}{|l|}{ Anos de estudo } \\
\hline$<10$ anos & $0 \%(0)$ & $14 \%(3)$ & \multirow{6}{*}{0,18} \\
\hline 10 anos & $0 \%(0)$ & $5 \%(1)$ & \\
\hline$>10<12$ anos & $0 \%(0)$ & $10 \%(2)$ & \\
\hline 12 anos & $86 \%(18)$ & $62 \%(13)$ & \\
\hline$>12<15$ anos & $10 \%(2)$ & $5 \%(1)$ & \\
\hline$>15$ anos & $5 \%(1)$ & $5 \%(1)$ & \\
\hline \multicolumn{4}{|l|}{ Estado civil } \\
\hline solteira & $57 \%(12)$ & $52 \%(11)$ & \multirow{3}{*}{0,82} \\
\hline casada & $33 \%(7)$ & $29 \%(6)$ & \\
\hline amigada & $10 \%(2)$ & $19 \%(4)$ & \\
\hline \multicolumn{4}{|l|}{ Raça } \\
\hline branca & $57 \%(12)$ & $62 \%(13)$ & \multirow{3}{*}{0,99} \\
\hline parda & $24 \%(5)$ & $19 \%(4)$ & \\
\hline negra & $19 \%(4)$ & $19 \%(4)$ & \\
\hline \multicolumn{4}{|l|}{ Idade (anos) } \\
\hline $18-25$ & $71 \%(15)$ & $76 \%(16)$ & \multirow{3}{*}{0,99} \\
\hline $26-30$ & $19 \%(4)$ & $14 \%(3)$ & \\
\hline $31-35$ & $10 \%(2)$ & $10 \%(2)$ & \\
\hline \multicolumn{4}{|l|}{ Peso $(\mathrm{kg})$} \\
\hline$<51$ & $14 \%(3)$ & $14 \%(3)$ & \multirow{3}{*}{0,4} \\
\hline $51 \mathrm{~kg}-70$ & $52 \%(11)$ & $71 \%(15)$ & \\
\hline$>70$ & $33 \%(7)$ & $14 \%(3)$ & \\
\hline
\end{tabular}

Altura (m) 


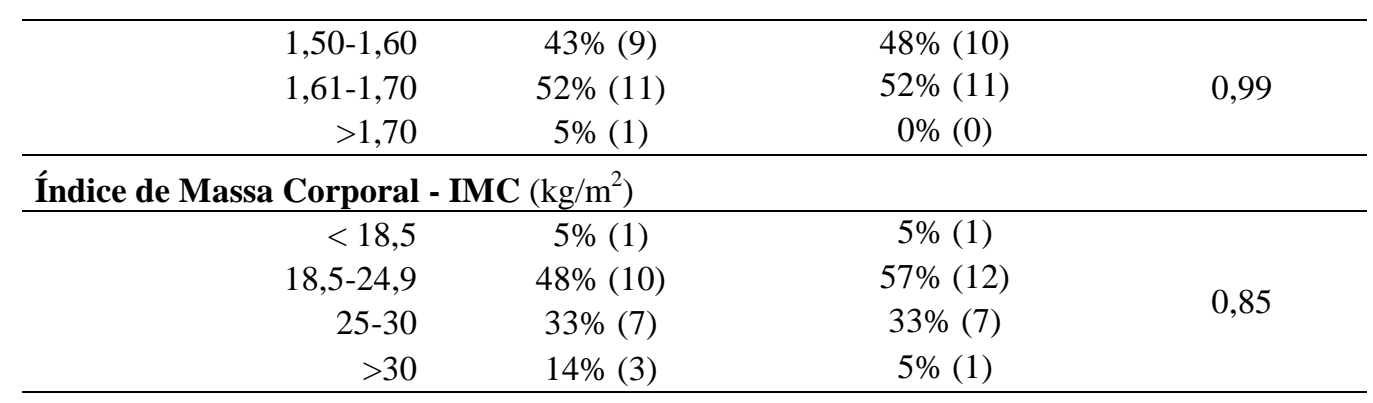

ANEXO F - Influência das covariáveis na graduação de força por escores da escala de Oxford modificada, primeiramente no grupo geral e a seguir em cada um dos grupos separadamente.

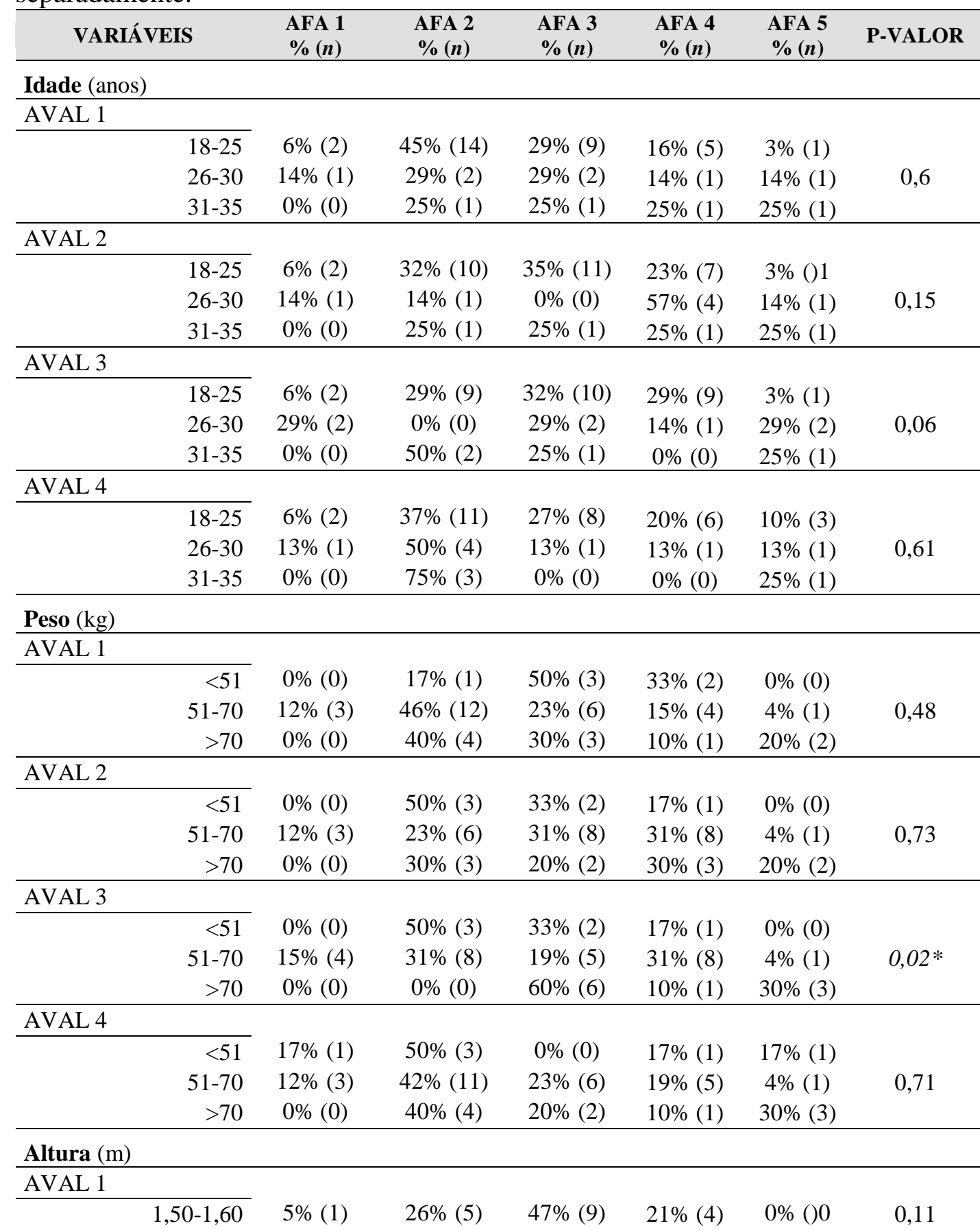




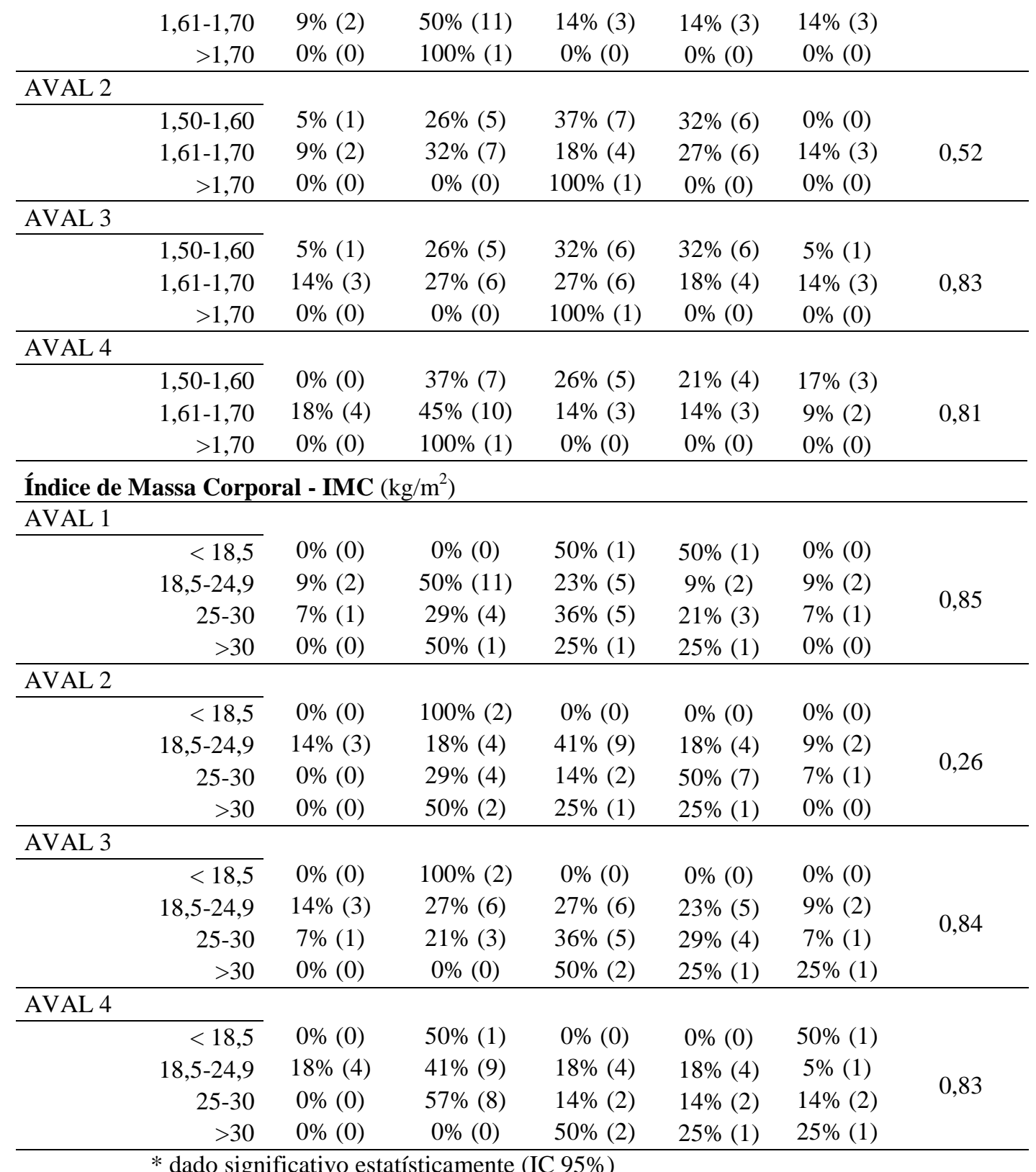


ANEXO G - Influência das covariáveis no relato de perda urinária nas avaliações 1 e 3.

\begin{tabular}{|c|c|c|c|}
\hline VARIÁVEIS & $\begin{array}{c}\text { SIM } \\
\%(n)\end{array}$ & $\begin{array}{l}\mathbf{N} \mathbf{A} \mathbf{0} \\
\%(n)\end{array}$ & P-valor \\
\hline \multicolumn{4}{|l|}{ Idade (anos) } \\
\hline AVAL 1 & & & \multirow{4}{*}{0,77} \\
\hline $18-25$ & $78 \%(14)$ & $71 \%(17)$ & \\
\hline $26-30$ & $11 \%(2)$ & $21 \%(5)$ & \\
\hline $31-40$ & $11 \%(2)$ & $8 \%(2)$ & \\
\hline AVAL 3 & & & \multirow{4}{*}{0,85} \\
\hline $18-25$ & $69 \%(9)$ & $76 \%(22)$ & \\
\hline $26-30$ & $23 \%(3)$ & $14 \%(4)$ & \\
\hline $31-40$ & $8 \%(1)$ & $10 \%(3)$ & \\
\hline \multicolumn{4}{|l|}{ Peso $(\mathrm{Kg})$} \\
\hline AVAL 1 & & & \multirow{4}{*}{0,9} \\
\hline$<51$ & $11 \%(2)$ & $17 \%(4)$ & \\
\hline $51-70$ & $67 \%(12)$ & $58 \%(14)$ & \\
\hline$>70$ & $22 \%(4)$ & $25 \%(6)$ & \\
\hline AVAL 3 & & & \multirow{4}{*}{0,07} \\
\hline$<51$ & $8 \%(1)$ & $17 \%(5)$ & \\
\hline $51-70$ & $46 \%(6)$ & $69 \%(20)$ & \\
\hline$>70$ & $46 \%(6)$ & $14 \%(4)$ & \\
\hline \multicolumn{4}{|l|}{ Altura (m) } \\
\hline AVAL 1 & & & \multirow{4}{*}{0,43} \\
\hline $1,50-1,60$ & $50 \%(9)$ & $42 \%(10)$ & \\
\hline $1,61-1,70$ & $44 \%(8)$ & $58 \%(14)$ & \\
\hline$>1,70$ & $6 \%(1)$ & $0 \%(0)$ & \\
\hline AVAL 3 & & & \multirow{4}{*}{0,36} \\
\hline $1,50-1,60$ & $38 \%() 5$ & $48 \%(14)$ & \\
\hline $1,61-1,70$ & $54 \%(7)$ & $52 \%(15)$ & \\
\hline$>1,70$ & $8 \%(1)$ & $0 \%(0)$ & \\
\hline \multicolumn{4}{|c|}{ Índice de Massa Corporal - IMC $\left(\mathrm{kg} / \mathrm{m}^{2}\right)$} \\
\hline AVAL 1 & & & \multirow{5}{*}{0,57} \\
\hline$<18,5$ & $6 \%(1)$ & $4 \%(1)$ & \\
\hline $18,5-24,9$ & $44 \%(8)$ & $58 \%(14)$ & \\
\hline $25-30$ & $44 \%(8)$ & $25 \%(6)$ & \\
\hline$>30$ & $6 \%(1)$ & $13 \%(3)$ & \\
\hline AVAL 3 & & & \multirow{5}{*}{0,23} \\
\hline$<18,5$ & $8 \%(1)$ & $3 \%(1)$ & \\
\hline $18,5-24,9$ & $31 \%(4)$ & $62 \%(8)$ & \\
\hline $25-30$ & $46 \%(6)$ & $28 \%(8)$ & \\
\hline$>30$ & $15 \%(2)$ & $7 \%(2)$ & \\
\hline
\end{tabular}


ANEXO H - Medidas descritivas da variável perineometria (pico e média) por grupo e por avaliação.

\begin{tabular}{|c|c|c|c|c|c|c|c|c|c|c|c|c|}
\hline \multirow{2}{*}{ GRUPO } & \multirow{2}{*}{ AVAL } & \multirow{2}{*}{ VARIÁVEL } & \multirow{2}{*}{ MÉDIA } & \multicolumn{2}{|c|}{ IC (95\%) PARA MÉDIA } & \multirow{2}{*}{$\begin{array}{c}\text { DESVIO } \\
\text { PADRÃO }\end{array}$} & \multirow{2}{*}{$\begin{array}{l}\text { COEFICIENTE } \\
\text { DE VARIAÇÃO }\end{array}$} & \multirow{2}{*}{ MÍNIMO } & \multirow{2}{*}{ MÁXIMO } & \multirow{2}{*}{$1^{\circ}$ QUARTIL } & \multirow{2}{*}{ MÉDIANA } & \multirow{2}{*}{$3^{\circ}$ QUARTII } \\
\hline & & & & LI & LS & & & & & & & \\
\hline \multirow{6}{*}{ Controle } & \multirow{2}{*}{1} & pico & 51,89 & 46,13 & 57,65 & 22,85 & $44,04 \%$ & 15,3 & 122,7 & 37,4 & 49,2 & 64,2 \\
\hline & & média & 33,71 & 28,59 & 38,84 & 20,35 & $60,35 \%$ & 10 & 91,9 & 18,3 & 26,1 & 43,5 \\
\hline & 2 & média & 35,43 & 30,46 & 40,39 & 19,7 & $55,62 \%$ & 9,5 & 95,1 & 21,4 & 31,7 & 47,8 \\
\hline & \multirow{2}{*}{3} & pico & 50,81 & 45,87 & 55,74 & 18,61 & $36,63 \%$ & 17,4 & 89,4 & 38,6 & 49 & 58,9 \\
\hline & & média & 33,06 & 29,12 & 37 & 14,85 & $44,92 \%$ & 9,8 & 67,2 & 24,7 & 31,4 & 38 \\
\hline & 4 & média & 29,42 & 24,86 & 33,97 & 18,09 & $61,5 \%$ & 4,3 & 77,3 & 14,8 & 24,7 & 45,7 \\
\hline \multirow{7}{*}{ Treinamento } & \multirow{2}{*}{1} & pico & 43,01 & 37,65 & 48,36 & 21,26 & $49,43 \%$ & 14,6 & 122 & 29,2 & 37,9 & 48,6 \\
\hline & & média & 26,09 & 24,45 & 31,97 & 14,92 & $52,9 \%$ & 8,4 & 82,3 & 19 & 25 & 33,8 \\
\hline & \multirow{2}{*}{2} & pico & 42,84 & 38,93 & 46,75 & 15,52 & $36,22 \%$ & 19,2 & 85,1 & 32,4 & 38,5 & 56 \\
\hline & & média & 30,7 & 27,59 & 33,81 & 12,35 & $40,21 \%$ & 10,1 & 58,4 & 20,8 & 27 & 40,5 \\
\hline & \multirow{2}{*}{3} & pico & 42,49 & 36,25 & 48,73 & 23,52 & $55,35 \%$ & 12,5 & 118,3 & 27,1 & 34,6 & 50 \\
\hline & & média & 28,21 & 21,93 & 28,48 & 12,34 & $48,96 \%$ & 10,8 & 56,8 & 15 & 23,4 & 30,4 \\
\hline & 4 & pico & 38,12 & 31,58 & 44,65 & 25,94 & $68,06 \%$ & 8,7 & 118,3 & 18,8 & 31,4 & 45,2 \\
\hline
\end{tabular}


ANEXO I - Teste exato de Fisher para AFA por grupo em cada uma das avaliações.

\begin{tabular}{|c|c|c|c|c|c|c|}
\hline \multirow{2}{*}{ GRUPO } & \multicolumn{5}{|c|}{ AFA (AVAL 1) } & \multirow{2}{*}{ P-VALOR } \\
\hline & 1 & 2 & $\mathbf{3}$ & 4 & 5 & \\
\hline Controle & $10 \%(2)$ & $33 \%(7)$ & $33 \%(7)$ & $14 \%(3)$ & $10 \%(2)$ & \multirow{2}{*}{0,81} \\
\hline Treinamento & $5 \%(1)$ & $48 \%(10)$ & $24 \%(5)$ & $19 \%(4)$ & $5 \%(1)$ & \\
\hline \multirow{2}{*}{ GRUPO } & \multicolumn{5}{|c|}{ AFA (AVAL 2) } & \multirow{2}{*}{ P-VALOR } \\
\hline & 1 & 2 & 3 & 4 & 5 & \\
\hline Controle & $10 \%(2)$ & $29 \%(6)$ & $33 \%(7)$ & $19 \%(4)$ & $10 \%(2)$ & \multirow{2}{*}{0,73} \\
\hline Treinamento & $5 \%(1)$ & $29 \%(6)$ & $24 \%(5)$ & $38 \%(8)$ & $5 \%(1)$ & \\
\hline \multirow{2}{*}{ GRUPO } & \multicolumn{5}{|c|}{ AFA (AVAL 3) } & \multirow{2}{*}{ P-VALOR } \\
\hline & 1 & 2 & 3 & 4 & 5 & \\
\hline Controle & $14 \%(3)$ & $19 \%(4)$ & $33 \%(7)$ & $14 \%(3)$ & $19 \%(4)$ & \multirow{2}{*}{0,11} \\
\hline Treinamento & $5 \%(1)$ & $33 \%(7)$ & $29 \%(6)$ & $33 \%(7)$ & $0 \%(0)$ & \\
\hline \multirow{2}{*}{ GRUPO } & \multicolumn{5}{|c|}{ AFA (AVAL 4) } & \multirow{2}{*}{ P-VALOR } \\
\hline & 1 & 2 & 3 & 4 & 5 & \\
\hline Controle & $14 \%(3)$ & $29 \%(6)$ & $33 \%(7)$ & $5 \%(1)$ & $19 \%(4)$ & \multirow{2}{*}{$<0,01 *$} \\
\hline Treinamento & $5 \%(1)$ & $56 \%(12)$ & $5 \%(1)$ & $29 \%(6)$ & $5 \%(1)$ & \\
\hline
\end{tabular}

ANEXO J - Concordância de AFA entre as avaliações (aval 1-aval 2, aval 2-aval 3, aval 1aval 3, aval 1-aval 4, aval 2-aval 4, aval 3-aval 4) em ambos os grupos.

\begin{tabular}{|c|c|c|c|c|c|c|c|c|}
\hline \multirow{2}{*}{$\begin{array}{l}\text { grau de força } \\
\text { (aval 1) }\end{array}$} & \multicolumn{5}{|c|}{ grau de força (aval 2 - CONTROLE) } & \multirow{2}{*}{$\begin{array}{c}\text { COEF. DE } \\
\text { KAPPA }\end{array}$} & \multicolumn{2}{|c|}{ IC $95 \%$ KAPPA } \\
\hline & 1 & 2 & 3 & 4 & 5 & & LI & LS \\
\hline 1 & $50 \%(1)$ & $50 \%(1)$ & $0 \%(0)$ & $0 \%(0)$ & $0 \%(0)$ & \multirow{5}{*}{0,53} & \multirow{5}{*}{0,25} & \multirow{5}{*}{0,81} \\
\hline 2 & $14 \%(1)$ & $29 \%(2)$ & $29 \%(2)$ & $29 \%(2)$ & $0 \%(0)$ & & & \\
\hline 3 & $0 \%(0)$ & $43 \%(3)$ & $57 \%(4)$ & $0 \%(0)$ & $0 \%(0)$ & & & \\
\hline 4 & $0 \%(0)$ & $0 \%(0)$ & $33 \%(1)$ & $67 \%(2)$ & $0 \%(0)$ & & & \\
\hline 5 & $0 \%(0)$ & $0 \%(0)$ & $0 \%(0)$ & $0 \%(0)$ & $100 \%(2)$ & & & \\
\hline \multirow{2}{*}{$\begin{array}{l}\text { grau de força } \\
\text { (aval 1) }\end{array}$} & \multicolumn{5}{|c|}{ grau de força (aval 2 - TREINAMENTO) } & \multirow{2}{*}{$\begin{array}{c}\text { COEF. DE } \\
\text { KAPPA }\end{array}$} & \multicolumn{2}{|c|}{ IC 95\% KAPPA } \\
\hline & 1 & 2 & 3 & 4 & 5 & & LI & LS \\
\hline 1 & $100 \%(1)$ & $0 \%(0)$ & $0 \%(0)$ & $0 \%(0)$ & $0 \%(0)$ & \multirow{5}{*}{0,42} & \multirow{5}{*}{0,09} & \multirow{5}{*}{0,75} \\
\hline 2 & $0 \%(0)$ & $40 \%(4)$ & $30 \%(3)$ & $30 \%(3)$ & $0 \%(0)$ & & & \\
\hline 3 & $0 \%(0)$ & $20 \%(1)$ & $40 \%(2)$ & $40 \%(2)$ & $0 \%(0)$ & & & \\
\hline 4 & $0 \%(0)$ & $25 \%(1)$ & $0 \%(0)$ & $75 \%(3)$ & $0 \%(0)$ & & & \\
\hline 5 & $0 \%(0)$ & $0 \%(0)$ & $0 \%(0)$ & $0 \%(0)$ & $100 \%(1)$ & & & \\
\hline \multirow{2}{*}{$\begin{array}{l}\text { grau de força } \\
\text { (aval 2) }\end{array}$} & \multicolumn{5}{|c|}{ grau de força (aval 3 - CONTROLE) } & \multirow{2}{*}{$\begin{array}{c}\text { COEF. DE } \\
\text { KAPPA }\end{array}$} & \multicolumn{2}{|c|}{ IC 95\% KAPPA } \\
\hline & 1 & 2 & $\mathbf{3}$ & 4 & 5 & & LI & LS \\
\hline 1 & $50 \%(1)$ & $50 \%(1)$ & $0 \%(0)$ & $0 \%(0)$ & $0 \%(0)$ & \multirow{5}{*}{0,47} & \multirow{5}{*}{0,19} & \multirow{5}{*}{0,76} \\
\hline 2 & $17 \%(1)$ & $17 \%(1)$ & $50 \%(3)$ & $0 \%(0)$ & $16 \%(1)$ & & & \\
\hline 3 & $0 \%(0)$ & $29 \%(2)$ & $57 \%(4)$ & $14 \%(1)$ & $0 \%(0)$ & & & \\
\hline 4 & $25 \%(1)$ & $0 \%(0)$ & $0 \%(0)$ & $50 \%(2)$ & $25 \%(1)$ & & & \\
\hline 5 & $0 \%(0)$ & $0 \%(0)$ & $0 \%(0)$ & $0 \%(0)$ & $100 \%(2)$ & & & \\
\hline \multirow{2}{*}{$\begin{array}{c}\text { grau de força } \\
\text { (aval 2) }\end{array}$} & \multicolumn{5}{|c|}{ grau de força (aval 3 - TREINAMENTO) } & \multirow{2}{*}{$\begin{array}{c}\text { COEF. DE } \\
\text { KAPPA }\end{array}$} & \multicolumn{2}{|c|}{ IC 95\% KAPPA } \\
\hline & 1 & 2 & 3 & 4 & 5 & & LI & LS \\
\hline 1 & $100 \%(1)$ & $0 \%(0)$ & $0 \%(0)$ & $0 \%(0)$ & $0 \%(0)$ & \multirow{5}{*}{0,73} & \multirow{5}{*}{0,54} & \multirow{5}{*}{0,92} \\
\hline 2 & $0 \%(0)$ & $100 \%(6)$ & $0 \%(0)$ & $0 \%(0)$ & $0 \%(0)$ & & & \\
\hline 3 & $0 \%(0)$ & $20 \%(1)$ & $60 \%(3)$ & $20 \%(1)$ & $0 \%(0)$ & & & \\
\hline 4 & $0 \%(0)$ & $0 \%(0)$ & $37 \%(3)$ & $63 \%(5)$ & $0 \%(0)$ & & & \\
\hline 5 & $0 \%(0)$ & $0 \%(0)$ & $0 \%(0)$ & $100 \%(1)$ & $0 \%(0)$ & & & \\
\hline grau de força & \multicolumn{5}{|c|}{ grau de força (aval 3 - CONTROLE) } & COEF. DE & \multicolumn{2}{|c|}{ IC 95\% KAPPA } \\
\hline
\end{tabular}




\begin{tabular}{|c|c|c|c|c|c|c|c|c|}
\hline (aval 1) & 1 & 2 & 3 & 4 & 5 & KAPPA & LI & LS \\
\hline 1 & $100 \%(2)$ & $0 \%(0)$ & $0 \%(0)$ & $0 \%(0)$ & $0 \%(0)$ & \multirow{5}{*}{0,54} & \multirow{5}{*}{0,27} & \multirow{5}{*}{0,82} \\
\hline 2 & $14 \%()$ & $14 \%(1)$ & $57 \%(4)$ & $0 \%(0)$ & $14 \%(1)$ & & & \\
\hline 3 & $0 \%(0)$ & $43 \% 3()$ & $4 \%(3)$ & $0,0()$ & $14 \%(1)$ & & & \\
\hline 4 & $0 \%(0)$ & $0 \%(0)$ & $0 \%(0)$ & $100 \%(3)$ & $0 \%(0)$ & & & \\
\hline 5 & $0 \%(0)$ & $0 \%(0)$ & $0 \%(0)$ & $0 \%(0)$ & $100 \%(2)$ & & & \\
\hline \multirow{2}{*}{$\begin{array}{l}\text { grau de força } \\
\quad \text { (aval 1) }\end{array}$} & \multicolumn{5}{|c|}{ grau de força (aval 3 - TREINAMENTO) } & \multirow{2}{*}{$\begin{array}{c}\text { COEF. DE } \\
\text { KAPPA }\end{array}$} & \multicolumn{2}{|c|}{ IC 95\% KAPPA } \\
\hline & 1 & 2 & 3 & 4 & 5 & & LI & LS \\
\hline 1 & $100 \%(1)$ & $0 \%(0)$ & $0 \%(0)$ & $0 \%(0)$ & $0 \%(0)$ & \multirow{5}{*}{0,46} & \multirow{5}{*}{0,17} & \multirow{5}{*}{0,75} \\
\hline 2 & $0 \%(0)$ & $50 \%(5)$ & $40 \%(4)$ & $10 \%(1)$ & $0 \%(0)$ & & & \\
\hline 3 & $0 \%(0)$ & $20 \%(1)$ & $40 \%(2)$ & $40 \%(2)$ & $0 \%(0)$ & & & \\
\hline 4 & $0 \%(0)$ & $25 \%(1)$ & $0 \%(0)$ & $75 \%(3)$ & $0 \%(0)$ & & & \\
\hline 5 & $0 \%(0)$ & $0 \%(0)$ & $0 \%(0)$ & $100 \%(1)$ & $0 \%(0)$ & & & \\
\hline \multirow{2}{*}{$\begin{array}{l}\text { grau de força } \\
\quad \text { (aval 1) }\end{array}$} & \multicolumn{5}{|c|}{ grau de força (aval 4 - CONTROLE) } & \multirow{2}{*}{$\begin{array}{l}\text { COEF. DE } \\
\text { KAPPA }\end{array}$} & \multicolumn{2}{|c|}{ IC $95 \%$ KAPPA } \\
\hline & 1 & 2 & 3 & 4 & 5 & & LI & LS \\
\hline 1 & $50 \%(1)$ & $50 \%(1)$ & $0 \%(0)$ & $0 \%(0)$ & $0 \%(0)$ & & & \\
\hline 2 & $14 \%(1)$ & $43 \%(3)$ & $29 \%(2)$ & $14 \%(1)$ & $0 \%(0)$ & & & \\
\hline 3 & $14 \%(1)$ & $29 \%(2)$ & $43 \%(3)$ & $14 \% 1()$ & $0 \%(0)$ & 0,41 & 0,1366 & 0,6993 \\
\hline 4 & $0 \%(0)$ & $0 \%(0)$ & $40 \%(2)$ & $60 \%(3)$ & $0 \%(0)$ & & & \\
\hline 5 & $0 \%(0)$ & $0 \%(0)$ & $0 \%(0)$ & $0 \%(0)$ & $0 \%(0)$ & & & \\
\hline \multirow{2}{*}{$\begin{array}{l}\text { grau de força } \\
\quad \text { (aval 1) }\end{array}$} & \multicolumn{5}{|c|}{ grau de força (aval 4 - TREINAMENTO) } & \multirow{2}{*}{$\begin{array}{l}\text { COEF. DE } \\
\text { KAPPA }\end{array}$} & \multicolumn{2}{|c|}{ IC $95 \%$ KAPPA } \\
\hline & 1 & 2 & 3 & 4 & 5 & & LI & LS \\
\hline 1 & $100 \%(1)$ & $0 \%(0)$ & $0 \%(0)$ & $0 \%(0)$ & $0 \%(0)$ & & & \\
\hline 2 & $0 \%(0)$ & $80 \%(8)$ & $10 \%(1)$ & $10 \%(1)$ & $0 \%(0)$ & & & \\
\hline 3 & $0 \%(0)$ & $60 \%(3)$ & $0 \%(0)$ & $40 \%(2)$ & $0 \%(0)$ & 0,52 & 0,2175 & 0,8279 \\
\hline 4 & $0 \%(0)$ & $20 \%(1)$ & $0 \%(0)$ & $80 \%(4)$ & $0 \%(0)$ & & & \\
\hline 5 & $0 \%(0)$ & $0 \%(0)$ & $0 \%(0)$ & $0 \%(0)$ & $0 \%(0)$ & & & \\
\hline \multirow{2}{*}{$\begin{array}{l}\text { grau de força } \\
\quad \text { (aval 2) }\end{array}$} & \multicolumn{5}{|c|}{ grau de força (aval 4 - CONTROLE) } & COEF. DE & IC $95 \%$ & KAPPA \\
\hline & 1 & 2 & 3 & 4 & 5 & KAPPA & LI & LS \\
\hline 1 & $100 \%(2)$ & $0 \%(0)$ & $0 \%(0)$ & $0 \%(0)$ & $0 \%(0)$ & & & \\
\hline 2 & $0 \%(0)$ & $50 \%(3)$ & $50 \%(3)$ & $0 \%(0)$ & $0 \%(0)$ & & & \\
\hline 3 & $14 \%(1)$ & $29 \%()$ & $43 \%(3)$ & $14 \%(1)$ & $0 \%(0)$ & 0,51 & 0,2204 & 0,811 \\
\hline 4 & $0 \%(0)$ & $17 \%(1)$ & $17 \%(1)$ & $67 \%(4)$ & $0 \%(0)$ & & & \\
\hline 5 & $0 \%(0)$ & $0 \%(0)$ & $0 \%(0)$ & $0 \%(0)$ & $0 \%(0)$ & & & \\
\hline grau de força & & au de força & al 4 - TRE & TAMENTO) & & COEF. DE & IC $95 \%$ & KAPPA \\
\hline (aval 2) & 1 & 2 & 3 & 4 & 5 & KAPPA & LI & LS \\
\hline 1 & $100 \%(1)$ & $0 \%(0)$ & $0 \%(0)$ & $0 \%(0)$ & $0 \%(0)$ & & & \\
\hline 2 & $0 \%(0)$ & $100 \%(5)$ & $0 \%(0)$ & $0 \%(0)$ & $0 \%(0)$ & & & \\
\hline 3 & $0 \%(0)$ & $67 \%(4)$ & $17 \%(1)$ & $17 \%(1)$ & $0 \%(0)$ & 0,53 & 0,2567 & 0,8062 \\
\hline 4 & $0 \%(0)$ & $33 \%(3)$ & $0 \%(0)$ & $67 \%(6)$ & $0 \%(0)$ & & & \\
\hline 5 & $0 \%(0)$ & $0 \%(0)$ & $0 \%(0)$ & $0 \%(0)$ & $0 \%(0)$ & & & \\
\hline grau de força & & grau de for & aval 4 - CC & TROLE) & & COEF. DE & IC 95\% & KAPPA \\
\hline (aval 3) & 1 & 2 & 3 & 4 & 5 & KAPPA & LI & LS \\
\hline 1 & $33 \%(1)$ & $67 \%(2)$ & $0 \%(0)$ & $0 \%(0)$ & $0 \%(0)$ & & & \\
\hline 2 & $50 \%(2)$ & $25 \%(1)$ & $25 \%(1)$ & $0 \%(0)$ & $0 \%(0)$ & & & \\
\hline 3 & $0 \%(0)$ & $29 \%(2)$ & $57 \%(4)$ & $14 \%(1)$ & $0 \%(0)$ & 0,49 & 0,2692 & 0,7228 \\
\hline 4 & $0 \%(0)$ & $14 \%(1)$ & $29 \%(2)$ & $57 \%(4)$ & $0 \%(0)$ & & & \\
\hline 5 & $0 \%(0)$ & $0 \%(0)$ & $0 \%(0)$ & $0 \%(0)$ & $0 \%(0)$ & & & \\
\hline grau de força & & au de força & val 4 - TRE & AMENTO) & & COEF. DE & IC $95 \%$ & KAPPA \\
\hline (aval 3) & 1 & 2 & 3 & 4 & 5 & KAPPA & LI & LS \\
\hline
\end{tabular}




\begin{tabular}{cccccccc}
\hline 1 & $100 \%(1)$ & $0 \%(0)$ & $0 \%(0)$ & $0 \%(0)$ & $0 \%(0)$ \\
\hline 2 & $0 \%(0)$ & $100 \%(6)$ & $0 \%(0)$ & $0 \%(0)$ & $0 \%(0)$ \\
\hline 3 & $0 \%(0)$ & $86 \%(6)$ & $14 \%(1)$ & $0 \%(0)$ & $0 \%(0)$ \\
\hline 4 & $0 \%(0)$ & $0 \%(0)$ & $0 \%(0)$ & $100 \%(7)$ & $0 \%(0)$ \\
\hline 5 & $0 \%(0)$ & $0 \%(0)$ & $0 \%(0)$ & $0 \%(0)$ & $0 \%(0)$ & & \\
\hline
\end{tabular}

ANEXO L - Concordância do relato de perda entre as avaliações 1 e 3 nos grupos controle e treinamento.

\begin{tabular}{|c|c|c|c|c|c|}
\hline \multirow{2}{*}{$\begin{array}{l}\text { RELATO DE PERDA } \\
\text { (aval 1) }\end{array}$} & \multicolumn{2}{|c|}{$\begin{array}{l}\text { RELATO DE PERDA } \\
\text { (aval } 3 \text { - CONTROLE) }\end{array}$} & \multirow{2}{*}{$\begin{array}{c}\text { COEF. DE } \\
\text { KAPPA }\end{array}$} & \multicolumn{2}{|c|}{ IC 95\% KAPPA } \\
\hline & NÃO & SIM & & LI & LS \\
\hline não & $80 \%(8)$ & $20 \%(2)$ & \multirow{2}{*}{0,52} & \multirow{2}{*}{0,16} & \multirow{2}{*}{0,89} \\
\hline sim & $27 \%(3)$ & $73 \%(8)$ & & & \\
\hline \multirow{2}{*}{$\begin{array}{l}\text { RELATO DE PERDA } \\
\text { (aval 1) }\end{array}$} & \multicolumn{2}{|c|}{$\begin{array}{c}\text { RELATO DE PERDA } \\
\text { (aval } 3 \text { - TREINAMENTO) }\end{array}$} & \multirow{2}{*}{$\begin{array}{l}\text { COEF. DE } \\
\text { KAPPA }\end{array}$} & \multicolumn{2}{|c|}{ IC 95\% KAPPA } \\
\hline & NÃO & SIM & & LS & LS \\
\hline não & $67 \%(12)$ & $33 \%(2)$ & \multirow{2}{*}{0,00} & \multirow{2}{*}{$-0,37$} & \multirow{2}{*}{0,37} \\
\hline $\operatorname{sim}$ & $67 \%(6)$ & $33 \%(1)$ & & & \\
\hline
\end{tabular}

ANEXO M - Comparações em relação a variável perineometria (pico e média), considerando grupo, avaliação e relato de perda.

\begin{tabular}{ccccc} 
COMPARAÇÕES & \multirow{2}{*}{ ESTIMATIVAS } & \multicolumn{2}{c}{ IC 95\% } & \multirow{2}{*}{ P-valor } \\
\cline { 3 - 4 } & & LI & LS & \\
\hline PERINEOMETRIA (pico) & & & & \\
\hline Controle aval 1 (não - sim) & $-2,55$ & $-7,32$ & 2,23 & 0,29 \\
Controle aval 3 (não - sim) & $-4,38$ & $-9,16$ & 0,40 & 0,07 \\
Controle sim (aval 1 - aval 3) & $-0,85$ & $-3,98$ & 2,28 & 0,59 \\
Controle não (aval 1 - aval 3) & 0,99 & $-2,15$ & 4,12 & 0,54 \\
\hline Treinamento aval 1 (não - sim) & 3,05 & $-1,29$ & 7,39 & 0,17 \\
Treinamento aval 3 (não - sim) & $-1,63$ & $-7,48$ & 4,22 & 0,58 \\
Treinamento sim (aval 1 - aval 3) & $-2,94$ & $-9,08$ & 3,20 & 0,35 \\
Treinamento não (aval 1 - aval 3) & 1,74 & $-0,91$ & 4,39 & 0,20 \\
\hline PERINEOMETRIA (média) & & & & \\
\hline Controle aval 1 (não - sim) & $-4,44$ & $-10,44$ & 1,56 & 0,15 \\
Controle aval 3 (não - sim) & $-0,09$ & $-6,09$ & 5,91 & 0,98 \\
Controle sim (aval 1 - aval 3) & 2,23 & $-1,84$ & 6,29 & 0,28 \\
Controle não (aval 1 - aval 3) & $-2,12$ & $-6,19$ & 1,94 & 0,30 \\
\hline Treinamento aval 1 (não - sim) & 5,85 & 0,29 & 11,41 & $0,04 *$ \\
Treinamento aval 3 (não - sim) & $-7,05$ & $-14,54$ & 0,44 & 0,07 \\
Treinamento sim (aval 1 - aval 3) & $-7,82$ & $-15,71$ & 0,06 & 0,05 \\
Treinamento não (aval 1 - aval 3) & 5,08 & 1,65 & 8,51 & $<0,01^{*}$ \\
\hline
\end{tabular}

* dado significativo estatísticamente (IC 95\%) 